NBER WORKING PAPER SERIES

\title{
THE ECONOMICS OF TOBACCO REGULATION: A COMPREHENSIVE REVIEW
}

\author{
Philip DeCicca \\ Donald S. Kenkel \\ Michael F. Lovenheim \\ Working Paper 26923 \\ http://www.nber.org/papers/w26923 \\ NATIONAL BUREAU OF ECONOMIC RESEARCH \\ 1050 Massachusetts Avenue \\ Cambridge, MA 02138 \\ April 2020
}

We gratefully acknowledge funding for this research from the National Institutes of Health, grant number 1R01DA042064-01A1. We thank Anne Burton and Hua Wang for excellent research assistance, and William Kenkel for advice about the neurology of nicotine addiction. Researchers' own analyses calculated (or derived) based in part on data from The Nielsen Company (US), LLC and marketing databases provided through the Nielsen Datasets at the Kilts Center for Marketing Data Center at The University of Chicago Booth School of Business. The conclusions drawn from the Nielsen data are those of the researchers and do not reflect the views of Nielsen. Nielsen is not responsible for, had no role in, and was not involved in analyzing and preparing the results reported herein. The views expressed herein are those of the authors and do not necessarily reflect the views of the National Bureau of Economic Research.

At least one co-author has disclosed a financial relationship of potential relevance for this research. Further information is available online at http://www.nber.org/papers/w26923.ack

NBER working papers are circulated for discussion and comment purposes. They have not been peer-reviewed or been subject to the review by the NBER Board of Directors that accompanies official NBER publications.

(C) 2020 by Philip DeCicca, Donald S. Kenkel, and Michael F. Lovenheim. All rights reserved. Short sections of text, not to exceed two paragraphs, may be quoted without explicit permission provided that full credit, including $(\odot$ notice, is given to the source. 
The Economics of Tobacco Regulation: A Comprehensive Review

Philip DeCicca, Donald S. Kenkel, and Michael F. Lovenheim

NBER Working Paper No. 26923

April 2020

JEL No. I12,I18,K32

\section{ABSTRACT}

Tobacco regulation has been a major component of health policy in the developed world since the UK's Royal College of Physicians' and the U.S. Surgeon General's reports in the 1960s. Such regulation, which has intensified in the past two decades, includes cigarette taxation, place-based smoking bans in areas ranging from bars and restaurants to workplaces, and regulations designed to make tobacco products less desirable. More recently, the availability of alternative products, most notably e-cigarettes, has increased dramatically, and these products are just starting to be regulated. Despite an extensive body of research on tobacco regulations, there remains substantial debate regarding their effectiveness, and ultimately, their impact on economic welfare. We provide the first comprehensive review of the state of research in the economics of tobacco regulation in two decades.

\author{
Philip DeCicca \\ Ball State University \\ 117 Whitninger Building \\ Muncie, IN 47303 \\ and NBER \\ ppdecicca@bsu.edu \\ Donald S. Kenkel \\ Department of Policy Analysis \\ and Management \\ College of Human Ecology \\ Cornell University \\ Martha Van Rensselaer Hall \\ Ithaca, NY 14853-4401 \\ and NBER \\ dsk10@cornell.edu
}

\author{
Michael F. Lovenheim \\ Department of Policy Analysis \\ and Management \\ ILR School, and Department of Economics \\ Cornell University \\ 264 Ives Hall \\ Ithaca, NY 14853 \\ and NBER \\ mfl55@cornell.edu
}




\section{Introduction}

Tobacco is perhaps the most heavily taxed and regulated product in the United States. As of January 2020, the average state plus federal excise tax on a pack of cigarettes was $\$ 2.82$, which represents almost $40 \%$ of the tax-inclusive retail price. ${ }^{1}$ Per-pack excise taxes range considerably across states, from a low of $\$ 0.17$ in Missouri to a high of $\$ 4.50$ in Washington, DC. Furthermore, many municipalities levy their own taxes. Smokers in New York City, for example, face an additional $\$ 1.50$ in excise tax, leading to a total federal, state, and local excise tax of $\$ 6.86$ per pack. In Chicago, there is a combined excise tax of $\$ 7.17$ per pack. In addition to the high excise taxes in most of the country, consumers are increasingly limited in where they can smoke. Thirty-five states ban smoking in restaurants and bars, while thirty ban smoking in workplaces. Hundreds of municipalities also have adopted these restrictions. Finally, federal law has required cigarette warning labels since 1965 and banned cigarette advertising on radio and television since 1973. The 2009 Tobacco Control Act (TCA) gives the Food and Drug Administration broad regulatory authority over the tobacco industry. The TCA requires new warning labels with graphic images, new restrictions on advertising, and ushers in the possibility of product-based regulations such as restricting nicotine content to non-addicting levels.

Internationally, other countries use various mixes of tobacco taxation and regulation. Many other high-income countries tax cigarettes at least as heavily as in the U.S. Using other English-speaking countries as examples, expressed in terms of the tax-inclusive price of the most popular brand, the cigarette excise tax in 2016 was 51 percent in Australia, 57 percent in Canada, 62 percent in New Zealand, and 47 percent in the United Kingdom (World Health Organization 2017, Appendix IX). Broadly speaking, many other countries have tended to lag the U.S. in the adoption of place-based restrictions on smoking in public places, although they are becoming more common in Europe following European Union guidance. A number of countries ban all cigarette advertising, and a few have already implemented product-based regulations such as banning menthol.

Although tobacco has long been taxed and regulated, the scope and extent of such regulations have increased markedly in the $21^{\text {st }}$ century. In 2000 in the U.S., average state and federal cigarette taxes were $\$ 0.76$ per pack, or $24.3 \%$ of the average price of a pack of cigarettes.

\footnotetext{
${ }^{1}$ A pack consists of 20 cigarettes. Cigarettes are also sold by the carton, which is typically 10 packs (or 200 cigarettes).
} 
Figure 1 shows the average state plus local cigarette tax as a percent of the average tax-inclusive price from 1965 through 2018 as well as the average nominal state plus federal cigarette tax. Cigarette taxes as a proportion of the total price were very high in the 1960s, although tax levels were quite low. The effective tax rate as a percent of price declined through the $1980 \mathrm{~s}$ as inflation eroded the real value of nominal taxes that were either constant or increased only modestly. The tax rate then held constant at around 25-30 percent throughout the 1990s. Since 2000, a federal tax increase and over 140 state excise tax hikes led average cigarette excise taxes to increase by over 252 percent. Per-pack taxes as a percent of the average price rose from 23.6 percent to 39.3 percent.

The sharp rise in cigarette excise taxes occurred during the same time as two other important regulatory trends. First, workplace, bar, and restaurant smoke-free indoor air laws became increasingly common. As of 2000, no state had yet passed a comprehensive ban on smoking in these areas, although some states had more targeted bans. From 2000-2009, the fraction of the U.S. population covered by smoke-free worksite laws increased from 3 percent to 54 percent and the fraction covered by smoke-free restaurant laws increased from 13 percent to 63 percent (Gonzalez et al. 2013). Second, following the 2009 TCA the FDA began to use its authority over tobacco products. FDA regulatory actions include new required graphic warning labels on cigarettes and new warning statements on a range of tobacco products, authorization for a manufacturer to market its snus smokeless tobacco as a "modified risk" product that poses lower risks than combustible cigarettes, and restrictions on the marketing of flavored ecigarettes. Furthermore, the minimum purchase age for all tobacco products including cigarettes and e-cigarettes was recently raised from 18 to 21 in the US. Since the turn of the century, the increased taxation and regulation of cigarettes and tobacco is unprecedented and dramatic.

Taxation and regulation of tobacco are based on three economic arguments. The oldest economic argument for taxation is the inverse elasticity rule: because the demand for cigarettes is relatively inelastic, a cigarette tax is an efficient way to raise government revenues (Ramsey 1927; Diamond and Mirrlees 1971). While still an important issue in some countries and in state and local public finance circles, the majority of tobacco-related research pertains to the remaining two rationales - externalities and internalities. Smoking creates direct externalities through second-hand smoke and fiscal externalities through the worse health, increased medical needs, and reduced productivity of smokers. Smokers also impose negative internalities on 
themselves through decisions that fail to maximize lifetime utility. A commonly cited example is that present-biased smokers fail to place enough weight on the future health consequences of smoking, which usually take decades to develop. Policymakers often argue that the combined economic arguments for tobacco taxation in particular pose strong justification for heavily taxing cigarettes: these taxes either will produce behavioral responses that limit negative externalities and internalities or will lead to higher government revenues without much deadweight loss.

Central to the arguments supporting smoking regulations is the empirical question of how they affect smoking behavior. Smoking rates have steadily declined for the past 50 years, as the health consequences of tobacco consumption have become more widely understood. Figure 2 shows trends in smoking participation from 1965 to 2018. In 1965, over 40 percent of the adult population in the US smoked, while by 2018 less than 14 percent did so. Figure 2 shows a steady decline in smoking participation over time, although there was a levelling off of the downward trend in the 1990s.

To what extent can the higher cigarette taxes, as shown in Figure 1, account for these declines? Comparing the time trends in the two figures suggests some skepticism is in order. Between 1965 and 1990, smoking rates declined despite very low nominal cigarette excise tax levels and declining tax rates as a percent of tax-inclusive prices. That said, it also is the case that smoking rates have fallen substantially since 2000 when nominal and real excise taxes increased the most, combined with increasingly stringent place-based smoking bans. While many have attributed the post-2000 reduction in smoking to rising cigarette taxes and smoke-free air laws, it is clear that these declines began well before these regulations were rolled out to their current levels. Indeed, as seen in the Sections 4 and 6, evidence from arguably the best-done studies on the impact of such policies on smoking behavior is less than definitive.

An alternative hypothesis is that the reduction in adult tobacco consumption is driven predominantly by consumers' responses to the evidence that smoking creates serious health problems. The anti-smoking public health campaigns that began with the 1964 Surgeon General's Report not only help explain the drop in smoking in the late 1960s and 1970s but also set the stage for future trends. Smoking is addictive, and at any point in time the stock of current smokers is much larger than the flows created by initiation, cessation, and mortality. The inherent dynamics that result mean that changes in population smoking are slow to appear and accumulate over time. For example, even without accounting for the increased taxation and 
regulation, the demographics of the smoking population in 1995 predicted most of the subsequent decline in smoking through 2010 (Méndez, Warner and Courant 1998, Warner and Méndez 2012, DeCicca and Kenkel 2015).

Although cigarettes are the most commonly used tobacco product in the U.S., consumers also use a variety of other tobacco products. In 2013-14 data from Wave 1 of the Population Assessment of Tobacco Health (PATH) Study, among adults aged 18 and over the prevalence of current (every day or some days) use was 18.1 percent for combustible cigarettes, 5.5 percent for electronic cigarettes, 4.5 percent for traditional cigars, 4.4 percent for cigarillos, 4.2 percent for hookah, and 3.4 percent for smokeless tobacco (Kasza et al. 2017). Among cigarette smokers, 42 percent were also current users of at least one additional tobacco product. In contrast to the steady downward trend in smoking in Figure 2, from 2000 to 2015 consumption of cigars, pipe tobacco, and smokeless tobacco products increased (Wang et al. 2016). E-cigarettes were introduced in the U.S. around 2007; in the 2017 National Health Interview Survey, 2.8 percent of adults reported e-cigarette use every day or on some days (Wang et al. 2018). Among youth, vaping e-cigarettes is now more common than smoking and the rapid increase has been termed an "epidemic" (FDA 2020). In the National Youth Tobacco Survey, the fraction of high school students reporting using e-cigarettes within the past 30 days increased from 11.7 percent in 2017 to 27.5 percent in 2019 (Cullen et al. 2018, Wang et al. 2019). It is worth noting that cigarettes have not always and everywhere dominated tobacco markets. In the late 1800 s in the U.S., although per capita consumption of tobacco was comparable to current levels, most tobacco was consumed as smokeless tobacco and cigars (U.S. Department of Agriculture 1995). Currently in Sweden, among men the use of snus (a form of smokeless tobacco) is more common than smoking (World Health Organization 2017).

The last comprehensive review of the research on tobacco regulation for the economics profession was conducted in 2000 by Chaloupka and Warner. ${ }^{2}$ There are four main developments that have occurred since that time that warrant an updated review of the literature:

\footnotetext{
${ }^{2}$ The more recent Handbook of Health Economics chapter on risky behaviors by Cawley and Ruhm (2011) only briefly discusses the cigarette tax literature. Gallet and List (2003) perform a meta-analysis of cigarette tax elasticities and conclude that estimates are quite sensitive to data and functional form choices. Like Chaloupka and Warner (2000), they focus almost entirely on pre-2000 research. Because of the relevance for policy, economic research on cigarette demand is also regularly reviewed for public health audiences. Reviews include the 2012 Surgeon General Report and the National Cancer Institute (2017) monograph. While these reviews include overviews of the literature on tobacco control policies, they do not provide critical analyses of the research focusing on the credibility of the evidence nor are they comprehensive in their treatment of the economics literature.
} 
1) Data innovations have occurred that provide researchers with information from repeated cross-sectional and panel surveys and allow them to measure with much greater accuracy the prices consumers pay, consumption patterns, consumer location, and demographic characteristics.

2) Methodological innovations have closely followed the "credibility revolution" in Economics (Angrist and Pischke 2008). Combined with the improvements in data availability, these methods allow researchers to move beyond the cross-sectional and time series models that were dominant in the pre-2000 literature to more credibly identify the effects of anti-smoking policies on prices and consumer behavior.

3) The large amount of tobacco regulation that has occurred since 2000 makes this time period particularly important for studying policy effects. The scope and volume of tax increases and place-based smoking bans over the past 20 years may have effects that are quite different from the effects of the more moderate policies in the pre-2000 period.

4) The growing popularity of new tobacco products that are potentially less harmful most notably electronic cigarettes - raises new research questions about product complementarity and substitutability. Combined with the possibility of the new attribute-based regulations made possible by the 2009 TCA, the answers to these new research questions will provide crucial information to guide future tobacco regulatory policy.

In light of these recent developments, it is not surprising that the economic research literature on tobacco remains large and robust. This literature includes contributions and insights from various sub-fields, including health economics, public economics, labor economics, and industrial organization.

These recent developments highlight four important policy issues that we address in this review:

1) What is the optimal level and geographic dispersion of cigarette taxes, taking into account internalities and externalities associated with smoking as well as cross-border tax avoidance?

2) Do smoking bans reduce smoking and improve public health? How expansive do these bans need to be to be effective? 
3) How does the rise of alternative tobacco products, such as e-cigarettes, change effective tobacco control policy?

4) How have new tobacco regulations, such as the recently implemented age- 21 purchasing limit and e-cigarette flavor restrictions, affected tobacco consumption? Our review examines these policy questions, focusing on areas of consensus as well as discussing the numerous topics that are ripe for future study due to a lack of consensus or a lack of credible research.

We begin with an overview of common data sources used to measure cigarette consumption and a comparison of smoking trends across datasets in Section 2. In Section 3, we discuss the economic rationales for government regulation of tobacco markets, focusing specifically on arguments and evidence related to public health (Section 3.1), externalities (Section 3.2), internalities (Section 3.3), and equity (Section 3.4). Section 4 reviews the behavioral impact of cigarette taxation. We first consider the literature on incidence; that is, what determines the extent to which cigarette taxes are passed through to consumers in the form of higher prices (Section 4.1). We next critique research on the impact of cigarette taxes on the smoking behavior of adults and youth separately, as well as research which attempts to link cigarette tax policy to relevant health outcomes (Section 4.2). Section 5 focuses on the increasingly important question of tax avoidance. We discuss tax avoidance across space, driven by large tax differences across uncontrolled state borders (Section 5.1). We also review the evidence on the extent to which cigarette taxes induce substitution to other tobacco products (e.g., e-cigarettes) as well as alcohol, marijuana, and food (Section 5.2).

Section 6 discusses and critiques research on the impacts of place-specific smoking bans, which is a relatively more recent development in the economics of smoking literature. We first critically discuss research on the impact of these bans on smoking behavior (Section 6.2), then examine research that investigates their impact on the hospitality industry (Section 6.3), and finally review research that attempts to link these bans to secondhand smoke exposure (Section 6.4) and relevant health outcomes (Section 6.5). In Section 7, we examine product-based tobacco regulation such as required warning labels (Section 7.1), tobacco advertising (Section 7.2), and the regulation of flavors and other product attributes (Section 7.3). Section 8 concludes with an overview of our findings and a summary of directions for future research. 


\section{Smoking Data and Trends}

Broadly, the datasets that have been used to study the effects of tobacco regulation can be broken down into two categories: survey measures of cigarette consumption and sales-based measures of cigarette purchases. Datasets from surveys are desirable because they link smoking behavior to a rich set of observed characteristics and other behaviors of individuals. However, they also rely for the most part on self-reports, which can suffer from measurement error. The most prominent survey-based U.S. datasets used to measure adult smoking are the Tobacco Use Supplements to the Current Population Survey (TUS-CPS), Behavioral Risk Factor Surveillance System (BRFSS), National Health and Nutrition Examination Survey (NHANES), the National Health Interview Survey (NHIS), the National Survey on Drug Use and Health (NSDUH), and the National Longitudinal Survey of Youth (NLSY). Prominent survey-based datasets used to measure youth smoking participation are the NLSY, Monitoring the Future (MTF), the National Youth Tobacco Survey (NYTS), and the Youth Risk Behavior Surveillance System (YRBSS). The Online Data Appendix provides an overview of these datasets.

The most commonly used sales measures of smoking come from tax-based sales data; they have the benefit that they accurately record all taxed sales. Hence, they are not subject to measurement error from self-reports. The main drawbacks from these data are that one cannot observe who buys the cigarettes, where purchasers reside, how purchases vary geographically within the taxing jurisdiction, and who consumes the cigarettes. Information on U.S. taxed sales data is presented in the Online Data Appendix.

In between the two extremes of taxed sales and survey data is sales transaction data linked to households. Reporting purchases of cigarettes as part of the overall purchase bundle of the household may lead to less stigma, and these data are not subject to recall bias. Hence, they may contain less measurement error than do survey measures. These data are household-based, so it is not possible to know who in the household smokes the purchased cigarettes and when they do so. The most prominent U.S. household scanner data come from the IRI/Nielsen Consumer Homescan Dataset, which is described in detail in the Online Data Appendix.

Figure 3 presents comparisons of trends in the adult smoking participation rate from four datasets: TUS-CPS, BRFSS, NHANES, and NHIS. ${ }^{3}$ The levels and trends align closely with one

\footnotetext{
${ }^{3}$ We do not show the trends from NLSY because these surveys are cohort-based, so one cannot disentangle age and year effects. As a result, trends over time are not comparable to those from nationally-representative cross-sections.
} 
another over time, although the TUS-CPS participation rate is consistently below those from other datasets. Additionally, trends from NHANES are noisy due to smaller sample sizes. There also is a jump in measured smoking in BRFSS in 2011. This jump coincides with the increase in the proportion of people being surveyed on cell phones, when the BRFSS changed its data collection, structure, and weighting methodology. It also coincides with a rise in the percentage of respondents with unknown smoking status. These patterns underscore the importance of considering measurement error in survey data and how different survey methods may affect such error.

Figure 4 presents similar patterns for the number of cigarettes smoked per day, including zeros, for TUS-CPS, NHANES, NHIS, taxed sales per capita, and Nielsen Homescan. These tabulations include both the intensive and extensive margin. The number of cigarettes smoked has declined over time in all datasets. The survey-based measures all align closely, while the taxed sales data show higher smoking rates and the Homescan data show lower smoking rates. The lower smoking rates in the Homescan data may be due to smokers not scanning in all purchases, or it could be the case that participants in the dataset smoke less. We use the Homescan projection factor to make the sample demographically representative, but the projection factor does not reflect smoking status or intensity. That taxed sales per capita are higher than survey-based smoking measures is consistent with prior research comparing taxed sales and survey-based smoking measures (Stehr 2005) and likely is due to under-reporting by smokers in surveys. If under-reporting and under-scanning exist and are related to cigarette taxes or regulation, the associated estimates of how consumers respond to these policies could be biased in either direction. This issue has received little attention in the economics literature.

\section{Economic Rational for Government Regulation of Tobacco Markets}

The economic rationale for regulating tobacco typically is based on two main objectives: 1) reducing externalities and internalities associated with tobacco consumption, and 2) raising revenue. Research on tobacco regulation has focused more on the first objectives, partly because externalities and internalities are harder to measure than revenue, and partly because revenue implications have become less prominent in public policy discussions. Our review thus focuses on the externality- and internality-driven rationales for government regulation of tobacco and the evidence supporting such regulation. 
We begin with an overview of the effect of smoking on public health, which is a core reason policymakers give for regulating tobacco. We then discuss evidence on the direct externalities associated with secondhand smoke exposure and the fiscal externalities from an individual's own cigarette consumption. The discussion subsequently turns to internalities, which requires a brief assessment of different theoretical models of tobacco addiction as well as the limited empirical evidence. The section concludes with a discussion of the equity of tobacco regulation. Our discussion mainly focuses on the fact that lower-income consumers smoke more and hence remit more taxes, but we also provide a brief discussion of the equity implications of place-based smoking bans and product-based regulations.

\subsection{Public Health}

Other than raising tax revenue, the economic rationales for tobacco regulation flow from the serious health consequences of cigarette consumption. ${ }^{4}$ The health consequences of secondhand smoke exposure create direct externalities. The health costs to smokers themselves create the potential for fiscal externalities and internalities. In this section, we briefly summarize public health research on the health consequences of smoking. For the economic rationales for regulation, three issues are important to keep in mind: the timing of the health consequences, dose-response relationships, and how the health consequences may differ between different tobacco products. Finally, we also discuss recent econometric research that adds to the evidence base on the effect of smoking on health.

Public health research has firmly established that smoking cigarettes increases the risks of serious chronic illness, with much of the excess risk occurring at older ages. The probability that a young adult smoker will eventually die prematurely due to smoking is estimated to be 32 percent (U.S. Department of Health and Human Services, 2014, p. 666). Jha et al. (2013) estimate that compared to never smokers, life expectancy among current smokers is shortened by ten years. However, as discussed below, recent econometric research suggests this estimate is over-estimated by upwards of 50 percent The health consequences mainly stem from inhaling cigarette smoke. Cigarette smoke contains both tar and carbon monoxide. Smoking is associated with increased risks of major illnesses including asthma, chronic obstructive pulmonary disease,

\footnotetext{
${ }^{4}$ Smoking also can have positive effects on consumers if it is a substitute for other unhealthy behaviors (e.g., drinking, smoking marijuana, over-eating) or if there are positive social benefits. We discuss the effect of tobacco taxes on drinking, marijuana consumption, and obesity in Section 5.2. While there is a large literature on peer effects in smoking, this is outside the scope of our review as our review is focused on tobacco regulation.
} 
heart disease and myocardial infarctions (heart attacks), lung and other cancers, and stroke (U.S. Department of Health and Human Services 2014). Public health research also suggests that exposure to secondhand smoke is associated with increased health risks (Institute of Medicine 2010). The fact that the health consequences of smoking typically occur decades after smoking initiation has important implications for the lifetime accounting of fiscal externalities. Part of the argument from behavioral economics that smokers impose internalities on their future selves also rests on the long average delays between choices and consequences.

Public health research establishes a strong dose-response relationship between the length of time someone has smoked and adverse health outcomes. Smokers who quit before age 35 avoid almost all of the excess mortality risk (Doll et al. 2004, Jha et al. 2013). Compared to the estimated 10 years of life expectancy loss among of current smokers, smokers who quit smoking at age 35 to 44 gain back 9 years of the life expectancy loss, smokers who quit at age 45 to 54 gain back 6 years, and smokers who quit at age 55 to 64 gain back 4 years (Jha et al. 2013). This dose-response relationship means that taxation and regulation can improve health not only by discouraging youth smoking initiation but also by encouraging adult smoking cessation. However, there is not strong evidence of a dose-response relationship between the number of cigarettes smoked daily and health outcomes. Much of the economics and public health research thus focuses on the effects of policies on the extensive margin (smoking participation).

More controversially, some public health research suggests that the use of non-combusted tobacco products may be substantially less harmful than smoking cigarettes. In his proposal published in the British Medical Journal for safer cigarettes, Russell (1976) observed that, "People smoke for the nicotine but die from the tar." Tar is the byproduct of combustion, so tobacco products that do not involve combustion offer the potential for harm reduction. Epidemiologic evidence from Sweden suggests that the use of snus, a form of smokeless tobacco, poses much lower risks than cigarette smoking (Lee 2013). The National Academy of Sciences (2018) concludes that: "There is conclusive evidence that completely substituting ecigarettes for combustible tobacco cigarettes reduces users' exposure to numerous toxicants and carcinogens present in combustible tobacco cigarettes." Depending upon assumptions about the dose-response relationships between toxicants and health consequences, Viscusi (2016) calculates that the risks of vaping might be as low as $1 / 100$ to $1 / 1000$ the risk of smoking. 
However, the policy statements of the American College of Physicians (Crowley 2015), the American Heart Association (Bhatnagar et al. 2014), and the American Lung Association (ALA 2015) emphasize the lack of long-term studies and the uncertainty about the possible health consequences of vaping. ${ }^{5}$ In 2019, the U.S. experienced an outbreak of what the CDC terms "e-cigarette, or vaping, product-use associated lung injury (EVALI)" which as of December 10, 2019 was linked to 2,409 cases requiring hospitalization and 52 deaths (Mikosz et al. 2020). The outbreak appears to be linked to illegal vaping products that contain THC, the active ingredient in marijuana. The outbreak peaked in September 2019 and does not appear to involve commercially available nicotine e-cigarettes. ${ }^{6}$

In concluding our discussion of public health research, we note that research on the health consequences of tobacco consumption relies on analysis of observational data and hence is subject to selection bias, a problem familiar to economists. Randomized controlled clinical trials are the gold-standard in health and medicine, but obviously it is unethical to randomly assign some people to smoke for 30 years and compare their health outcomes to a control group randomly assigned not to smoke. In a way, the first path-breaking studies on the health consequences of smoking used a quasi-experimental design. Before people knew that it was unhealthy to smoke, the differences in smoking status in the 1940s and 1950s reflected more-orless random factors, such as the U.S. military's provision of free cigarettes to soldiers in World War II. In later birth cohorts, however, as the information about the health consequences became more widespread, smoking status became less random and more endogenous. In recent decades, smokers are clearly different than non-smokers in many observable ways - completed schooling, income, and occupation. It is likely that they also differ from non-smokers in other ways that are unobserved in most data sets, such as predilection for addiction and time and risk preferences. ${ }^{7}$ Unobserved heterogeneity leads to the potential for selection bias in the public health studies of the health consequences of smoking.

\footnotetext{
${ }^{5}$ We use the terms e-cigarettes, electronic cigarettes, and vaping interchangeably throughout this review.

${ }^{6}$ In December 2019 the CDC released four reports about the outbreak (https:/www.cdc.gov/media/releases/2019/p1220-cases-EVALI.html). The findings strengthened the link between lung injury and Vitamin $\mathrm{E}$ acetate, which is sometimes added to illegal vaping products that contain THC. Vitamin $\mathrm{E}$ acetate is not found in commercially produced nicotine e-cigarettes.

7 The CBO (2012, Box 3-1) uses the Medical Expenditure Panel Survey (MEPS) data to show the differences in observed characteristics between current smokers, former smokers, and non-smokers.
} 
Darden, Gilleskie and Strumpf (2018) use an econometric framework that controls for unobserved heterogeneity to estimate the causal effects of smoking on mortality. The authors use 46 years of longitudinal observations of the original adult subjects in the Framingham Heart Study. These data include detailed information over time, which allows them to employ rich observable controls to estimate a joint model of smoking decisions and health that incorporates correlated unobserved heterogeneity. The unconditional difference in mean life expectancy between smokers and non-smokers in the data is 9.3 years, which is very similar to epidemiologic estimates in public health (Jha et al. 2013). The econometric model results predict a difference of only 4.3 years, suggesting that the public health research over-estimates the health consequences of smoking by about 50 percent.

\subsection{Externalities}

\subsubsection{Overview}

The externalities from tobacco consumption provide a straightforward rationale for taxation; if the tax is set at the optimal Pigouvian rate and equals the marginal external cost, despite the externalities the market will reach the efficient outcome. A series of studies reach the perhaps surprising result that even in the 1980s and 1990s U.S. cigarette taxes were already high enough to correct for the externalities due to smoking. The seminal study by Manning et al. (1989) makes the key distinction between the internal costs to the smokers themselves versus the external costs imposed on others in society. Their analysis accounts for the large direct costs of cigarette consumption such as health insurance, mortality, and social program expenditures. They find that smokers generate a net negative externality equal to about 15 cents per pack (in 1989 dollars). This was less than half of the average per-pack tax at the time of 38 cents. A series of updated estimates continue to suggest that cigarette taxes were set about right or perhaps above the Pigouvian rate (Viscusi 1995, 1999, 2002). To the best of our knowledge, the most recent comprehensive U.S. estimates of the externalities due to smoking are from Sloan et al. (2004). Consistent with prior work, they conclude that as of 2000 cigarette taxes were set about right. Adjusting for inflation since 2000, the results imply that smokers generate a negative externality equal to about $\$ 0.66$ per pack in January 2020 dollars. ${ }^{8}$ As noted above, in January

\footnotetext{
${ }^{8}$ In Table 11.3 (p. 341), Sloan et al (2004) present an estimate that the external cost per pack of cigarettes equals $\$ 2.20$. In further discussion, they point out that their estimate includes $\$ 1.78$ of cross-subsidies from non-smokers to smokers, which may no longer occur because most life insurance policies adjust for smoking status. We therefore
} 
2020 the average per-pack tax was $\$ 2.82$. Based on these estimates, the numerous tax hikes since 2000 cannot be justified on Pigouvian grounds.

The exercise of comparing estimates of the externalities to prevailing tax rates necessarily rests on strong assumptions. We turn now to a more detailed discussion that includes noncomprehensive studies that provide estimates of one or more of the components required to estimate the externalities due to smoking.

\subsubsection{Direct Externalities from Secondhand Smoke}

Secondhand smoke is a popular and simple classroom example of a negative externality. However, the question of whether secondhand smoke provides a strong economic rationale for taxation or regulation is more complex than it might first appear. Secondhand smoke exposure is most significant in confined spaces including homes, workplaces, restaurants, and bars. In these settings, property rights are often fairly clearly defined and transactions costs are low. As a result, indoor air pollution from secondhand smoke does not necessarily create the same degree of market failure as, say, ambient air pollution from industrial production. Coasian transactions might not eliminate indoor secondhand smoke, but they might reach approximately the right balance between the benefits to non-smokers from reducing their secondhand smoke exposure and the costs smokers incur to achieve the reduction (Coase 1960).

Sloan et al. (2004, Table 11.2) estimate that the costs of secondhand smoke exposure to members of the smoker's household are worth on average $\$ 5.44$ per pack ( $\$ 8.18$ in $\$ 2020$ ). They take an agnostic view on whether the costs are internal or external and refer to them as "quasiexternal." However, they note that if quasi-external costs are included, higher cigarette taxes are warranted, a conclusion which still holds in comparison to current tax levels. An argument against including the quasi-external costs is based on within-household altruism. If smokers are sufficiently altruistic, their smoking decisions will reflect the costs of exposing their partners and children to secondhand smoke. Or, smokers might make compensating pro-health investments that offset the health consequences of secondhand smoke. ${ }^{9}$ Less cooperative within-household bargaining will not necessarily yield the efficient outcome, however. A related concern is that

take $\$ 2.20-\$ 1.76=\$ 0.44$ as their best estimate of the external cost in 2000 ; adjusted for inflation this is worth $\$ 0.66$ in January 2020.

${ }^{9}$ Almond, Chay, and Lee (2005) find the health costs of smoking-induced low birthweight to be much lower than the cross-sectional health costs of low birthweight. This finding is consistent with smoking mothers making compensatory health investments, but it also is consistent with a positive bias in the cross-sectional relationship between health outcomes and birthweight. 
household bargaining could systematically harm vulnerable populations, including children and the partner with fewer economic resources.

Workers and customers are exposed to secondhand smoke in workplaces, restaurants, hotels, bars, and other places of business. Instead of altruism, in these settings employers and business owners have profit incentives to assign property rights to indoor smoking efficiently. As discussed in more detail below, Bitler, Carpenter and Zavodny (2010) suggest that state-level smoking bans may be less than fully binding, perhaps due to pre-existing voluntary bans that make the state bans irrelevant. Because the ownership of the airspace within their properties was both established and relatively easy to police, many hotel chains and some restaurant chains enacted smoking bans long before state or local laws required them to (Institute of Medicine 2010). In spite of some transaction costs — enforcement of the bans within their airspace-these voluntary bans were market successes. Hotel and restaurant owners could increase their profits by guaranteeing more valuable, clean air to their nonsmoking customers who were willing to pay for access to it. Below in Section 6, we provide more discussion of research on the impact of smoking bans on profits in the hospitality industry.

While the direct externalities from secondhand smoke provide a possible rationale for cigarette taxes, place-based smoking bans are a more targeted public policy response. Although it may seem self-evident that smoking bans will reduce the externalities associated with secondhand smoke exposure, in actuality the effect of these policies on such exposure is ambiguous. On the one hand, those who work in banned workplaces or eat and drink in banned bars and restaurants will be exposed less to second-hand smoke. The countervailing effect comes from how smokers respond to these bans. If they smoke more at home or in the car, their partners and children in particular may experience an increase in second-hand smoke exposure. In such a case, a greater number of people are less exposed to a smaller amount of second-hand smoke, while a smaller number may experience a sizable increase in exposure, so the resulting welfare implications are difficult to assess. Especially since many in this group are children, it is not clear that the change in the externality from second-hand smoke exposure from a place-based smoking ban is welfare-improving. We discuss the literature on this aspect of smoking bans in Section 6.

\subsubsection{Fiscal Externalities}


The adverse health effects of smoking can generate several fiscal externalities associated with worse health of smokers themselves:

- Increases in publicly-subsidized healthcare expenditures

- Reduced labor productivity

- Increases in reliance on social assistance programs.

Smoking among pregnant women also can produce negative externalities through reduced birthweight, which is a marker of lower health capital. As we discuss in Sections 4.2.4 and 6.5, research on the impact of anti-smoking policy on such outcomes is relatively thin and comes to mixed conclusions. In this section, we focus mainly on the fiscal externalities associated with smoking outcomes among adults.

As with the direct externalities from secondhand smoke, the question of whether fiscal externalities from tobacco consumption provide a strong economic rationale for taxation or regulation is more complex than it might first appear. The first issue is whether fiscal externalities should even be included in welfare analysis, for example as a term in the expression for the optimal Pigouvian tax. The second issue is whether the fiscal externalities are on net negative or positive. The third issue is whether existing empirical research provides credible evidence of fiscal externalities. We discuss each of these issues in turn.

Whether welfare analysis should include fiscal externalities from tobacco consumption depends upon the nature of public programs that experience the fiscal effects (Browning 1999). For example, if public subsidies distort healthcare decisions, the effect of tobacco use on healthcare expenditures magnifies the pre-existing distortion in the healthcare market. In this case, welfare analysis should include the fiscal externalities; reducing the fiscal externalities increases social welfare by reducing the distortion in the healthcare market. However, Browning (1999) points out that public subsidies also can be viewed as correcting distortions in the healthcare market; the public healthcare subsidies could be set at the optimal Pigouvian level to correct for altruistic externalities from healthcare consumption. Welfare analysis hence should not include the fiscal externalities because reducing them does not improve social welfare. In a general equilibrium expression for the impact of a tobacco tax or regulation on social welfare, the terms involving the change in healthcare consumption will fall out due to the envelope 
theorem if spending is optimal prior to the reform. ${ }^{10}$ However, the result depends on the nature of the altruistic externality; for example instead of their healthcare consumption, the altruistic externality might be driven by concerns for smokers' health. In such a case, fiscal externalities will be less relevant. Beginning with Manning et al. (1989), studies of the externalities from tobacco consumption implicitly treat the subsidies as distortions and include the fiscal externalities. An important direction for future work is to consider more carefully whether the prices in other markets are set at the efficient level or represent pre-existing distortions.

Due to the timing of the health consequences of tobacco consumption, many of the fiscal externalities are estimated to be positive. Whether the fiscal effects of smoking on public health insurance programs are positive or negative depend on whether smokers' lifetime healthcare costs are higher (because of smoking-related illness) or lower (because of their reduced life expectancies). Similarly, the fiscal effects of smoking on the U.S. Social Security program depend on whether smokers' lower lifetime payroll tax payments (due to lower wages and more absenteeism before age 65) are greater or less than their reduced lifetime Social Security benefits (because of their reduced life expectancy). Shoven, Sundberg, and Bunker (1989) simulate the effect of smoking on Social Security payments, employing life tables that are gender and smoking participation specific. They find that the reduction in Social Security benefits is large relative to the other costs of smoking (including healthcare). Sloan et al. (2004) estimate that even after adjusting for their lower lifetime contributions, smokers save the Medicare and Social Security programs money but cost the Medicaid program money. The CBO (2012) presents simulations that indicate that higher cigarette taxes would decrease federal spending through lower healthcare costs in the short run (including lower Medicaid costs for low birthweight infants) but in the long run would increase spending through increased Social Security and Medicare costs. Positive fiscal externalities help explain why the net externalities from smoking are estimated to be relatively small (Manning et al. 1989, Sloan et al. 2004).

Empirical studies face difficult challenges to develop credible estimates of the third-party effects that lead to fiscal externalities, which stem from selection into smoking. A sizable

\footnotetext{
${ }^{10}$ Harberger (1964) and Chetty (2009) show in general that the effects of a tax on a single good on the consumption of other goods contributes to social welfare only to the extent that there are pre-existing distortions in the other markets. Goulder and Williams (2003) stress that the large magnitude of the pre-existing tax distortion in the labor market means that it is particularly important to consider labor market effects. As will be discussed in more detail below, DeCicca et al. (2017) use the Harberger/Chetty approach to develop an expression for the impact of tobacco regulations on social welfare. However, the authors do not discuss fiscal externalities.
} 
literature has arisen that seeks to estimate the effect of smoking on healthcare costs. Most studies rely on selection-on-observables models, mostly using surveys that ask about smoking and healthcare costs. Some studies refer to these models as providing estimates of the healthcare spending of "non-smoking smokers" (Manning et al. 1989, Sloan et al. 2004). Interpreting such estimates as causal is complicated by the fact that those who smoke are likely to have unobserved attributes that make them unhealthier absent their smoking behavior. This will bias upward estimates of the effect of smoking on contemporaneous healthcare spending.

$\mathrm{Xu}$ et al. (2015) is an illustrative example of studies in this literature. They use data from the 2006-2010 Medical Expenditure Panel Survey linked to the 2004-2009 National Health Interview Survey (NHIS). The NHIS data contain rich information on socioeconomic status (e.g., education, income, and household composition) as well as health behaviors (alcohol consumption, BMI, and health insurance status). In a selection-on-observables model that controls for this set of observed characteristics, the authors first estimate the likelihood of having any health expenditures as a function of smoking status and then the level of health expenditure conditional on having positive spending. While one can certainly object to the strong identifying assumptions employed in this approach, as well as the use of potentially endogenous control variables such as health insurance and drinking behavior, there are no obvious alternative approaches that would allow researchers to obtain estimates of the effect of smoking on healthcare expenditures for a representative swath of the adult population. Although the results need to be interpreted carefully, this approach represents the frontier of research on this question.

$\mathrm{Xu}$ et al. (2015) estimate models separately for current and former smokers and find that smoking is responsible for $\$ 170$ billion in healthcare spending per year, which is $8.7 \%$ of total spending. Only $3.2 \%$ is attributable to current smokers, with former smokers adding $5.5 \%$ to healthcare expenditures in their model. This is a curious result and is not due to differences in the relative size of these populations. ${ }^{11}$ Using data from the National Health Expenditure Accounts, they calculate that $57.8 \%$ of these expenditures are from public healthcare programs, such as Medicare, Medicaid, and veterans affairs benefits. These estimates likely are an upper bound on the healthcare costs of smoking among smokers due to negative health selection into smoking. However, they also likely understate the total effect of smoking on healthcare costs because they ignore costs associated with second-hand smoke and maternal smoking.

\footnotetext{
11 There are 9,866 current smokers and 9,647 former smokers in the sample.
} 
Another approach taken by the literature is to use state-year level panel data to estimate the effect of lagged smoking consumption on current-year healthcare expenditures (Lightwood and Glantz 2016). In a model with state and year fixed effects as well as state-year varying demographic controls, they find an elasticity of current healthcare expenditures with respect to the lagged smoking participation rate of 0.12 and a similar elasticity with respect to the lagged number of cigarettes smoked of 0.11 . These estimates suggest that healthcare expenditures are correlated with lagged smoking behavior at the state level, though the causal interpretation of these estimates rests on the strong assumption that smoking variation at the state aggregate level is exogenous with respect to healthcare expenditures. It is likely that unobserved factors, such as macroeconomic conditions, influence both variables. ${ }^{12}$ Taken together, the estimates in Lightwood and Glantz (2016) and Xu et al. (2015) provide suggestive evidence of a negative externality of smoking that comes through the deadweight loss of the general taxation needed to fund higher public health insurance expenditures.

While smoking can cause short-run increases in healthcare costs because of higher disease prevalence, if smokers experience higher mortality at earlier ages, the aggregate long-run effect of smoking on healthcare costs may be negative. Healthcare costs increase substantially with age, and because of Medicare, healthcare expenditures by the elderly are heavily subsidized by public funds. Identifying the causal effect of smoking on age-specific mortality is difficult not only because of selection into smoking but also because of the unknown lag structure of how smoking affects health and mortality. The latter concern makes it hard to ascribe a given health or mortality outcome to any past or present smoking behavior.

Researchers have taken two main approaches to estimating the effect of smoking on mortality. ${ }^{13}$ The first is an "indirect" method first developed by Preston, Glei, and Wilmoth (2010). The idea behind their approach is that in high-income countries, the lung cancer rate among smokers is high but among non-smokers it is very low. Assuming that the lung cancer rate is predominantly due to smoking, they estimate smoking-attributable deaths from other

\footnotetext{
12 Maciosek et al. (2015) take a third approach, which is to first estimate the prevalence of smoking-attributable diseases by age and sex. They then allocate these diseases to smokers and non-smokers using external estimates of the effect of smoking on the risk factors associated with each disease. Finally, they estimate the healthcare costs for each disease using disease-related hospitalization days. They estimate that quitting smoking reduces medical expenditures by $72 \%$, but these results are based on the ability to correctly apportion disease prevalence across smokers and non-smokers and the assumption that smokers and non-smokers with the same disease diagnosis will experience similar medical costs.

13 These methods are discussed more in depth in Lariscy, Hummer and Rogers (2018).
} 
causes by correlating lung cancer with other mortality at the country-year-sex-age group level in a negative binomial regression model. Using this method, Preston, Glei, and Wilmoth (2010) estimate that $24 \%$ of deaths were due to smoking in 2003 among those 50 years of age or older. Fenel and Preston (2013) use this approach on US data alone and find that smoking increases mortality by $21 \%$ among men and $17 \%$ among women in the $50-84$ age group. This method has been widely used in the literature, but it rests on assumptions that are not very plausible. In particular, the assumption that the regression-adjusted correlation between lung cancer deaths and mortality from other causes reflects only smoking behavior is strong. Furthermore, lung cancer deaths before age 50 are relatively rare, which makes this method difficult to use to identify the full distribution of smoking-related mortality.

The second approach is more direct and uses survey data to trace mortality outcomes of smokers and non-smokers. Time since smoking cessation and the non-random nature of smoking decisions more broadly are key endogeneity concerns associated with this approach. To attempt to address these problems, much of this literature focuses on mortality from smoking-attributable diseases, such as lung cancer, diabetes, and ischemic heart disease. However, which diseases are indeed caused by smoking is an open question, and recent work indicates that the set of such diseases is larger than what researchers have traditionally considered (Carter et al. 2015). Estimates using this approach for smoking-attributable diseases and for all diseases show that smoking is associated with a somewhat larger increase in mortality, especially among those over the age of 50 (Lariscy, Hummer, and Rogers 2018; Carter et al. 2015; Thun et al. 2013). Notably missing from this research is the effect of smoking on the age-pattern of mortality, which is important in assessing the net impact on health expenditures. This is a critical missing piece in the literature that we highlight here as an important area for future research.

With publicly provided or subsidized health insurance, any healthcare increases from smoking are likely to induce a negative externality, as the increased healthcare expenditures must be financed by taxes that generate excess burden. Changes in private healthcare expenditures that are financed completely out-of-pocket, on the other hand, are a transfer and do not figure into welfare gains or losses from smoking. However, among those without public health insurance, most healthcare expenditures are financed by private health insurance plans.

At actuarially fair prices charged separately to smokers and non-smokers, the higher healthcare costs of smoking will not generate an externality. If smokers and non-smokers are 
pooled together, smokers will generate a negative externality on non-smokers by raising premiums. Essentially, non-smokers will subsidize higher expenditures by smokers. In practice, insurers can and do charge higher premiums for smokers. There still is risk-sharing across the smoking and non-smoking populations, so the direction of the externality depends on whether the increased premiums for smoking are actuarially fair. If not, then insurance for one group is underpriced and for the other it is over-priced. For example, if prices are actuarially unfair for non-smokers, it could increase moral hazard among smokers (potentially causing them to smoke more) and could exacerbate adverse selection among non-smokers (because prices are too high).

Kaplan, Graetz, and Waters (2014) use the 2007-11 MEPS data to compare the health care costs of smokers and non-smokers. Unlike the research reviewed above, because the Affordable Care Act (ACA) does not allow premiums to vary with other factors, Kaplan, Graetz, and Waters do not control for any variables other than age. In this way, their analysis corresponds to the actuarial calculation allowed by the ACA of whether smoking is an indicator of a person who uses a different amount of healthcare, regardless of whether the difference is due to a causal effect of smoking. Kaplan, Graetz, and Waters find that smokers' healthcare expenditures were slightly lower than non-smokers $(\$ 4,280$ versus $\$ 4,417)$. The results imply that under the restrictions of the ACA on risk-rating, the actuarially fair premium for smokers should be about the same as for non-smokers. Because smokers are estimated to be generating small positive fiscal externalities, charging smokers the premium surcharge allowed by the ACA will not help and might hurt the risk pool.

In practice, there are sizable differences across states in the regulatory environment that govern the size (and hence actuarial fairness) of smoking premium surcharges in private health insurance plans. The ACA caps the surcharge that private insurers can impose on smokers at $50 \%$, but many states have regulations that impose lower caps. In Arkansas, Colorado and Kentucky, surcharges are under 50\%, and in California, Massachusetts, New Jersey, New York, Rhode Island, Vermont, and Washington DC, plans cannot charge higher premiums to smokers. The rest of the states implement the maximum 50\% surcharge to smokers (HealthMarkets Insurance Agency, n.d.). It is not clear how often the state caps on surcharges are binding on health insurers' choices. Kaplan, Graetz, and Waters (2014) collected insurance premium data for tobacco users and non-users for 36 states. Overall, they find that 89 percent of the insurance plans charged smokers a surcharge less than the state cap; the median surcharge was 10 percent. 
In states that used the federal maximum cap of 50 percent, the median surcharge actually imposed was 15 percent. It should be noted that the premium data are for 2014, the first year the ACA smoker surcharges were effective. Based on their subsequent claims experiences, health insurers might be adjusting the smoker surcharges upwards or downwards. Depending upon how often the fact that surcharges are restricted to be in the range from zero to the state cap, the fiscal externalities generated by smoking through the private health insurance system will vary across states; this has received no attention to date in the literature.

In addition to healthcare, smoking can generate externalities through the labor market. Smoking reduces health capital, which is an important component of human capital. As a result, workers can become less productive when working, can miss more days due to illness, or can drop out of the labor market because of an inability to work. These productivity effects can generate negative externalities if they reduce the amount of economic activity in the economy (e.g., if smoker absences reduce the productivity of complementary workers). Similarly, increased mortality at earlier ages reduces the supply of workers, which can have negative effects on economic growth.

The effect of smoking on worker productivity is difficult to measure, and most research in this area has focused on estimating the effect on wages. In a perfectly competitive labor market, wages reflect worker marginal product, so one can interpret any wage effect as a measure of worker productivity. Any wage effects also could reflect discrimination by employers or unobserved productivity differences between smokers and non-smokers that are unrelated to smoking per se (e.g., different time preferences that alter the decision to invest in human capital on the job). ${ }^{14}$ These estimates thus should be interpreted carefully.

Researchers have used both selection-on-observables and instrumental variables methods for identifying the effect of smoking on income or wages. Researchers often jointly model cigarette and alcohol consumption as well. Levine, Gustafson, and Velenchik (1997) employ a selection-on-observables model with data from the NLSY and find that smoking reduces wages by $4-8 \%$. Auld (2005a) models the decision to smoke and drink in a simultaneous equations model and uses the prices of alcohol and cigarettes as well as religiosity as instruments for substance use. In OLS models, he finds that smoking reduces earnings by $8.3 \%$, while his IV

\footnotetext{
${ }^{14}$ Cowan and Schwab (2011) find evidence of a third possibility: smokers are paid lower wages because of their higher expected healthcare costs.
} 
estimate is a much larger $-26.8 \%$. Van Ours (2004) also estimates the effect of smoking and drinking jointly on wages in an IV model using survey data from the Netherlands. He uses whether individuals started smoking (or drinking) before age 16 as an instrument for smoking and drinking. This instrument is suspect because it is likely correlated with unobserved attributes of workers that also influence wages; he finds that tobacco use reduces male wages by between 12 and 23 percent, depending on the set of instruments used. In both the Auld (2005a) and Van Ours (2004) studies, the IV estimates are 2-3 times larger than the OLS estimates, and the results are rather sensitive to the specific set of instruments used. This pattern of estimates indicates potential endogeneity concerns with the approaches taken in these studies. ${ }^{15}$

One might rightly question whether these findings reflect the causal effect of smoking on wages, not to mention productivity. Selection into smoking is a first-order concern, and the extant research on this topic uses instruments that are potentially problematic. Both Grafova and Stafford (2009) and Anger and Kvasnicka (2010) present evidence using longitudinal data on smoking histories that urge caution in applying a causal interpretation to these results. Grafova and Stafford (2009) use the Panel Study of Income Dynamics and show that there is no crosssectional wage gap between former smokers and never smokers. Among smokers, those who in the future will quit smoking currently earn more than those who will continue to smoke. These findings suggest that unobserved heterogeneity drives much of the observed wage penalty associated with smoking. Similarly, Anger and Kvasnicka (2010) use data from the German Socioeconomic Panel to show that the effect of smoking on wages is cut in third if past smoking is controlled for. The results from these studies underscore that the effect of smoking on wages, and more generally on worker productivity, still is an open question in the literature.

Viscusi and Hersch (2001) present further evidence that the relationship between smoking and earnings is difficult to interpret as causal. They show that smokers select into riskier jobs but are compensated for that risk at lower rates than are non-smokers. Hence, smokers have a flatter wage-risk tradeoff than do non-smokers, which affects the jobs into which they sort and on-the-job risk. Essentially, they argue that smokers and non-smokers face a

\footnotetext{
${ }^{15}$ The smoking wage penalty also appears when comparing twins, as was done in Böckerman, Hyytinen, and Kaprio (2015) using a sample of Finnish twins. While use of twins accounts for family-level confounders and genetics, they do not solve the problem of selection into smoking. Indeed, comparing twins may exacerbate selection problems, as the reasons twins make different decisions may be more related to underlying productivity differences than is the case in the general population.
} 
segmented labor market due to differences in risk tolerance, which makes it difficult to interpret even regression-adjusted wage differences as reflecting the productivity effects of smoking.

Related to any reductions in labor market productivity, smoking can generate externalities through the takeup of disability insurance or from increased use of government programs like unemployment insurance, cash welfare (TANF), and food stamps. Like with healthcare spending, the direction of the externality on these programs is ambiguous because of the tradeoff between higher short-run usage and lower longer-run expenditures from increased mortality. There is scant research examining the effect of smoking on these programs, ${ }^{16}$ which is surprising given the volume of research that has focused on health and labor market outcomes.

\subsection{Internalities}

\subsubsection{Overview}

In neoclassical welfare economics, market failures such as negative externalities provide a rationale for tobacco taxation and regulation. Research in behavioral welfare economics adds rationales based on individual failures, i.e. the possibility that smokers are not making decisions in their own best interest. The starting point is the fact that smokers impose substantial health costs on themselves. Estimates of the monetary value of the internal costs of smoking range from $\$ 34$ to \$338 per pack (Cutler 2002, Sloan et al. 2004, Viscusi and Hersh 2008). ${ }^{17}$ If smokers neglect a substantial fraction of their internal costs, the resulting individual failures to make fully optimizing decisions about tobacco consumption will generate policy-relevant internalities. Although as reviewed above estimates of neoclassical externalities tend to suggest that current cigarette tax rates cannot be justified on Pigouvian grounds, internalities are potentially much larger and could justify substantial tax hikes and other tobacco regulations.

Because tobacco contains the addictive chemical nicotine, it also is important to consider the dynamics of tobacco consumption. With addiction and the time-inconsistency and selfcontrol problems documented in behavioral economics research, welfare analysis becomes difficult. The reason is that one's "future self" desires less consumption than one's "current self," which commonly is referred to as an "internality" (Herrnstein et al. 1993). O’Donoghue and

\footnotetext{
${ }^{16}$ Rozema and Ziebarth (2017) present evidence that cigarette taxes induce low-income households to take up food stamps. This reduces the net fiscal benefits of cigarette taxes somewhat, but it does not speak to whether smoking itself causes higher takeup of means-tested programs.

${ }^{17}$ The estimates have been adjusted for inflation through January 2020. Viscusi and Hersh (2008) provide a range of estimates and show that the estimates are sensitive to the assumed exponential discount rate.
} 
Rabin (2006) show that when consumers have self-control problems, taxes can be Paretoimproving by reducing or eliminating the negative internality. The intuition is that one's future self is made better off by the reduced consumption imposed on the current self by the higher price. Essentially, higher taxes on such goods today can reduce "over-consumption" in the future.

To further assess the relevance of internalities as a justification for tobacco taxation and regulation, we next discuss the underlying theoretical models of consumer behavior that lead to internalities, followed by a discussion of quantified estimates of internalities from smoking.

\subsubsection{Rational and Alternative Models of Tobacco Addiction}

The canonical "rational addiction" model and alternative models of addiction yield sharply different implications about the need for cigarette taxes or other regulations. In the rational addiction model, consumers are forward looking and have stable preferences (Becker and Murphy 1988). Current consumption increases future consumption because of the addictive properties of cigarettes. But, smokers understand these dynamics and the addictive nature of cigarettes; they make smoking decisions taking into account these addiction dynamics but their decisions come out of a purely rational and forward-looking optimization problem. Under rational addiction, the addictive nature of cigarettes does not produce any rationale for government intervention because consumers are making fully rational optimization decisions that take into consideration that cigarettes are unhealthy and addictive.

Gruber and Köszegi (2001) expand the rational addiction model to allow for self-control problems. Their model embeds hyperbolic discounting (i.e., time-inconsistency) into a model with addiction. While the empirical implications are similar to those in the rational addiction model, there are critical normative differences. In the Gruber-Köszegi model, the addictive nature of cigarettes combined with limited self-control produces an internality: future utility is

lowered by current consumption. Cigarette taxes can help to reduce this internality by reducing current consumption. Combined with the traditional externalities of smoking discussed above, the "self-control" dimension of cigarette taxes can substantially increase their social welfare benefits.

Bernheim and Rangel (2004) develop an alternative behavioral model of cue-triggered addiction. The model assumes that addiction choices are frequently mistakes, in particular mistakes which are made when the consumer enters a "hot" decision-making mode that favors 
consumption of the addictive good. Environmental cues trigger mistaken usage, but in their "cold" decision-making mode consumers understand their susceptibility to the cues and take steps to avoid them. Bernheim and Rangel argue that their model can account for important patterns documented in psychological research on addiction. The implications for optimal tax policy are complex and depend upon usage patterns. Under some conditions, even when consumers make mistakes, taxation reduces consumer welfare and the optimal tax on the addictive good is negative, i.e. a subsidy. We are not aware of any applied studies that use the Bernheim and Rangel model to derive a specific optimal tax on cigarettes (or some other addictive good). However, the contrast between the theoretical results of Gruber and Köszegi (2001) and Bernheim and Rangel (2004) show that the policy implications from structural behavioral economics can be very model-specific.

Several additional theoretical models yield further insights into the rationale for tobacco taxation and regulation. One concern is that the rational addiction model fails to capture the reality of addiction as experienced by the addicts and the healthcare professionals who treat them. Orphanides and Zervos (1995) model consumers who misperceive their addictive propensity and as a result begin addictions that they later regret. Suranovic, Goldfarb, and Leonard (1999) emphasize withdrawal costs and argue that a key feature of addiction is that consumers want to quit or cut down their addictive consumption but are unable to do so. Gul and Pesendorfer (2007) model compulsive consumption that responds to temptations and define a harmful addiction as the gap between the addict's choice and what she would have chosen before experiencing the temptation. ${ }^{18}$

A possible direction for future research is to explore whether theoretical models adequately capture what is now known about nicotine addiction from modern biological and neurological research. Nicotine stimulates the release of dopamine, a neurotransmitter which plays a role in the feeling of pleasure. Not only is smoking pleasurable in itself, but recent research suggests that nicotine enhances the pleasure of other activities such as watching videos and listening to music (Perkins, Karelitz, and Boldry 2017). Casey, Getz and Galvan (2008) review evidence for a biologically plausible conceptualization of the neural mechanisms that

\footnotetext{
${ }^{18}$ See Cawley and Ruhm (2011) for a review of the behavioral literature on health economics more generally. DellaVigna (2009) provides a broad review of behavioral economics research. Robinson and Hammitt (2011) give an overview of conducting cost-benefit analysis in the context of behavioral economics.
} 
might explain why nicotine addiction and other risk-taking behaviors typically begin during adolescence. The "dual systems model" argues that adolescent risk-taking emerges from an increase in sensitivity to reward and lagging executive control. Neuroanatomical findings generally support this idea by showing different brain regions responsible for these constructs mature at different rates. As one review puts it: "Smokers' brains have learned to smoke, and just like unlearning to ride a bike, it is incredibly hard to unlearn that simple, mildly rewarding behavior of lighting up a cigarette.” (National Institute on Drug Abuse 2018).

The implications of recent biological and neurological research for tobacco regulation remain ambiguous. Suranovic, Goldfarb, and Leonard (1999) suggest that higher taxes might help people avoid or free themselves from an addictive consumption "trap," although they also caution that higher taxes impose additional costs on non-quitters. Like Bernheim and Rangel's (2004) analysis, Gul and Pesendorfer (2007) conclude that higher taxes can reduce the welfare of addicts.

Another rationale for tobacco regulation is that consumers are poorly informed about the health and addiction consequences of tobacco use. Information problems have long been recognized as a source of neoclassical market failure, but behavioral economics research raises additional concerns. Historically, many consumers were unaware of the health and addiction consequences of tobacco use, a situation which cigarette manufacturers exploited and contributed to (Brandt 2007). In high-income countries, almost all consumers are now aware of the major consequences of the use of combustible tobacco products (Kenkel and Chen 2000). Evidence suggests that many consumers are less well-informed about the lower relative risks of noncombusted products including snus and e-cigarettes (Fong et al. 2019, Viscusi 2016). Even when consumers are aware of the evidence, psychological and behavioral economics research suggests that consumers might not use the information in their tobacco use decisions. For example, consumers might not see the consequences as salient, or they might have undue optimism that they will be able to avoid the health or addiction consequences.

An issue that cuts across many behavioral economics models is the welfare-relevance of different types of individual preferences. In models with time-inconsistent preferences, the addictive choice is optimal from the perspective of short-run preferences but sub-optimal from the perspective of long-run preferences. Gruber and Kőszegi (2001) and others analyze internalities from the perspective of long-run preferences, but as Bernheim and Rangel (2007) 
point out, this approach assumes that short-run preferences have no welfare-relevance. Put differently, if addicts are of "two minds" about their addictions, it is not clear which mind should be considered in welfare analysis. For example, instead of focusing solely on the internality costs imposed on the future self, the analysis could also consider the withdrawal costs imposed on the present self. Welfare analysis with internalities is still in its infancy, which leads to much uncertainty as to how tobacco regulation affects individual or social welfare.

\subsubsection{Quantifying the Internalities from Smoking}

Although internalities provide a possibly strong rationale for tobacco regulation, there are surprisingly few quantitative estimates of the magnitude of the internalities from smoking. Gruber and Kőszegi (2001) use the results of their structural model of cigarette addiction with quasi-hyperbolic discounting to quantify the optimal cigarette tax that corrects the internalities. They present a range of estimates. The challenges to this approach stem from the strong modeling assumptions required for structural estimation in general. The specific empirical challenge is to use consumer responses to price changes at different points in the future to back out two discounting parameters: the standard exponential discount rate $\delta$, and the $\beta$ discount rate that captures quasi-hyperbolic discounting and leads to present-biased decisions. Because of the strong modeling assumptions, Gruber and Köszegi note that they are unable to empirically distinguish the addiction model with quasi-hyperbolic discounting from Becker and Murphy's (1988) rational addiction model. Instead, they assume values for $\delta$ and $\beta$, which then drive the size of the optimal tax. Ashley, Nardinelli, and Lavaty (2015) use the Gruber and Konszegi estimates of the optimal tax as a way to estimate the size of the internality.

The FDA used the same approach as in Ashley, Nardinelli, and Lavaty (2015) to measure internalities in a cost-benefit analysis of the graphic warnings label requirement of the 2009 TCA. Levy, Norton, and Smith (2018) discuss in more detail the approach and the ensuing controversy. The FDA cost-benefit analysis of the graphic warnings label requirement began by estimating the value of the health improvements due to reduced cigarette consumption, i.e. the reduction in the internal costs of smoking. The analysis then assumed that smokers' loss of consumer surplus offset part of the value of the smokers' improved health. The FDA used the results of Gruber and Köszegi (2001) to quantify the consumer surplus offset. To illustrate the approach, suppose the health costs smokers impose on their future selves is on average worth $\$ 33$ per pack. Fully rational smokers must receive at least $\$ 33$ of consumer surplus per pack, or 
else they would not smoke. In the fully rational case there is $100 \%$ consumer surplus offset and no internality. A less than fully rational smoker might receive less than $\$ 33$ of consumer surplus per pack. For example, if the smoker only receives consumer surplus of $\$ 11$ per pack, the consumer surplus offset is $33 \%$ (which is within the range used by the FDA) and the internality is $\$ 22$ per pack.

The FDA analysis concluded that due to the internalities the benefits of graphic warning labels exceeded the costs. However, the approach attracted skepticism in the media (including a Doonesbury comic strip) for the implication that smokers lose anything of value when they reduce their cigarette consumption. ${ }^{19}$ Chaloupka, Gruber, and Warner (2015) argue against the consumer surplus offset mainly based on what they term "the principle of insufficient reason." They argue that laws restricting youth access to cigarettes mean that for individuals under the legal age "society has clearly decided that the decision to initiate smoking is an irrational decision.” (p. 116). Levy, Norton, and Smith (2018) show that the consumer surplus offset is consistent with standard behavioral welfare economic analysis.

A working paper by Chaloupka, Levy, and White (2019) develops an estimate of smoking internalities based on the results of a behavioral economics experiment, which then are used to estimate a structural model. The experimental intervention uses financial incentives to encourage cessation in a sample of 397 current smokers. The study identifies behavioral biases by comparing how the smokers actually responded to the incentives (revealed preferences) to their prior predictions about how they think they will respond to the incentives (stated preferences). Compared to their actual responses, the smokers in the experiment were extremely optimistic about their responses to the financial incentives. The estimated structural model implies that smokers impose internalities on themselves worth $\$ 400$ per week, or about $\$ 57$ per pack (for a pack-a-day smoker). The study also estimates that the short-term withdrawal costs of smoking are worth $\$ 8,100$ per week. The estimated dollar values of these behaviors are large because the structural model yields a very small estimate of the marginal utility of income.

As an alternative to strong structural modeling assumptions, another set of studies applies the reduced-form approach to behavioral welfare economic analyses described by Chetty (2015) to evaluate tobacco taxation and regulation (DeCicca et al. 2017). The approach distinguishes the

\footnotetext{
${ }^{19}$ A legal challenge against the graphic warning label requirement was also successful, based on manufacturers' right of free commercial speech.
} 
consumer's decision utility that drives her choices from the consumer's experienced utility, which is assumed to be welfare relevant. Instead of specifying a psychology such as present-bias or lack of salience, the reduced-form approach models the wedge between these utilities. The wedge is a money-valued metric of the distortion where the consumer's choice does not maximize experienced utility. Mullainathan, Schwartzstein and Congdon (2012) use a simple general equilibrium model that incorporates internalities to derive an expression that shows the marginal welfare-effect of a tax on the internality-producing good. Similar to a Pigouvian externality-correcting tax, the expression involves a term that reflects the reduction in internalities. In a similar model tailored to tobacco regulations, DeCicca et al. (2017) derive expressions for the marginal effects of taxation and different forms of regulation on social welfare.

Cutler et al. (2015) and Jin et al. (2015) provide worked examples to estimate the social benefits of regulations that reduce cigarette consumption. The strategy is to use evidence from comparison groups of consumers whose consumption choices appear likely to reveal their true preferences. The strategy is comparable to the idea of using a "counterfactual normative consumer" to quantify the extent of the behavioral bias or internality. ${ }^{20}$

A related insight is that observing consumers' responses to nudges provides evidence about the size of the internality (Levy, Norton, and Smith 2018). Fully rational consumers will not respond to a nudge that removes a behavioral bias, by definition, so consumer responses to nudges reveal the bias. Jin et al. (2015) use this strategy to conduct a benefit-cost analysis of U.S. anti-smoking policies from 1965 through 2010. The observed data on how the consumer demand curve shifted over time in response to the informational nudges over time reveals the value of reducing the internality. To complete the analysis, Jin et al. compare the observed demand curve to the smoking behavior of normative consumers, in this case highly educated and well-informed consumers. As an illustrative result, Jin et al. estimate that in 2010 the marginal internality from smoking was $\$ 3.61$ per pack.

\subsection{Equity}

Cigarette taxes and regulations generate equity concerns that are a function of the strong negative correlation between smoking and income. Figure 5 shows the number of cigarettes

\footnotetext{
${ }^{20}$ In a study of soda consumption, Allcott, Lockwood, and Taubinsky (2019) consider a normative consumer who is as knowledgeable about nutrition as a dietician or nutritionist and who has perfect self-control.
} 
smoked (including zeros) from the 1992-1993 and 2014-2015 TUS-CPS by income bins. Two patterns are apparent. First, cigarette consumption has declined dramatically over time in all income bins. Second, cigarette consumption declines strongly and monotonically with income in both periods: those in the lowest income bin smoke on average about 11 cigarettes per day in 1992-1993 and 3 cigarettes per day in 2014-2015, while those in the top earnings bins smoke about 5 cigarettes per day in 1992-1993 and 0.5 cigarettes per day in 2014-2015. Hence, the amount paid in cigarette taxes also strongly declines with income.

Figures 6 and 7 show the pattern of cigarette taxes paid by each income group directly. We calculate the amount of cigarette taxes paid by multiplying the number of packs smoked per year for each consumer in the TUS-CPS by the per-pack tax in their state and year. We then take the average within each income group. Figures 6 and 7 demonstrate that cigarette taxes are highly regressive. ${ }^{21}$ In Figure 6, the total amount of taxes paid declines with income, as suggested by the differences in average smoking rates by income. Interestingly, taxes paid in each income group is higher in the later period despite smoking rates being much lower, which is due to the rise in cigarette tax rates over this period.

Figure 7 shows the dramatic regressivity of cigarette taxes once one accounts for the share of income paid. The figure shows the average tax rate for each income bin, which is calculated by dividing the total taxes paid by the median income point in each income bin. ${ }^{22}$ In 2014-2015, the lowest-income consumers pay about 2.5 percent of their income in cigarette taxes, while the highest-income group pays under a tenth of a percent. Assuming that cigarette taxes are passed through to consumer prices (an issue discussed in more detail below), the burden of cigarette taxes falls disproportionately on lower-income consumers. The figure shows that as cigarette taxes have risen and smoking rates have declined over time, these taxes have become more regressive. The bottom two income groups paid substantially less as a percentage of their income in 1992 than they did in 2014, while the tax burden among higher-income groups remained constant.

\footnotetext{
21 These figures understate the extent of regressivity because higher-income consumers are more likely to go across states to avoid high local state taxes. We do not incorporate that cross-border shopping behavior into these calculations, and so the amount of taxes paid is likely to be somewhat lower for higher-income consumers than we calculate.

${ }^{22}$ For the top income bins, we use $\$ 75,000$ in $1992-1993$ and $\$ 150,000$ in $2014-2015$.
} 
The conclusions from Figures 5-7 align with those in Colman and Remler (2008). They explore the contention proffered in Chaloupka and Warner (2000) that if low-income smokers are more tax-elastic, cigarette taxes may not be regressive. Colman and Remler's first contribution is to clarify that Chaloupka and Warner are using a tax-expenditure based definition of regressivity/progressivity. From a consumer-welfare based perspective, a tax increase decreases consumer surplus even when their tax expenditures fall. This points to a limitation of the tax-expenditure based definition of regressivity/progressivity. For example, it would seem odd to conclude that a tax on bread that starved the poor is progressive because their tax expenditures fell.

The second contribution of Colman and Remler is to use TUS-CPS data to estimate tax elasticities by income group. They find that while low-income consumers are more tax-elastic than high-income consumers, the difference is not large enough to overcome the negative income-smoking gradient. The results indicate that cigarette taxes are not progressive under either the tax-expenditure based or consumer-welfare based measures. Gospodinov and Irvine (2009) find a similar pattern of results by education group using Canadian data from a time period with very high cigarette taxes. Such findings are not universal, however: Goldin and Homonoff (2013) find that low-income consumers are about half as price-responsive to excise taxes as are high-income consumers using data from BRFSS. They also show that low-income consumers are more responsive to cigarette sales taxes (which are assessed at the register), so income differences in responses to cigarette taxes vary by whether the state charges sales taxes on cigarettes. The results from these papers suggest that the regressivity of cigarette taxes may be somewhat higher or lower than is indicated by Figure 7 due to how different consumers respond to taxes. Yet, even taking into account the potentially larger response of lower-income smokers to taxes found in some of this research, cigarette taxes still are strongly regressive. ${ }^{23}$

Reducing internalities also can reduce the regressive nature of cigarette taxes. Gruber and Köszegi (2004) show that with quasi-hyperbolic discounting, the traditional utility-based tax burden measure is altered by a multiplicative factor that is a function of the degree of time inconsistency and the time horizon. Using data from the Current Expenditure Survey (CEX),

\footnotetext{
${ }^{23}$ One concern with only examining tax-responsiveness is if the incidence of cigarette taxes differs across the income distribution. Harding, Leibtag, and Lovenheim (2012) show that the effect of cigarette taxes on prices of purchased cigarettes varies little with household income, which suggests tax changes do not generate systematic differences in price changes for consumers with different income levels.
} 
Gruber and Köszegi conduct a simulation exercise and demonstrate that under plausible parameter values cigarette taxes are much less regressive and even can be progressive. A core feature of this simulation is the difference in price-responsiveness by lower- vs. higher-income consumers. They find large differences in the CEX data, but as previously discussed, such findings are not universal in this literature. If price-responsiveness does not exhibit a large income gradient, cigarette taxes remain regressive even when consumers have self-control problems (Colman and Remler 2008). Allcott, Lockwood, and Taubinsky (2019) provide a general formula for the optimal sin tax with terms that reflect both the corrective and redistributive motives for taxation.

Up to now, our discussion has focused on the regressivity of cigarette taxes. To the extent that other tobacco regulations make smoking more costly, the same equity arguments apply. However, to the extent they impose different costs on certain population sub-groups, tobacco regulations raise new issues regarding vertical and horizontal equity.

Place-based smoking bans include bans on smoking in workplaces, bars and restaurants, and public spaces. In general, it is not known the extent to which the use of places where smoking is banned, and thus the burden of the bans, varies systematically with income. One exception is that effective July 31, 2018 the Department of Housing and Urban Development requires conventional low-income public housing to ban smoking in all interior spaces including dwelling units. Estimates suggest that about $25 \%$ of the 2 million residents of public housing smoke (Geller, Rees, and Brooks 2016). Future research might usefully explore the equity implications of this and other place-based bans. In addition to the impact on smokers, a complete analysis should account for the impact on the non-smoking users of the places where smoking is banned. For example, some of the first actions regarding workplace smoking were taken to protect workers such as flight attendants from unsafe working environments.

Place-based bans raise additional issues about horizontal equity because they are harder to avoid than taxes. All smokers have to pay cigarette taxes in some form, although one can avoid local taxes by going to a lower-taxing jurisdiction. In contrast, only those who go to bars and restaurants, who work in workplaces covered by the bans, and who use banned public spaces are affected by place-based bans. However, those affected by place-based bans cannot avoid them in the same ways as excise taxes can be avoided. Place-based bans can change the location of smoking (e.g., more smoking in unregulated places like home) - a topic we discuss in Section 
6 - but one cannot avoid them unless one moves permanently to another jurisdiction or takes a job in another jurisdiction without a smoking ban. As a result, the bans will place different burdens on consumers with similar incomes, violating the principle of horizontal equity.

The equity implications of product-based tobacco regulations depend on the extent to which different population sub-groups have different preferences for the regulated product. For example, the patterns of use of different tobacco products in the U.S. vary across racial and ethnic groups. Among current smokers, 74 percent of African-American smokers regularly smoke menthol cigarettes, compared to 21 percent of white non-Hispanic smokers (FDA 2013). A ban on menthol, which the FDA is considering, would have a strongly disproportionate impact on African-Americans. The FDA is also considering banning flavors in little cigars, which would again have a larger impact on African-Americans. African-American young adults are more likely than white non-Hispanic young adults to smoke little cigars (5.7\% versus $1.4 \%$ ), and African-American little cigar smokers are more likely to use flavored little cigars ( $40.8 \%$ versus 20.1\%) (Glasser et al. 2017). In contrast, FDA regulations of e-cigarettes will have larger impacts on white non-Hispanics. For example, white non-Hispanic high school students are almost twice as likely to report using e-cigarettes in the past 30 days than are African-American high school students (32.4\% versus $17.7 \%$ ) (Wang et al. 2019). Complete analysis of the equity implications of product-based regulations raises issues that parallel the discussion above of tax regressivity, including the impact on quitting and the role of internalities. This is an important direction for future work.

\subsection{The Effect of Cigarette Taxes on Consumers}

In this section, we review work on the impact of cigarette taxes on consumer smoking behavior. Since the impact of any tax on smoking behavior depends on the degree to which a given tax increase is passed-through to retail price, we start with a discussion of research on cigarette tax incidence. In section 4.2, we focus on the impact of cigarette taxation on smoking behavior for adults and children, separately, since they embody very different data generating processes that imply different policy effects. We conclude Section 4 with a discussion of the impact of cigarette taxes on health outcomes. We discuss both the potential difficulties in understanding such relationships, but also some recent papers that attempt to overcome such issues and contribute to our knowledge of the health impacts of cigarette taxation. 


\subsection{Incidence}

Understanding how cigarette taxes are passed through to prices is important for several reasons. First, if taxes have little effect on prices, they will not have much of an effect on smoking (though they will affect tax revenues). Second, the pass-through of taxes to prices yields insight into the economic incidence of these taxes: who bears the economic burden of cigarette taxation. Our understanding of the incidence of commodity taxes stems from the seminal work of Harberger (1962). He derives the canonical tax formula that shows the incidence of a tax - how the deadweight loss is split between reducing consumer versus producer surplus - is a function of the relative size of the supply and demand elasticities. The pass-through of taxes to consumer prices is directly related to the relative size of these elasticities and thus provides direct insight into the economic incidence of a tax.

A small literature has sought to estimate the incidence of cigarette taxes. This literature has been constrained until recently by the lack of accurate and non-aggregate price data on which to base such analyses. The early papers examining this question tended to find more-than-full pass-through of taxes to prices. Keeler et al. (1996) estimates over-shifting of between 3 and 26 percent using a state-year panel of aggregate prices from The Tax Burden on Tobacco. The use of aggregate prices is problematic because as Harding, Leibtag, and Lovenheim (2012) and Chiou and Muehlegger (2014) demonstrate, cigarette taxes lead consumers to switch to higherpriced cigarettes. This occurs because cigarette prices are per-pack rather than ad-valorem, so a given tax increase changes the price of high-quality cigarettes less than low-quality cigarettes. This quality upgrading is one reason why prices may appear to increase more than one-to-one with higher taxes. Another potential explanation for over-shifting is market power among producers.

Hanson and Sullivan (2009) extend this literature by conducting a survey of cigarette prices at stores throughout Wisconsin surrounding a 2008 tax hike. They ask about the price of one generic and one name-brand cigarette brand and find that a one-dollar increase in the tax increases prices by between $\$ 1.13$ and $\$ 1.18$. Hence, over-shifting is evident in these data even though they focus on two specific products. The examination of one tax change, however, makes their estimates more subject to bias from secular price trends.

Two papers employ scanner data to analyze this question. Scanner data represent a clear advance over prior work because they provide less error-prone measures of the prices of 
cigarettes purchased as well as detailed product-level information on what cigarettes are purchased. Harding, Leibtag, and Lovenheim (2012) use Nielsen Homescan Data from 20062007 to examine the effect of tax changes on prices. These data include the price and UPC code of every transaction, so the paper can control for the composition of cigarettes purchased. The Homescan data also contain detailed geographic and demographic information, which is a benefit over store-level data because they allow the authors to account for consumer demographics. In a panel model with state, month, and UPC fixed effects, they find a passthrough of 0.845 and can rule out that the pass-through is one at the $5 \%$ confidence level. Excluding the UPC fixed effects leads to an estimate of 0.90 (0.04).

One of the benefits of using high-frequency transaction data is the ability to test for both pre-treatment trends and the time-pattern of effects. Figure 8, reproduced from Harding, Leibtag, and Lovenheim (2012), shows event study estimates of prices surrounding tax changes in their data. There is clearly no pre-tax-change trend in prices, and within two weeks the full shifting of taxes to prices has occurred. This not only validates the panel design of such studies, but it indicates that prices respond quickly to taxes.

Chiou and Muehlegger (2014) perform an analysis that is similar to that in Harding, Leibtag, and Lovenheim, except that they use store-level scanner data from the Dominicks retail chain in Chicago. Focusing on Lorriard, Liggett, and R.J. Reynolds cigarettes, they estimate a pass-through of 0.8 . They also report that the pass-through rate is 0.11 higher for discount cigarettes, which suggests the incidence is a function of cigarette quality. These results match those in Harding, Leibtag, and Lovenheim (2012) closely, although their baseline estimate is somewhat smaller. This is surprising, as they use store-level data rather than consumer data. Part of the effect of taxes on prices may operate through consumer search: as taxes rise, consumers are induced to seek out better prices. Hence, the effect of taxes on consumer prices should be smaller than the effect on prices at a given store. The fact that the Chiou and Muehlegger estimate is below the estimate in Harding, Leibtag, and Lovenheim suggests consumer search, on average, does not drive much of the price effect. We discuss how cross-state purchasing behavior, which is another form of price search, affects the incidence of cigarette taxes in Section 5.1 .

The only recent analysis on cigarette tax incidence that does not use scanner data is DeCicca, Kenkel, and Liu (2013a). They use the TUS-CPS from 2003 and 2006-2007, which 
asks individuals both where they bought their last pack and what price they paid. They estimate full pass-through of taxes to prices with a coefficient on the excise tax of 1.020. They also estimate a larger pass-through of pack versus carton buyers, though both estimates are above 0.8 .

Although the research on cigarette tax incidence uses different data sources, geographies and time periods, the estimates together indicate that most if not all of tax increases are passed through to consumer prices. Because the incidence of a tax is a function of the relative supply and demand elasticities, the incidence of a tax reflects the market structure of the good being taxed (Besley and Rosen 1999). The full pass-through of taxes to prices is consistent with supply being perfectly elastic. ${ }^{24}$

\subsection{The Effect of Cigarette Taxes on Smoking Behavior}

\subsubsection{Background}

One of the central questions in the economics of tobacco regulation is how cigarette taxes affect smoking. Consequently, there is a large literature that attempts to answer this question. In this section, we review this evidence, focusing on adult and then youth smoking. We then summarize evidence on studies that attempt to causally link cigarette taxes to health outcomes. U.S.-based studies dominate this literature due largely to data availability and the federalist structure of the United States that creates fifty-one separate sources of cigarette tax variation.

Cigarette taxes vary considerably by location and over time, which provides an opportunity to exploit within-place variation to estimate their impact on core outcomes like smoking and adverse health shocks. Most studies that estimate the causal impact of antismoking policies use some combination of spatial and temporal variation to identify policy effects. It is worth noting that this sort of variation may not be valid if the policy process is endogenous - that is, if policy implementation, or change, is correlated with other determinants of cigarette smoking. One prominent example of such a potential confounder is "anti-smoking sentiment." Anti-smoking sentiment is largely unobservable and likely correlated with antismoking policies (such as cigarette taxes). Failing to account for this unobserved component of the policy process will bias cross-sectional estimates of the impact of anti-smoking policies on smoking behavior away from zero. Indeed, this is one of the strongest critiques against the early

\footnotetext{
${ }^{24}$ We know of no recent papers that directly estimate the price elasticity of supply. Such estimates would be of much interest to help further understand the incidence of cigarette excise taxes.
} 
studies on the tax-responsiveness of smoking, most of which relied on point-in-time cross sectional data.

Especially since 2000, the available datasets on smoking (see the Online Data Appendix) allow researchers to exploit time and place variation. Most modern studies include place and time fixed effects. The former accounts for place-specific time-invariant unobservables, while the latter is intended to account for secular time trends that impact all locations in the same manner. Effectively, this means that the relevant identifying policy variation is within-place over time. This strategy is sometimes referred to as "two-way" fixed effects. With sufficient within-place variation, it should improve upon older cross-sectional studies that rely solely on place-specific variation to generate their estimates. That said, such a strategy has its own potential pitfalls, as it assumes the strict time-invariance of potentially troublesome unobservables, like anti-smoking sentiment. Furthermore, a recent working paper by GoodmanBacon (2019) highlights problems that can arise in a difference-in-difference setting with timevarying treatments (e.g., states raising cigarette taxes at different times). He shows that when there are time-varying treatment effects, two-way fixed effects models are likely to be biased. This is an important issue for the analysis of cigarette taxes that has not been sufficiently explored by researchers.

The modern smoking demand studies that combine place and time variation are effectively a version of more explicit difference-in-differences models; they are sometimes referred to as "generalized" difference-in-differences. As such, they incorporate the traditional difference-in-difference identification assumptions: the non-changing areas in a given year accurately represent the counterfactual outcomes (conditional on the controls) of states that change their taxes. Put differently, individuals in areas without tax changes must represent what would have happened to those in areas with tax changes had no implementation occurred; individuals in non-changing areas serve as the policy's counterfactual. This identification assumption can be split into two parts: "parallel trends" and the absence of unobserved shocks that are correlated with excise tax changes. The parallel trends assumption refers to the necessity of treatment and control areas trending similarly prior to the tax change. If treatment and control areas have different underlying secular trends in smoking behavior, then the parallel trends assumption will not hold and difference-in-differences estimates, including those from the oftused two-way fixed effects models, will be systematically biased. 
The two-way fixed effect model accounts only for secular trends in smoking that are common to all places. More precisely, it does not account for secular trends that are specific to a given taxing jurisdiction. As a result, the main concern with such a research design is that secular trends in smoking in a given jurisdiction are correlated with the policy changes it implements. For example, if states with already declining smoking rates are more likely to increase cigarette taxes (or increase them by a larger amount), then estimated tax effects will tend to be biased away from zero, ceteris paribus. This concern has led many researchers to include state-specific time trends in their two-way fixed effect models. Indeed, in recent work, including controls for state-specific time trends has become all but standard. However, such a strategy may be problematic if policies like cigarette taxation have not just an immediate (i.e., short-run) impact but also have impacts that develop over time (i.e., longer-run impacts), since the place-specific trend variable will tend to capture these non-immediate impacts.

The issue is highly relevant in estimating the impact of cigarette taxes since, particularly in more recent years, several U.S. states have increased their cigarette taxes at multiple points in time, often in reasonably close temporal proximity. While it is understandable to want to account for state-specific trends, there should be a recognition of the possibility that their inclusion might represent over-controlling. Indeed, this is a more general issue as demonstrated by the recent debate regarding the inclusion of state-specific trends when estimating the impact of the minimum wage on employment (Dube, Lester and Reich 2010, Neumark, Salas and Wascher 2014, Meer and West 2016). We suggest that researchers should at least report estimates with and without the associated controls in order to gain some sense of how much extra legitimate policy variation state-specific trends are absorbing. Researchers also can test for parallel trends more directly by using event study methods, but this is not common in the cigarette literature likely due to the difficulty of estimating event studies when there are multiple "events" (i.e., tax changes) per locality. Understanding whether the parallel trends assumption holds in two-way fixed effects studies at the state-year level is an important direction for future research.

Contemporaneous shocks are a second source of potential bias in the generalized difference-in-difference model. ${ }^{25}$ For example, if states systematically pair cigarette tax increases

\footnotetext{
${ }^{25}$ A third source of bias is measurement error: individuals may misreport whether and how much they smoke. Comparisons of reported smoking to blood cotinine levels (Adda and Cornaglia 2006; Nesson 2017b) and
} 
with other anti-smoking policies, the difference-in-difference estimate will overstate the effect of taxes on prices. Since most papers using this method include multiple tax changes from many states, it is less likely that contemporaneous shocks or other policies will generate bias. However, no prior research has systematically examined this issue.

Generally speaking, economists focus on the two main dimensions of smoking behavior: the extensive margin (i.e., smoking participation or whether or not one reports being a daily smoker) and the intensive margin (i.e., the number of cigarettes smoked, conditional on being a smoker). Historically, researchers in the economics of smoking have examined smoking participation and smoking intensity (or "conditional demand") separately, often via "two-part" models that assume the independence of these two outcomes. Below, we focus largely on smoking participation because public health goals focus on smoking initiation and cessation, which are both extensive margin behaviors. Moreover, a focus on smoking participation keeps the discussion tractable. It also is the case that continuing smokers may compensate for higher cigarette taxes by smoking higher tar cigarettes and/or smoking cigarettes longer or harder (c.f., Evans and Farrelly 1998; Adda and Cornaglia 2006; Chiou and Muehlegger 2014), which complicates the interpretation of intensive margin tax elasticities.

\subsubsection{Cigarette Taxes and Adult Smoking Behavior}

While considerable debate continues regarding the price elasticity of youth smoking (see Section 4.2.3), it is widely accepted that adult smoking is relatively insensitive to price. As noted earlier, the literature relating cigarette taxes to smoking behavior is dominated by U.S. studies. Nevertheless, in what follows, we cite non-U.S. studies where appropriate. Given the relatively large increases in cigarette taxes, in the U.S. and elsewhere since 2000, we place greater attention on studies that have been published over the past two decades.

In their Handbook of Health Economics chapter, Chaloupka and Warner (2000) claim a consensus price elasticity estimate of between -0.4 and -0.7 for adult smoking behavior. Similarly, a well-cited meta-analysis by Gallet and List (2003) based on 523 published studies reports a mean price elasticity of demand of -0.48 with a standard deviation of -0.43 . This is in

comparisons of taxed sales to reported consumption (Gruber, Sen, and Stabile 2003, Stehr 2005) suggest much misclassification error in reported smoking. Hausman, Abrevaya, and Scott-Morton (1998) show that when a binary dependent variable is measured with error, treatment effect estimates will be biased. They propose a maximum likelihood estimator that will account for this bias and provide a measure of the extent of misclassification. Kenkel, Lillard, and Mathios (2004) explore this approach in estimates of a model of smoking participation. 
the lower-middle of the Chaloupka and Warner (2000) range but exhibits a large variance. In both studies, the authors are interested in the total price elasticity of demand for smoking, where "total" refers to the simple sum of the price elasticity of participation and the price elasticity of demand conditional on smoking.

Chaloupka and Warner (2000) state that the consensus is that the participation price elasticity and the conditional demand (intensive margin) elasticity contribute equally to the total price elasticity. This implies that each elasticity ranges from -0.2 to -0.35 , which suggests that adult cigarette smoking participation is quite insensitive to price. In general, it is best practice for authors to report marginal effects and their implications (e.g., the impact of a one-dollar tax increase), rather than price participation elasticities that are highly sensitive to the levels of smoking participation and prices in the sample in question. Because price elasticities are the most commonly-reported metric, we focus on them in this review.

In large part, the consensus estimates by Chaloupka and Warner (2000) and Gallet and List (2003) are generated from relatively early studies of the price responsiveness of aggregate cigarette sales or adult smoking behavior (c.f., Lewit and Coate 1982; Mullahy 1985; Jones 1989; Wasserman et al. 1991; Hamilton et al. 1997; Evans and Farrelly 1998; Jiménez-Martin, Labeaga, and López 1998; Labeaga 1999). Compared to more recent studies, many of these earlier studies used either time series analysis or cross-sectional research designs and consequently have more limited ability to control for factors such as anti-smoking sentiment. Many of the earlier studies were also limited to identifying tax effects with relatively small cigarette tax increases. Despite these drawbacks, more recent studies that use more credible methods and incorporate larger tax changes collectively confirm the relative insensitivity of adult smoking to price (c.f., Cameron and Williams 2001; Farrelly, Bray, Pechacek, and Woollery 2001; Gruber, Sen, and Stabile 2003; Zhao and Harris 2004; Tauras 2006; Chung et al. 2007; DeCicca and McLeod 2008; Lovenheim 2008; Aristei and Pieroni 2009; Gospodinov and Irvine 2009; Harding, Leibtag, and Lovenheim 2012; Callison and Kaestner 2014; Maclean, SikoraKessler and Kenkel 2016; Nesson 2017a).

Figure 9 shows this insensitivity graphically. Each point in the figure comes from either a separate study or from different specifications within one study. We collected these estimates from all papers written since 2000 in which we could either find or calculate from results shown extensive margin price elasticities, also known as price participation elasticities. The $\mathrm{x}$-axis 
shows the median year used in the study, which provides insight into whether extensive margin elasticities have changed over time. We also characterize estimates separately by whether they include state fixed effects and whether they analyze taxes or prices. The estimates are quite stable, with most estimates falling in the range of -0.1 to -0.3 . Despite the need to account for unobserved state heterogeneity, the estimates in Figure 9 exhibit little difference between those that control for state fixed effects and those that do not. ${ }^{26}$ This is a surprising result; a potential reason why the estimates without state fixed effects are similar to those with such controls is that the former include rich enough controls to account for unobserved state-specific heterogeneity that is correlated with taxes/prices and with smoking participation. We also see little difference in the estimates between those that use taxes as a source of exogenous price variation and those that use retail prices. This also is a somewhat surprising result, since retail price variation is less likely to be exogenous as it could reflect unobserved supply and demand factors (e.g., the level of price search by smokers in a given market). Overall, the findings from the empirical literature since 2000 suggest a consensus range slightly more inelastic than the consensus range of -0.2 to 0.35 from Chaloupka and Warner (2000).

Although the majority of estimates fall within a range that is aligned with prior research, several recent studies suggest that this consensus overstates extensive margin elasticities. ${ }^{27}$ One of the smallest elasticities in Figure 9 comes from Callison and Kaestner (2014). Their result is notable because they employ cutting-edge econometric techniques coupled with substantial within-state variation in cigarette taxes and find a much smaller elasticity than much of the rest of the literature. Using data from the TUS-CPS from 1995 to 2007, Callison and Kaestner (2014) estimate standard two-way fixed effects models, along with a novel paired difference-indifferences technique that matches states that implemented large cigarette tax increases with those who did not increase their cigarette tax rate but who have similar pre-increase characteristics. This model, which is inspired by the synthetic control method of Abadie, Diamond, and Hainmueller (2010), explicitly recognizes that the set of all non-tax increasing states is not necessarily a valid control group for states that implement large tax increases. The

\footnotetext{
${ }^{26}$ The exception is the elasticity estimate over -0.5 , which does not control for state fixed effects. This result is an outlier and likely is biased upward in absolute value because of the absence of state fixed effects.

${ }^{27}$ One implication of small extensive margin elasticities is that taxes will not be a sufficiently strong instrument for smoking. This creates additional challenges to empirically estimating the effect of smoking on health (or other) outcomes.
} 
authors focus on a "large change sample" of nineteen states that implemented twenty-two tax increases over their sample period. They then match non-increasing states to states in their "large change sample" based on similar pre-tax trends in smoking participation. Estimates from these models suggest a very small effect of cigarette taxes on adult smoking participation: the main estimate from this matched model specification implies a price participation elasticity of -0.015 . Corresponding elasticities from two-way fixed effects models that do and do not restrict their sample to large cigarette tax increases are -0.058 and -0.026 , respectively. These estimates suggest that doubling the cigarette tax rate would reduce smoking participation by at most between five and six percent.

DeCicca and Kenkel (2015) provide evidence aligned with the findings in Callison and Kaestner (2014) that the prior consensus estimates from Chaloupka and Warner (2000) and Gallet and List (2003) are too large in absolute value. These authors implement a dynamic population model, which projects smoking rates based on US population demographics from 1995 to 2010, a period of numerous and often large cigarette tax increases. Strikingly, they show that changing population characteristics alone predict almost all of the observed trend in adult smoking participation. When their model is extended to include various price participation elasticity estimates that are consistent with the above-mentioned consensus, however, they find that the model substantially under-predicts adult smoking participation. For example, adding the impact of price to the model, via imposing a price participation elasticity of -0.2 , suggests that the actual 2010 smoking rate should be roughly ten percent lower than observed in U.S. National Health Interview Survey data. In other words, if the true elasticity were - 0.2 , the observed smoking rate should be about ten percent lower than observed. Their model continues to underpredict the true 2010 smoking rate at even a price participation elasticity of -0.1 , but overpredicts it at an elasticity of zero. Therefore, their simulation results suggest that the true elasticity lies between zero and -0.1 , which is considerably smaller than typical consensus estimates, but consistent with the findings of Callison and Kaestner (2014). While we cannot be certain, we suspect that these consensus estimates, particularly for smoking participation, are biased upwards in magnitude. In this regard, it is possible that publication bias, which favors statistically significant results, as well as historical inattention to time-varying factors correlated positively with cigarette tax policy and smoking rates, may be responsible for the observed difference. 


\subsubsection{Cigarette Taxes and Youth Smoking Behavior}

Over the past quarter-century the impact of anti-smoking public policies, particularly cigarette taxation, on youth smoking behavior has garnered more interest than adult smoking. Perhaps the primary reason for this attention is that most lifetime smokers report starting regular smoking as teenagers (Chaloupka and Warner 2000; Glied 2002). The underlying logic assumes that if policies can deter youth smoking, they will prevent lifetime smoking, and though there is limited causal evidence to back this notion, it has intuitive appeal (Auld 2005b; Glied 2002; Glied 2003; Breslau and Peterson 1996). Researchers also have posited that youth should be more price-sensitive to cigarette taxation than their adult counterparts for two primary reasons (Chaloupka and Warner 2000). First, the addictive nature of cigarettes implies that established adult smokers will be less price sensitive than youth who are presumably less addicted since they have either not yet started smoking (i.e., smoking initiation) or have smoked for relatively short periods of time. Second, youth are thought to have fewer financial resources available so that the resource effect associated with any given tax-induced price increase will tend to be relatively larger than for adults. However, it is not obvious a priori that youth should be more price sensitive than adults. Indeed, other reasons mentioned less frequently in the literature imply that youth may be less price sensitive. For example, it often is claimed that youth produce social acceptance by smoking. Hence, they should be willing to pay more, all else equal, for cigarettes, which is supported by the fact that teen smokers almost universally smoke more expensive brand name cigarettes rather than generic and discounted ones. Finally, since youth often have to obtain their cigarettes illegally, they likely are willing to pay more than other smokers and are probably less price sensitive.

The earliest youth smoking studies primarily used cross-sectional data. As noted, such studies are particularly vulnerable to omitted variables bias, which overstates the causal impact of anti-smoking policies. These early studies of youth smoking often found smoking participation elasticity estimates near unity, implying that a one percent increase in cigarette price would decrease the probability of youth smoking by one percent (c.f., Lewit, Coate and Grossman 1981; Lewit and Coate 1982; Townsend, Roderick, and Cooper 1994; Chaloupka and Grossman 1996; Chaloupka and Wechsler 1997; Chaloupka and Pacula 1999; Harris and Chan 1999; Gruber and Zinman 2001; Emery, White, and Pierce 2001). The study by Lewit, Coate and Grossman (1981), which used data from Cycle III of the Health Examination Survey in the 
late $1960 \mathrm{~s},{ }^{28}$ represents the early literature on youth smoking reasonably well. While these authors employed a cross-sectional research design, they controlled for anti-smoking publicity, cigarette advertising and other factors that might affect youth smoking and be correlated with state-specific cigarette tax policy. Their estimates imply a total price elasticity of -1.44 , most of which was due to a very large participation elasticity of -1.20 . This estimate is large in absolute value, even for the early studies cited above. Taken together, the participation elasticities of these earlier studies are much larger in magnitude, on average, than more recent studies.

More recent analyses that use now readily-available data with time and place variation in smoking and prices tend to find much smaller participation price elasticities for youth smoking behavior (c.f., Hansen, Sabia and Rees 2017; Lillard, Molloy and Sfekas 2013; Nonnemaker and Farrelly 2011; Sen and Wirjanto 2010; Sen, Ariizumi and Driambe 2010; Carpenter and Cook 2008; DeCicca, Kenkel and Mathios 2008; Sloan and Trogdon 2004; DeCicca, Kenkel and Mathios 2002; Dee 1999). DeCicca, Kenkel, and Mathios (2002) was one of the first papers to employ longitudinal data and to cast doubt on the large participation elasticities found in prior work. They use the National Educational Longitudinal Study of 1988 (NELS:88), which is a nationally representative dataset of $8^{\text {th }}$ graders in 1988 who are followed up until the year 2000. They show that cross-sectional models produce estimates that are similar to those in prior work, but examining how tax changes affect onset of smoking in high school produces estimates that are much smaller and that are not statistically significantly different from zero.

Carpenter and Cook (2008) examine this question using the 1991-2005 YRBSS data in a two-way fixed effects model. They find price elasticities of smoking participation between -0.23 and -0.56, which is between the null estimates of DeCicca, Kenkel and Mathios (2002) and the extant cross-sectional estimates. Hansen, Sabia and Rees (2017) update this analysis by adding four newer waves of the Youth Risk Behavior Surveys (YRBS) to their analysis (i.e., 2007, 2009, 2011, and 2013). They find that the estimated impact of cigarette taxes on youth smoking participation becomes much smaller than implied by the estimates of Carpenter and Cook (2008) and more consistent with those in DeCicca, Kenkel and Mathios (2002). When restricting their models to data from 2007 to 2013, Hansen, Sabia, and Rees (2017) show little systematic evidence of any negative relationship between cigarette taxes and youth smoking participation. Their explanation of these findings is that the composition of youths at-risk for smoking has

\footnotetext{
${ }^{28}$ The Health Examination Survey is an early precursor to the NHANES dataset.
} 
changed over time, such that the youths who now at risk are less price sensitive. While plausible, they are not able to test this potential explanation directly.

Finally, Lillard, Molloy and Sfekas (2013) estimate the effect of prices and taxes on youth initiation using NELS:88, PSID, and TUS-CPS data. The participation elasticities implied by their estimates range from -0.03 to -0.23 depending on the age subsample in question, and they highlight that youth initiation elasticities are sensitive in particular to the window over which initiation can be observed. While they do find statistically significant participation elasticities, their estimates are consistent with the recent research discussed above in showing that youth are decidedly price inelastic in their smoking initiation decisions.

In sum, the literature on the impact of cigarette taxes on smoking behavior suggests that the smoking behavior of both adults and youth are inelastic. This topic is likely to continue to be front and center in the economics of tobacco regulation literature, especially as cigarette taxes increase to ever higher levels and better data on smoking behavior become available. Additionally, new research that takes into account the evolving context in which smoking decisions are made is an important direction for future work. For example, the introduction of ecigarettes as an alternative to cigarettes adds a layer of complexity to modeling smoking decisions since such an innovation may be a precursor to future cigarette smoking or perhaps a longer-run substitute for it. We discuss the limited evidence on cigarette alternatives in Section 5.2, which we expect to be an increasingly important area of study to understand more fully how smoking behavior reacts to cigarette taxes.

\subsubsection{The Impact of Cigarette Taxes on Health Outcomes}

Understanding the link between anti-smoking policies and actual health outcomes may be the "holy grail" of the economics of smoking literature. A major reason we care about whether anti-smoking policies reduce smoking behavior is an often-implicit assumption that reductions in smoking will translate into improvements in health. That said, economists often draw a distinction between the health effects smokers impose on themselves and those they impose on others, as discussed in Section 3. In what follows, we discuss both types of health outcomes.

The connection between tax-induced behavior changes and improved health outcomes is difficult to establish for two main reasons. First, it is very difficult to link policies to long-run health outcomes like mortality. Many health conditions associated with smoking such as heart disease, lung cancer, emphysema, and overall premature mortality are processes that develop 
over long periods of time. As a result, causally linking current or past policies to such outcomes is subject to the effects of potential confounders. Indeed, the types of generalized difference-indifferences methods that dominate smoking-related research are amenable to capturing impacts that occur relatively immediately, but they are less able to plausibly identify causal effects for conditions that develop more slowly. Moreover, even if there is a causal connection, it is difficult to know the appropriate lag between policy implementation and disease onset and progression. Second, from a pure data perspective, individuals are mobile, and it is difficult with existing data to characterize the policy regime faced throughout their lives. For example, doing so for adult outcomes requires detailed information regarding one's place of residence from at least the teenage years through late adulthood. For these reasons, there are not many studies that attempt to causally link tax policy and long-run adult health outcomes.

We discuss the more recent public health literature on the relationship between smoking and mortality in Section 3. Here, we focus on the small literature in Economics that has studied this question. Moore (1996) is the first and one of the only papers in economics to attempt to causally link cigarette taxes to morbidity and mortality in a rigorous manner. Using a two-way fixed effects approach, he estimates models that examine the contemporaneous impact of state cigarette tax rates on state-level death rates from cardiovascular disease and respirator cancers separately, using data from 1954 to $1988 .{ }^{29}$ He finds a negative relationship between cigarette taxes and these health outcomes.

Moore (1996) serves to highlight some of the difficulties of trying to causally link antismoking policies to morbidity and perhaps especially, mortality. Of these issues, those surrounding timing are likely the largest hurdle to estimating valid causal effects. In particular, it is difficult to understand both the appropriate lag structure between any anti-smoking policy and the disease in question and to adequately characterize the policies actually faced by an individual over his or her lifetime due to residential mobility. ${ }^{30}$ Perhaps because of an increased recognition of such issues, economics research on the health impacts of smoking turned to birth and infant health outcomes in the late 1990s and early 2000s. And, while it is not clear that exposure to

\footnotetext{
${ }^{29}$ This method is in between the "indirect" and "direct" methods used by more recent researchers discussed in Section 3.

${ }^{30}$ While explicitly linking changes in regulation to mortality is very difficult, as noted above, Bedard and Deschenes (2006) provide reasonably compelling evidence that access to heavily subsidized cigarettes led to reduced lifespans for WWII and Korean War veterans.
} 
parental smoking truly imposes external costs on smokers' children, since compensation may be made within the household, such exposure is clearly more likely to involve external costs than any harm smokers may do to themselves.

Evans and Ringel (1999) was the first published study in economics to examine the impact of cigarette excise taxes on maternal smoking behavior during pregnancy and subsequent birth outcomes. Using data from the 1989-1992 Natality Detail Files, these authors find systematic effects of higher cigarette taxes on maternal smoking participation and birth weight. With respect to maternal smoking participation, their estimates imply a price participation elasticity of about -0.50 . They use this estimate, in conjunction with a reduced-form estimate of the impact of cigarette taxes on birth weight, to construct an instrumental variables estimate that suggests that tax-induced cessation among pregnant women leads to an average birth-weight gain of about 400 grams (i.e., roughly thirteen ounces or three-quarters of a pound) to her newborn child. While strongly suggestive of improved newborn health, it is unclear that such tax-induced quitting occurs in the lower tail of the birthweight distribution; estimates of the effect on "low" and "very low" birthweight births do not point to a systematic relationship between taxes and these adverse birth outcomes. In other words, the distributional impact of these authors' main estimated effect is unclear, and this matters since gains in birthweight at the lower end of the distribution are almost certainly more indicative of improved newborn health than gains higher in the distribution.

Other studies that use data from time periods similar to and somewhat later than Evans and Ringel (1999), as well as comparable methods, find similarly large effects on maternal smoking participation. For example, Ringel and Evans (2001) find an implied price participation elasticity of -0.70 , with significant heterogeneity across certain demographic groups, while Gruber and Kőszegi (2001) and Gruber and Zinman (2001) find price participation elasticities between -0.30 and -0.40 for pregnant women and pregnant teenagers, respectively. Like the original Evans and Ringel (1999) study, all of these studies use data from the Natality Detail Files. More specifically, Ringel and Evans use data covering 1989-1995, Gruber and Kőszegi (2001) use 1991-1997 data, and Gruber and Zinman (2001) use 1989-1996 data. Bradford (2003), using data from the National Maternal and Infant Health Survey for the years 1988 and 1991, finds a nearly identical price participation elasticity of -0.34 , but his estimates imply a similar elasticity for non-pregnant women of the same ages, which suggests that the impact may 
be specific to the age group, rather than due to pregnancy. Colman, Grossman and Joyce (2003) cover a reasonably similar time period but take a different approach to estimating the price sensitivity of maternal smoking behavior based on better detail on the timing of smoking by pregnant women. Using data from the 1993-1999 waves of the Pregnancy Risk Assessment Monitoring System (PRAMS), which contains information on smoking at multiple points in time - in particular, before, during and after pregnancy - the authors find implied price elasticities of prenatal smoking cessation and postpartum relapse that are close to unity. Their findings suggest a strong response of maternal smoking behavior to prices.

A common shortcoming of these studies is that they necessarily exploit relatively small cigarette tax increases. More recent studies rely on larger increases and/or use sources of price variation that are plausibly more exogenous than previous work. Lien and Evans (2005) examine the impact of four large increases in state cigarette taxes, ranging from fourteen to fifty cents per pack that occurred in 1993 and 1994. These authors estimate price participation elasticities among pregnant women ranging from -1.83 in Massachusetts to -0.10 in Illinois. Corresponding elasticities in the other two states analyzed-Michigan and Arizona-were -0.22 and -0.33 , respectively. Aside from the very large Massachusetts elasticity, the authors find relatively small tax impacts on maternal smoking participation. With respect to birthweight, the authors find that smoking cessation leads to a 189 gram, or roughly seven-ounce, increase in birth weight when they pool data from three of their four large-increase states, a figure substantially smaller than the corresponding 400-gram weight gain implied by Evans and Ringel (1999). Estimates from regressions that model the low birthweight threshold provide some evidence that these gains occur in the lower tail of the birthweight distribution. However, there is not a strong correspondence between price-sensitivity and improved birth outcomes. For example, despite the much greater price-sensitivity of smoking participation by Massachusetts mothers, the implied impacts on Massachusetts birth outcomes in reduced form and instrumental variables models do not differ much from the other three large-increase states.

Levy and Meara (2006) exploit the per-pack price increase of roughly forty-five cents that followed the Master Settlement Agreement to examine the impact of higher cigarette prices on maternal smoking behavior. ${ }^{31}$ Using data from the January 1996-February 2000 Natality

\footnotetext{
${ }^{31}$ The Master Settlement Agreement (MSA) was an agreement whereby forty-six states and the four largest tobacco companies resolved these states' legal claims against these cigarette manufacturers for smoking-related expenses
} 
Detail Files, these authors find evidence of much less price sensitivity on the part of pregnant women, relative to the other studies cited, though they find greater sensitivity among teen mothers. In particular, their estimates imply price participation elasticities of -0.13 for all women and between -0.30 and -0.40 for teen mothers, consistent with Gruber and Zinman (2001). As the authors note, a key shortcoming is that all forty-six states that participated in the MSA experienced the same forty-five cents per pack increase in price. Such before-and-after type variation implies the lack of a well-defined control group. To address this, Levy and Meara (2006) also examine relative price changes induced by the flat forty-five cent increase but find no evidence of price sensitivity in the smoking participation of pregnant women in these models. These authors speculate that recent reductions in smoking participation during pregnancy and the resulting increase in the fraction of "intransigent" smokers in the remaining pool of smokers may be partially responsible for their smaller estimates.

Markowitz et al. (2013), using PRAMS data from twenty-nine states from 1996 to 2008, corroborates the conclusions from Levy and Meara (2006). They find a limited effect of cigarette taxation on two birth outcomes - weeks of gestation and birthweight. In particular, these authors detect effects only for younger women, and no such effects for women over twenty-four years old. Moreover, the birthweight impacts for younger women are relatively small in magnitude. For example, they find that a one-dollar tax increase is associated with a thirty-gram increase in birthweight for teen mothers, but this is based on a marginally statistically significant coefficient as can be seen in their Table 2. Finally, a recent review style article by Lakdawala and Simon (2017) documents the declining elasticity of smoking participation among pregnant women over time and then considers four possible explanations: a change in statistical methodologies, a change in the rate at which tax is passed-through to cigarette price, the "local price environment" of tobacco products, and a composition change in the population of maternal smokers. The authors find suggestive evidence that there has been a compositional change in the population of maternal smokers. Specifically, the fraction of mothers thirty-five and over who smoke has fallen dramatically from the early 1990 s to the middle 2000 s, and these mothers tend to be more sensitive to price. They argue that this compositional shift has driven the absolute decline in the

\footnotetext{
incurred via their Medicaid programs. The original settlement called for payment of roughly $\$ 200$ billion over a twenty-five-year period. Levy and Meara (2006) estimate that the MSA led to a roughly forty-five cent increase in cigarette price, which they then treat as exogenous variation to examine the impact of price on the smoking behavior of pregnant women.
} 
elasticity of maternal smoking participation that they identified, though they note that more work needs to be done to better understand the true underlying cause.

The economics literature also has directly examined how cigarette taxation affects infant and child health outcomes. As with birth outcomes, an advantage of studying infant and child health is that the period between the policy in question (here, cigarette taxes) and the measure of child health is likely not so lengthy as to make two-way fixed effect modeling overly suspect. This is particularly true if early childhood health outcomes are examined. Almond, Chay, and Lee (2005) estimate how maternal smoking relates to health outcomes in a selection-onobservables model with US Natality Detail File data. They find little evidence that lower birthweight induced by smoking leads to adverse health outcomes. ${ }^{32}$ This finding is quite controversial and suggests that the lower birthweights from smoking do not lead to adverse health outcomes in the manner suggested by the cross-sectional relationship.

A recent study by Simon (2016) provides evidence that Almond, Chay, and Lee (2005) understate the impact of smoking on child health and development. He examines the impact of exposure to cigarette smoke in-utero and infancy on school absences and physician visits, as well as hospital admissions and asthma. This paper is the current gold standard because the focus on later-in-childhood outcomes allows him to directly assess the medium-term consequences of early-childhood or in-utero exposure to cigarette smoke. Using restricted-access data from the National Health Interview Surveys on children aged two to seventeen, he finds that a one-dollar tax increased experienced during pregnancy results in a ten percent decrease in school absences and nearly a five percent reduction in having two or more doctor visits. While Simon uses data from 1997 to 2010, roughly three-quarters of the main sample is from the 1990s when tax increases were much smaller than in the first decade of the twenty-first century. Nevertheless, taken as a whole, the results of Simon (2016) suggest that cigarette excise tax policy may have effects that extend beyond birth. Given the recent deep interest in the persistence of positive policy-induced program effects (Hoynes, Schanzenbach and Almond 2016), we expect to see more research of this kind in the coming years.

\section{Tax Avoidance}

\footnotetext{
${ }^{32}$ One reason for the lack of an effect could be that the health benefits from avoiding in-utero nicotine exposure are balanced by higher stress hormone exposure induced by quitting smoking while pregnant.
} 
The high level of cigarette taxes in many areas of the United States provide extensive scope for tax evasion and avoidance behaviors. ${ }^{33}$ Such behaviors can substantially alter the effect of cigarette tax increases on smoking behavior, net health effects, and social welfare.

Cigarette tax evasion, or "organized smuggling" is relatively rare in the US. It became a Federal crime in 1978 with the passage of the Contraband Cigarette Act. The Act led to a large decline in organized smuggling (ACIR 1985), with the best estimates suggesting between 3 and 7 percent of purchased cigarettes coming from such illegal sources (Thursby and Thursby 2000). Organized smuggling has received little attention in the literature as a result, and we hence do not focus on it in this review.

In contrast, tax avoidance, or "casual smuggling," is quite prevalent in the United States and around the world. Much of this avoidance behavior comes from consumers traveling across states or countries to lower-tax jurisdictions or purchasing low-tax cigarettes over the Internet. In the US and Europe, there are large differences across uncontrolled states/country borders that make it relatively easy and lucrative for many smokers to avoid local taxes by driving to a lowertax area. Depending upon the jurisdiction and quantity purchased, such tax avoidance behavior can be legal. Consumers also can avoid cigarette taxes by substituting to untaxed or lower-taxed forms of tobacco (e.g., e-cigarettes, cigars, cigarillos) or to other products such as alcohol, marijuana, or food. The extent and impact of tax avoidance on smoking and on substitution behaviors represents a large and growing area in the study of tobacco regulation. In this section, we first review the large body of evidence on geographic tax avoidance. This more traditional form of tax avoidance has received considerable attention in the literature and has been a recent focus in the economics of tobacco regulation. Next, we discuss the evidence on the less-studied source of tax avoidance: cross-product substitution. We review the small literature on this type of tax-induced substitution behavior and highlight areas for future research.

\subsection{Tax Avoidance Across Space}

Cigarette taxes vary considerably across space, which creates ample opportunity for avoidance and evasion behavior by consumers. The extent of cigarette tax avoidance is important

\footnotetext{
${ }^{33}$ Tax avoidance refers to legal behaviors that lead consumers to avoid paying a given tax, while evasion refers to illegal behaviors. The difference between avoidance and evasion is subtle for cigarettes. Much cross-state purchasing activity falls under "avoidance" because it is not illegal to purchase cigarettes in another state or jurisdiction. Most states allow consumers to purchase two or three cartons from other states without paying use tax. In practice, many consumers likely purchase more than this amount, and virtually no use tax is paid on cigarettes in the US.
} 
to understand because it threatens the seemingly benign tradeoff between raising revenue and reducing smoking: avoidance can lead to a situation in which taxes neither reduce smoking nor raise revenue for the tax-increasing jurisdiction. Instead, it imposes excess burden on consumers in the form of avoidance costs. By functionally lowering the taxes smokers face and by inducing smokers to buy in bulk and stockpile, smoking intensity can actually increase.

To illustrate the large difference in taxes across uncontrolled borders in the US, Figure 10 shows the absolute difference in state cigarette excise taxes for every state border pair in the lower 48 states (plus D.C.), as of the start of 2018. Only one border, Connecticut and New York, has no tax difference. Sixty-five borders (60.2\% of the total) have tax differences of 50 cents or larger, and 32 (29.7\%) have differences of one dollar or larger. The average excise tax is $\$ 1.75$ per pack, so the excise tax savings across many borders is quite large. The two largest tax differential borders are Idaho-Washington (\$2.46) and Washington D.C.-Virginia (\$4.20). The former border is relatively unpopulated while the latter is highly populous, which underscores the straightforward but important point that border tax differences matter most to consumer behavior when there are larger populations living near them.

State borders are not the only borders that are relevant for cross-border purchasing. Many cities and counties levy their own cigarette taxes as well. Because of the relatively small geographic coverage of these local taxes, they often are easy to avoid. New York City and Chicago are the two cities with the largest combined tax levels: New York City has a per-pack tax of $\$ 1.50$, which brings the total per-pack tax to $\$ 5.85$, while the City of Chicago and Cook County have a combined tax of $\$ 4.18$, which leads to a total per-pack tax of $\$ 6.16$.

Native American reservations are another common source of tax avoidance. Because of their semi-autonomous legal status, sales on reservations are not automatically subject to state sales taxes. The Supreme Court case in Moe v. Confederated Salish and Kootenai established the legal authority for states to impose excise taxes to sales occurring on Native American reservations to non-tribal members. States have acted unevenly to tax these sales through state laws and compacts with individual tribes. Currently, 27 states have legislation or tribal compacts for the taxation of sales on Native American reservations. These regulations are heterogeneous, however, and may not all have similar effects on prices. Furthermore, enforcement is made difficult by the fact that only sales to non-tribal members are taxable. It is not obvious that the special tax status of Native American reservations will lead to lower prices, as the tax status 
generates market power. In an analysis of New York State from a period before the state began collecting taxes on reservation sales, DeCicca, Kenkel, and Liu (2015) find that for all but one reservation the tax savings are fully passed through to consumers in the form of lower prices.

A final source of lower-tax cigarettes is from Internet sales. In the early 2000s, when Internet penetration rates were rising, consumers increasingly purchased tax-free cigarettes online. These cigarettes often came from Native American reservations. Despite the increased use of the Internet for commerce, online cigarette sales have become rare. This change occurred because the major mail carriers in the US no longer ship cigarettes and the major credit card companies have agreed not to process payments for online cigarette purchases. These effective online sales bans occurred in two stages. In October 2005, Federal Express and UPS voluntarily agreed to stop shipping cigarettes from Internet vendors. Credit card companies and PayPal joined this agreement to cease processing payments as well. ${ }^{34}$ However, it still was possible to ship cigarettes through the US Postal Service. This became illegal in 2010 with the Federal Contraband Cigarette Trafficking Act and the Prevent All Cigarette Trafficking Act (PACT). The laws functionally eliminated the ability to purchase cigarettes online to avoid local taxes.

Avoidance behavior leads to lower revenue for the taxing jurisdiction and can undermine any efficiency gains from the tax. The effect of avoidance behavior on the efficiency gains or losses from cigarette taxes comes through the effect on prices that consumers face as well as through the direct cost of the avoidance behavior. Tax avoidance leads consumers to face lower prices for two reasons. The first is mechanically due to the fact that consumers are purchasing in a lower-tax jurisdiction. The second is that differences in taxes across space combined with the willingness of consumers to travel to avoid local taxes generates spatial competition. This competition induces stores in areas that are closer to lower-tax borders to increase prices less in response to a tax increase. Both the mechanical and the competition effects lead to more smoking as a result of lower prices.

Cross-border tax avoidance also may increase cigarette consumption because of the fixed cost of avoidance. If smokers travel to another jurisdiction, they are likely to stockpile cigarettes such that the tax savings is more than the fixed cost of travel (including their time). Consumers are then faced with a stockpile of an addictive good, which can lead to increased consumption. Lovenheim (2008) presents suggestive evidence of this effect by examining smoking behavior

\footnotetext{
${ }^{34}$ See Ribisl et al. (2011) for more details on the US shipping bans and credit card agreements.
} 
within MSAs that split state lines. He shows that smoking is systematically higher on the hightax side of the border, which is consistent with stockpiling behavior increasing consumption.

Harding, Leibtag, and Lovenheim (2012) present direct evidence of how cross-border avoidance affects cigarette purchases. They use distance from a lower-tax border, the tax difference between the home and lower-tax state, and the interaction of the two as instruments for cross-border purchasing. Cross-state purchasing reduces the price paid by about $\$ 1.00$ and increases the number of cigarettes purchased by about 3.7 packs, or almost 75 cigarettes. This is a large quantity response, which could be driven by the fact that marginal cross-state purchasers are more price-elastic and/or by stockpiling behavior.

If the externalities and internalities associated with smoking net of taxes are negative, tax avoidance reduces the efficiency gains from taxation by muting the smoking reduction. Importantly, it also increases excess burden of the tax as the cost of travel is pure deadweight loss. DeCicca, Kenkel, and Liu (2013b) make this point explicitly by estimating an endogenous switching regression model in which the decision to purchase cigarettes in a nearby lower-tax locality is endogenous to both the tax difference and the distance to the locality. They find that higher taxes induce smokers to cross-border shop. When they embed this effect into a Pigouvian optimal tax framework, they estimate that cigarette taxes are $20 \%$ too high on average. Intuitively, the size of the net externality is attenuated by the deadweight loss from cross-border shopping, which lowers the optimal tax level.

Together, the estimates in DeCicca, Kenkel and Liu (2013b) and Harding, Leibtag, and Lovenheim (2012) underscore that cross-border tax avoidance reduces the amount of revenue raised, undermines the goal of reducing smoking, and generates socially wasteful costs that are borne by consumers. If cross-border avoidance behavior reduces the desirability of cigarette taxes on efficiency grounds, from a policy perspective it may simply argue for a uniform tax across states that is much harder to avoid.

Tax avoidance also can alter the equity implications of cigarette taxes, but here the predictions are more ambiguous. How avoidance affects equity rests on which consumers crossborder shop and whether income is correlated with distance to a lower-tax border. The effect of tax differences across areas on consumption and prices has received considerable attention in the literature, but to date income-based heterogeneity in these responses and the resulting impact on cigarette tax equity have remained largely unexplored. 
Though the literature is dominated by US studies, cross-border tax avoidance is by no means a US-only phenomenon. Particularly in Europe, similar incentives exist across borders. For example, when France raised cigarette prices in 2001-2004, cigarettes in France became substantially more expensive than in bordering Germany, Italy, Spain, Luxembourg and Belgium (Lakhdar, Vaillant, and Wolff 2016). The open-border European Union policies generate the ability for tax avoidance similar to those in US states.

\subsubsection{Tax Avoidance and Price Elasticities of Demand}

Estimating the effect of cross-border avoidance on consumer behavior is important for two reasons. The first, as discussed in Section 3, is that avoidance increases deadweight loss from taxation and threatens the tradeoff between smoking reductions and revenue increases. Hence, understanding the extent of cross-border purchasing behavior as well as what characteristics correlate with such avoidance is of first-order concern when considering the optimal design of cigarette taxation.

The second reason that it is important to identify the extent and character of cross-border cigarette smuggling is that it generates a bias in traditional estimates of tax elasticities of smoking. Consider a straightforward log-linear demand model as in Lovenheim (2008): $\ln \left(Q_{i}\right)=\beta_{0}+\beta_{1} \ln \left(T_{j}\right)+\gamma X_{i}$,

where $Q_{i}$ is the quantity of cigarettes consumed by individual $i$ and $T_{j}$ is the per-pack tax rate in jurisdiction $j \in\{$ home, border $\}$. For simplicity, assume $\left(T_{h}>T_{b}\right)$. Letting $S_{i}$ be an indicator for whether the individual smuggles (i.e., purchases in the border state), we can re-write equation $(\mathrm{X})$ as:

$$
\begin{aligned}
\ln \left(Q_{i}\right) & =\left(1-S_{i}\right)\left(\beta_{0}+\beta_{1} \ln \left(T_{h}\right)+\gamma X_{i}\right)+S_{i}\left(\beta_{0}+\beta_{1} \ln \left(T_{b}\right)+\gamma X_{i}\right) \\
& =\beta_{0}+\beta_{1}\left(\ln \left(T_{h}\right)\left(1-S_{i}\right)+\ln \left(\mathrm{T}_{\mathrm{b}}\right) S_{i}\right)+\gamma X_{i} .
\end{aligned}
$$

The elasticity with respect to the home state price is

$$
\epsilon_{h}=\beta_{1}\left(1-S_{i}\right)-\frac{\Delta S_{i}}{\Delta \ln \left(T_{h}\right)} \beta_{1} \ln \left(\frac{T_{h}}{T_{b}}\right) .
$$

If $S_{i}$ is zero, and thus all purchases occur in the home state, $\epsilon_{h}=\beta_{1}$. However, when $S_{i} \neq 0$, the home state tax elasticity will be biased towards zero in absolute value (i.e., $\epsilon_{h}<\beta_{1}$ ). The bias is a function of the extent of cross-border purchases, the sensitivity of cross-border purchases to the home state tax, and the tax difference across states. 
Note that when $\epsilon_{h}<\beta_{1}$, both parameters are of interest. $\epsilon_{h}$ shows the policy effect of how smoking responds to a change in home-state taxes that incorporates endogenous cross-state behavior. In contrast, $\beta_{1}$ shows the elasticity of smoking with respect to the full tax rate faced by consumers. Hence, the former is a policy parameter while the latter is a more structural parameter that shows how smoking responds to prices. Assuming taxes are fully passed through to prices, $\beta_{1}$ is the price elasticity of demand. This distinction is important in practice, as sometimes researchers are interested in identifying the sensitivity of smoking to prices while other times they are interested in estimating the policy effect of a given tax change.

\subsubsection{Empirical Evidence on Tax Avoidance}

How extensive is cross-border purchasing behavior and how does such behavior influence the smoking and revenue effects of excise taxes? There is a sizable literature that has emerged to answer these questions. This literature faces a core measurement problem: most datasets do not ask the location of purchase, and even in those that do there is concern about truthful reporting. Because cross-border purchasing is quasi-legal, people may misreport avoidance behavior even when asked.

Researchers have taken several approaches to identifying the extent and impact of casual cigarette smuggling:

1) Use differences between administrative taxable sales rates and reported smoking rates at the state level.

2) Leverage variation in the costs and benefits of avoidance: the distance to lower-tax jurisdictions and the level of tax differences across borders.

3) Examine tax stamps on discarded cigarette packs that show the location of purchase.

4) Use datasets that record the location of purchase.

The National Research Council and Institute of Medicine (2015, pp. 102-103) reviews estimates from these approaches that imply that cross-border purchases account for between $8.5 \%$ and $21 \%$ of aggregate cigarette sales in the U.S. Each of the approaches has strengths and weaknesses that highlight the difficulty in identifying cross-border cigarette purchasing behavior. We discuss the research related to each of these methods in turn below. Together, the studies using these different methods provide a rich picture of how cross-border purchasing affects responses of consumers to local tax changes. 
The early literature on cigarette tax avoidance focused on the difference between taxable sales at the state level and consumer-reported smoking within each state. If consumers avoid local state taxes, the estimated tax elasticity using taxed sales data will be biased upward (in absolute value), while the elasticity using consumption data will be biased downward (in absolute value). This occurs because avoidance generates a decline in state taxed sales while weakly increasing cigarette consumption.

Stehr (2005) and Gruber, Sen, and Stabile (2003) are the most prominent examples of this early approach. ${ }^{35}$ Stehr's study focuses on the U.S. context and compares smoking at the state level from BRFSS to taxed sales. He finds a consumption elasticity of -0.38 and a sales elasticity of -1.1 , which is evidence consistent with substantial levels of tax avoidance. He then directly estimates the effect of raising the state cigarette tax on the log of the ratio of sales to consumption. The findings indicate that raising the excise tax lowers this ratio considerably, which is consistent with cigarette tax avoidance. ${ }^{36}$ Assuming that all of this effect represents avoidance, Stehr (2005) calculates that $12.7 \%$ of cigarettes in 2001 were purchased without payment of home-state taxes. Gruber, Sen, and Stabile (2003) provide a similar analysis for Canada. They show that sales and consumption elasticities diverged in the provinces and years in which smuggling was known to be high, while they aligned in other years.

Although the comparison of consumption and administrative sales data has intuitive appeal, this method rests on two strong assumptions. The first is that measurement error in reported smoking is not responsive to tax changes. Measurement error in reported smoking likely is extensive: reported consumption levels are about half the size of per-capita taxed sales (Stehr 2005). This difference is consistent with individuals under-reporting smoking. If tax changes affect reporting behavior, the change in reported consumption will reflect both changes in actual smoking and changes in reporting. It is likely that individuals inflate consumption changes when there is a tax increase, which would bias the effect of taxes on avoidance toward zero. However,

\footnotetext{
${ }^{35}$ Goolsbee, Lovenheim, and Slemrod (2010) also use this method as a robustness check, showing that higher Internet penetration makes taxable sales more tax-elastic but does not have the same effect on reported consumption. Instead of estimating and comparing the consumption and sales elasticities, the NRC/IOM (2015) compares adjusted self-reported consumption by state to tax-paid sales. An important limitation is that the adjustment to self-reported consumption corrects for the degree of under-reporting in the consumption data at the national level. As a result, the $\mathrm{NRC/IOM} \mathrm{approach} \mathrm{assumes} \mathrm{that} \mathrm{under-reporting} \mathrm{does} \mathrm{not} \mathrm{vary} \mathrm{across} \mathrm{states.}$

${ }^{36}$ Tax avoidance should lower this ratio because taxed sales are persistently higher than measured consumptionsee Figure 4.
} 
it also is possible that recall bias leads smokers to under-report behavioral changes, which would lead to an over-estimate of the effect of taxes on avoidance.

The second assumption underlying this method is that youth smoking responds similarly to tax changes as adult smoking. The datasets used to analyze consumption in these studies do not include youth, but the taxable sales data do include cigarettes ultimately consumed by those under 18 (even if they were not purchased by an underage smoker). If youth are less responsive to tax changes than adults (see Section 4.2.3), then avoidance estimates using this method will be attenuated. Taken together these two sources of bias suggest that comparisons of self-reported cigarette consumption and taxed sales lead to a lower bound on the extent of tax avoidance and how tax avoidance responds to excise tax increases. ${ }^{37}$

The second approach used in the literature uses combinations of distances consumers live to lower-tax borders and the differences in tax rates at those borders as measures of the net return to avoidance. The earliest research using these types of methods employs taxed sales data and simply controls for the minimum border state price (Baltagi and Levin 1986; 1992) or for the average border state price/tax differentials weighted by the size of border county populations (Chaloupka and Saffer 1992; Coats 1995; Keeler et al. 2001; Yurekli and Zhang 2000). These papers find that taxable sales respond to border tax variation and that accounting for these prices reduces the elasticity of taxed sales with respect to the home state tax.

Lovenheim (2008) advances this literature by using individual consumption data at the MSA level from the TUS-CPS and explicitly modeling cigarette demand as a function of the home state price, the distance to the closest lower-price state, the price difference between the home and closest lower-price state and the interaction of the distance and price difference variables. The idea behind this approach is that the interaction between distance and the price difference is a measure of the net benefit of cigarette tax avoidance. A core concern is that people who live closer to lower-price borders are systematically different than those who live farther away. Lovenheim employs MSA fixed effects to account for this issue, essentially leveraging changes in home and border state taxes to identify the tax and distance parameters of the model. ${ }^{38}$

\footnotetext{
${ }^{37}$ The second assumption may not result in too much bias, if violated, since youth smokers, as a group, consume a small fraction of total cigarettes (National Research Council and Institute of Medicine, 2015).

${ }^{38}$ Measuring distance is difficult in this context because the location of stores that sell cigarettes is not in the data. Lovenheim (2008) addresses this issue by calculating the straight-line distance between each Census block and each
} 
Using the 1992-2002 TUS-CPS, Lovenheim (2008) estimates demand models and then calculates both the mean home state price elasticity (see equation 3 ) and the full price elasticity ( $\beta_{1}$ in equation 2 ). He shows that the former is essentially zero: on average consumers live close enough to lower-price borders that price increases generate no change in smoking behavior. The full price elasticity, which represents the price elasticity without smuggling, is between -0.4 and 0.5. As discussed in Section 4.2.2., the full price elasticities align closely with the prior literature that estimates price responsiveness among adult smokers. ${ }^{39}$ Lovenheim then backs out the percentage of cigarettes purchased across borders as the ratio of the predicted amount smoked if distance is zero (and thus there is full cross-border avoidance) to the predicted amount smoked if the price difference is zero (and thus there is no incentive to purchase in another state). His estimates indicate that $13 \%$ of cigarettes are purchased in a lower-tax state. This is almost identical to the percentage in Stehr (2005), though it is important to note that Stehr attributes little of the avoidance behavior to cross-state purchases. Lovenheim's estimate increases substantially - to $25 \%$ - when he includes Native American reservations.

This method of measuring and accounting for cross-border purchasing behavior has been used repeatedly by researchers and forms a large part of this literature (Beatty, Larsen, and Sommervoll 2009; Lakhdar, Vaillant and Wolff 2016; Nicholson, Turner, and Alvarado 2016; Bishop 2018). The findings from these studies align closely with those in Lovenheim (2008) in demonstrating that distance to the border and the tax/price differences at those borders strongly influence smoking behavior. Indeed, Bishop (2018) highlights the important implication of these findings that raising cigarette taxes in higher-tax states does little to reduce smoking; instead, the power to significantly curb smoking is in the hands of the lower-tax states.

The main assumption underlying this approach to measure cigarette tax avoidance is that the only reason smoking behavior differs by distance to a lower-price border and/or with the border price difference is because of avoidance. Especially with geographic fixed effects that account for fixed unobserved characteristics of local populations, this is not a terribly strong assumption. Because these models are identified off of changes in tax policies, the largest threat

major road crossing for a state and Native American reservation. He then takes the population-weighted average of the minimum distance to any one area across Census blocks. This method creates a population-weighted minimum distance from each city (MSA) to each potential tax avoidance opportunity.

${ }^{39}$ The estimates reported here are for total cigarettes smoked, including zeros. Lovenheim (2008) also examines the intensive and extensive margin separately. He finds the same qualitative pattern; about half of the full elasticity is driven by extensive margin behavior and the other half is driven by intensive margin changes. 
to identification comes if those who are least price responsive sort into areas in which avoidance opportunities become larger. Cigarette tax changes are unlikely to spur residential mobility, which is the main mechanism that would generate bias.

Although the assumptions underlying this method are not strong, a main drawback is that cross-border purchases are inferred rather than observed. Ideally, we would be able to see crossborder purchases to both get a direct measure of $S_{i}$ and an estimate of $\frac{\Delta S_{i}}{\Delta \ln \left(T_{h}\right)}$. The last two methods utilize such information to estimate these parameters.

There are two datasets that include the location of purchase: the TUS-CPS and the AC Nielsen/IRI Homescan data. In both datasets, consumers report where they purchased their cigarettes, so they rely on accurate reporting of cross-border behavior. To the extent that individuals under-report illegal (or quasi-legal) activity, these datasets are likely to provide a lower bound on actual cross-border tax avoidance. Chiou and Muehlegger (2008) is the first paper to use direct measures of cross-border purchasing from the 2003 waves of the TUS-CPS. They calculate centroid-based distances to the closest lower-tax state at the county level, and they embed this distance measure into an endogenous switching regression model in which consumers can purchase in the home state, a border state, or over the Internet. Critically, because they use only one year of data, they are unable to control for county fixed effects. As a result, their estimates are essentially cross-sectional in that they are comparing purchase decisions of consumers who live farther vs. closer to a lower-price border.

They find that consumers are more responsive to distance than to price: on average consumers are willing to travel 3 miles to save $\$ 1$ on cigarettes. Using a non-parametric distance function, they also show that the marginal cost of distance declines with distance - those who live far from a border experience a lower marginal cost per mile traveled than do those close to the border. Among everyday smokers, the marginal cost per dollar saved is much lower, suggesting that cross-border purchasing is much more common among heavy smokers. Using their direct estimates of cross-border purchasing, their model predicts that only $4 \%$ of cigarettes are purchased in another location. While notably lower than the estimates in Lovenheim (2008), as discussed above the direct estimates are likely attenuated because of under-reporting of quasilegal activity.

DeCicca, Kenkel and Liu (2013b) conduct a similar analysis using the 2003 and 20062007 TUS-CPS. This paper is distinguished from Chiou and Muehlegger (2008) by the use of 
more years that permit geographic (here, MSA) fixed effects. They focus on the elasticity of cross-border shopping with respect to prices, which comes directly out of the endogenous switching regression model. This elasticity is large, at 3.1: a 10 percent increase in the home state price increases the likelihood of purchasing cigarettes in a neighboring state by $31 \%$. That consumers are highly sensitive to home state prices when they make purchasing location decisions is aligned with the large estimates of cross-border avoidance found in prior studies. However, it is harder to square with the relatively low levels of observed cross-border purchasing in the TUS-CPS of between 4 and 5 percent.

DeCicca, Kenkel, and Liu (2013b) further use their results to estimate how much of the home state sales effect is accounted for by cross-border purchases. They find that about $25 \%$ of the drop in taxable sales is driven by such avoidance. While large, this is smaller than prior estimates that have found estimates of 33\% (Gruber, Sen, and Stabile 2003), 85\% (Stehr 2005) and 100\% (Lovenheim 2008). As discussed in Section 3, they are able to calculate the deadweight loss associated with cross-border purchasing to estimate the how avoidance alters the optimal tax rate. On average, they argue that cigarette taxes should be $20 \%$ lower as a result of the excess burden associated with cross-border avoidance behavior.

Harding, Leibtag, and Lovenheim (2012) is the only other paper to use direct information on purchase location, which they obtain from the Nielsen Homescan data. These data record the store of purchase for most items, which then can be linked to store location information (at the zip code level). The proportion of cigarettes purchased out-of-state is $5 \%$ in these data, which is almost identical to the percentage in the TUS-CPS. Since consumers are not asked directly where they purchased their cigarettes but instead report the store, it is less likely that cross-state avoidance will be under-reported. However, it also is possible that consumers do not report every purchase, and they may be less likely to report cigarette-only purchases that occur across state lines (i.e., casual smuggling). Harding, Leibtag, and Lovenheim calculate that on the border with a lower-tax state, the elasticity of cross-border purchases with respect to the home-state tax is 4.68. This is similar to the estimate of 3.1 in DeCicca, Kenkel and Liu (2013b). When the distance to a lower-tax border doubles, this elasticity is attenuated by 1.15 .

The concern that people may under-report cross-border purchasing behavior motivates a fourth approach that relies on discarded cigarette packs rather than on individual reporting. This method was pioneered by Merriman (2010), who collected discarded cigarette packs in the 
greater Chicago metropolitan area in summer 2007. The city of Chicago has its own cigarette tax as does Cook County (one of the counties that constitutes Chicago), leading to the highest cigarette tax level in the US. Avoidance opportunities are rampant, as one can leave the city limits, go across counties, or travel to nearby Indiana to obtain less expensive cigarettes.

The innovation of this approach to measuring cigarette tax avoidance is that discarded cigarette packs typically include a tax stamp that shows in what taxing jurisdiction the pack was purchased. Merriman collected littered packs in specific areas across Chicago (including outside of the city borders) as well as in border areas in Indiana. Comparisons of cigarette tax stamps in different locations provide direct evidence on the extent of tax avoidance in a local area. He finds evidence of extensive avoidance: only $25 \%$ of packs in Chicago have a Chicago tax stamp and only $36 \%$ in Cook County have a Cook County stamp. Fifty-nine percent of Chicago packs have an Illinois tax stamp, while $76 \%$ have such a stamp in Cook County (in areas outside of the City) and in DuPage County. Only 3\% of packs in Indiana have an Illinois stamp, which is sensible because the excise tax is much lower in Indiana than in Illinois. Importantly, he also finds that the likelihood of finding a pack with a given jurisdiction's tax stamp declines with distance to that jurisdiction.

Merriman and his co-authors have subsequently repeated this analysis in New York City (Chernick and Merriman 2013) and for a national sample (Wang, Merriman, and Chaloupka 2019), finding similar patterns of results. The estimates in Chernick and Merriman (2013) are notable for finding increases in the share of packs without tax stamps (from 15 to 24 percent) after a tax increase in New York and closer to Native American Reservations. In their national sample, Wang, Merriman and Chaloupka (2019) find that 21\% of packs do not have the tax stamp associated with the locality in which they were discarded. This estimate of the extent of cigarette tax avoidance is larger than those from prior estimates except for the $25 \%$ estimate that incorporates Native American Reservations in Lovenheim (2008).

The discarded cigarette tax approach is an innovative advance in the literature because it allows researchers to observe direct measures of tax avoidance that are not dependent on survey responses. However, this method rests on several important assumptions. First, discarded cigarette packs need to include the cellophane that has the tax stamp on it. In Merriman (2010), only $48 \%$ of the packs have a tax stamp. One key assumption is that the likelihood of observing a stamp does not vary with avoidance opportunities. While sensible, this assumption is not 
possible to test. Second, one must assume that the likelihood of littering is unrelated to the likelihood of avoiding local taxes. If those who engage in tax avoidance are more likely to litter, this method will over-state the extent of avoidance behavior. Merriman (2010) provides some evidence that this assumption is valid by examining non-littered packs thrown into trash bins in different areas throughout Chicago. However, this evidence does not address a third assumption: that the likelihood of discarding cigarettes on the street (whether littered or not) is unrelated to tax avoidance. Heavier smokers and smokers in certain occupations may be more likely to discard cigarettes on the street. Fourth, it is not possible to know if littered packs come from tourists or commuters rather than local residents. Because large cities tend to be tourist destinations and employ workers from the surrounding areas, this is an issue of prime importance in these studies when they focus on specific large cities.

Taken together, the evidence on cigarette tax avoidance using multiple methods indicates that higher border price differences and shorter distances to borders generate cross-border shopping that undermines the intention of these taxes in raising local revenue and reducing smoking. The estimates of the extent of cross-border purchases vary across methods, from $5 \%$ to $25 \%$. The smallest estimates come from direct observation of purchase location in survey or shopping data, and the largest estimates come from indirect estimation using consumer location and border price differences as well as littered cigarette packs. While the particular magnitudes vary, the literature is unified in demonstrating that cross-border tax avoidance is a first-order concern in understanding how consumers respond to cigarette taxes.

The research discussed above focuses on cross-border tax avoidance and largely ignores the Internet as a source of avoidance. Goolsbee, Lovenheim, and Slemrod (2010) use sales data from 1980-2005 combined with CPS data on Internet penetration by state. They show that taxable sales become more sensitive to tax changes when Internet connectivity rates rise. As discussed above, the ability to purchase tax-free cigarettes was eliminated in 2010. To our knowledge, no research examines the effect of this change on consumer responses to local cigarette excise taxes.

Because taxes induce avoidance behavior through cross-border shopping, it also can affect how taxes are passed through to prices. That is, cross-border competition can reduce the pass-through of taxes to prices. Harding, Leibtag, and Lovenheim (2012) examine this question directly using Nielsen Homescan data that includes not only the Census tract in which each 
household resides but also the zip code of the store in which each cigarette transaction occurred. They estimate models very similar to those in Lovenheim (2008), except with price rather than quantity as the dependent variable. The estimates indicate that the availability of lower-tax cigarettes in a nearby locality has a large effect on tax incidence. For a consumer on the border, a one cent increase in cigarette excise taxes increases cigarette prices by 0.49 cents. Recall that the average effect was about 0.9 , so a little more than half of the total pass-through effect is eroded by avoidance pressures. The pass-through rises sharply with distance, such that $2 / 3$ of a tax increase is passed on to consumers just 10 miles from the border.

The effects found in Harding, Leibtag, and Lovenheim (2012) are driven both by direct consumer search behavior as well as by increased competitive pressure on stores due to the availability of cheaper cigarettes in a nearby locality. They separate these effects by examining the price effect as a function of store rather than consumer distance to lower-tax borders. A onecent increase in taxes increases prices among stores on the border by 0.57 cents. This is a larger pass-through than the estimates using consumer distance, which suggests that prices respond more at stores on the border than do prices paid by consumers who live on the border. The effect also fades less rapidly with distance when measured at the store rather than the consumer level. These estimates suggest that consumer search intensity is partly responsible for the lower passthrough near the border, though the competitive pressure from lower-priced cigarettes nearby is the dominant force driving these results.

DeCicca, Kenkel, and Liu (2013a) find similar patterns of effects and draw similar conclusions using the TUS-CPS. They estimate the incidence of cigarette taxes separately by observed price search behavior. As discussed above, pack buyers and home-state carton buyers experience almost full pass-through of taxes to prices. However, those who purchase cartons outof-state have a pass-through coefficient of 0.174 that is not statistically significantly different from zero at conventional levels. These findings highlight the fact that for those who avoid local taxes by purchasing in another state, increases in the home-state tax do not lead to increases in the prices they face. The results in DeCicca, Kenkel, and Liu (2013a) and Harding, Leibtag, and Lovenheim (2012) point strongly to the conclusion that the effect of taxes on prices is a function of avoidance opportunities. In high-avoidance areas, tax increases have a much smaller effect on prices and induce consumers to avoid local taxes, thereby undercutting both the smokingreducing and revenue-generating goals of these taxes. 


\subsection{Tax Avoidance Across Products}

\subsubsection{Other Tobacco Products}

Although cigarettes are the most popular tobacco product, the extent and trends in multiple tobacco product use suggests that there might be scope for economically significant tobacco product substitution and cross-price effects driven by high and rising cigarette taxes. This is especially the case because most of these alternative products currently are not taxed or are taxed at much lower rates than are cigarettes. For example, 17 states (including DC) levy taxes on vape liquid that contains nicotine, but only in a few of these states is the tax pegged directly to the price of cigarettes. Most states also tax cigars as a percent of their wholesale price. Because cigarette taxes are not linked directly to taxes on these other products, large cigarette price changes might induce multi-product users to shift away from cigarettes and might induce the 58 percent of cigarette smokers who only smoke cigarettes to move to dual- or multi-product use, or to switch entirely to another tobacco product.

The effect of cigarette taxes on the use of alternative tobacco products is a nascent area in the economics of tobacco regulation. With the rise in vaping in particular, understanding how cigarette taxes affects use of other tobacco products is of high importance. Estimating these substitution patterns also is critical to assess the health consequences of cigarette tax changes (or any tobacco regulation), because the health effects of these products vary. For example, vaping delivers similar levels of nicotine to consumers without the carbon monoxide or carcinogenic properties of combusted tobacco. Price-induced substitution from cigarettes to vaping may alter health outcomes even if it does not lead to lower nicotine consumption. We review the small extant literature on cross-product substitution here, but we emphasize that too little is known about these substitution behaviors; this is a ripe area for future exploration.

Zheng et al. (2017) estimate a system of linear demand equations using the Almost Ideal Demand System (AIDS) model with six tobacco products. The AIDS model is estimated using Nielsen retailer scanner data in 30 markets from November 2009 through April 2013. They find an elasticity of e-cigarettes with respect to cigarette prices of 1.86 and an elasticity of cigarettes with respect to e-cigarette prices of 0.004 . Why these cross-prices elasticities are so different is unclear, but the estimates indicate that these goods are substitutes for one another. The other cross-price elasticities suggest that large cigars and little cigars/cigarillos are substitutes and cigarettes and smokeless tobacco are complements. It is important to emphasize that they also 
find an own-price elasticity of cigarettes equal to -0.98 , which is well outside of the range of the estimates from the cigarette tax literature (see Section 4.2.2).

One potential explanation for some of these surprising results is that they do not correct for endogeneity of prices in their estimation. ${ }^{40}$ Furthermore, AIDS models can be biased by corner solutions that lead to zero budget shares for different items. This concern is mitigated somewhat by the use of market-month level data, as there are few markets and months with no purchases of these goods. Many of the alternative tobacco products are quite rarely purchased, though, and the very low budget shares for many items may lead to empirical issues in the estimations.

While the results of Zheng et al. (2017) tend to suggest that e-cigarettes and cigarettes are substitutes, other findings suggest caution in interpreting these estimates. Zheng et al. (2016) use the same Nielsen scanner dataset to estimate a dynamic system of demand for tobacco products that incorporates myopic addiction. Surprisingly, and in contrast to Zhang et al. (2017), they find that e-cigarettes are neither substitutes nor complements for cigarettes. This is clearly an important area for further research.

Using a differences-in-differences approach, Cotti, Nesson and Tefft (2018) estimate that cigarette tax hikes reduce consumption of both combustible cigarettes and e-cigarettes, suggesting that the products are complements. They use 2011-2015 data from the Nielsen Homescan Consumer Panel and include state fixed effects, state-specific linear time trends, and household fixed effects. The results are somewhat sensitive to the inclusion of household fixed effects. In the data, e-cigarette purchases are rare: in an average quarter only 0.4 percent of households purchased e-cigarettes; and among ever-purchasers, the mean number purchased was 1.4 e-cigarettes, compared to 341 cigarettes per quarter. In light of the rapid growth of the market for e-cigarettes, the observed demand patterns and tax effects in this study might mainly reflect the behavior of e-cigarette experimenters.

Saffer et al. (2019) extend this literature in their working paper by examining the first tax past on e-cigarettes in Minnesota in 2010, as well as the subsequent tax increase in 2013 that increased the tax to 95 percent of the wholesale price. They use a "synthetic control difference-

\footnotetext{
${ }^{40}$ In a robustness check, they use cigarette taxes and prices outside of the given market for other goods as instruments for price. However, they weight the price instruments by the inverse distance to the market. As argued in Harding and Lovenheim (2017), such weights likely make the instrument sensitive to local unobserved demand heterogeneity, which can bias the price estimates.
} 
in-difference" model that involves constructing a weighted control group that exhibits similar smoking trends to Minnesota prior to 2010. With data from TUS-CPS, they examine how the ecigarette tax affects smoking and smoking cessation behavior. They find that the e-cigarette tax increases smoking participation by almost 1 percentage point (or 5.4 percent relative to the pretreatment mean). The e-cigarette tax also reduced smoking cessation by over 1 percentage point, which indicates that the increased smoking participation is driven by a reduction in quits. This evidence points to e-cigarettes and traditional cigarettes being substitutes.

Studies of tobacco product advertising provide additional but indirect evidence on whether alternative forms of tobacco consumption are substitutes or complements to cigarette smoking (Dave and Saffer 2013, Dave et al. 2019). ${ }^{41}$ Dave et al. (2019) find evidence that ecigarette advertising increases smoking quit rates. This finding suggests that cigarettes and ecigarettes are substitutes. Section 7.2 below provides more discussion of these and other studies of tobacco product advertising.

While the studies reviewed so far focus on contemporaneous demand relationships, a central tradeoff in tobacco product regulation involves whether, for youth, cigarettes and ecigarettes are intertemporal substitutes, complements, or neither. A line of public health research focuses on the possibility that vaping serves as a gateway to smoking, i.e. that for youth ecigarettes and cigarettes are intertemporal complements. The possibility of gateway effects provides a rationale for e-cigarette taxation or product regulations designed to discourage youth vaping, for example by restricting the availability of flavors popular among youth. Section 7 below provides more discussion of attribute-based product regulation.

The empirical approach in public health research on the gateway effect can be interpreted as a form of a structural demand equation for an addictive good; the probability of cigarette use at time $t$ is modeled as a function of e-cigarette use at time $t-1$. Becker, Grossman, and Murphy (1994) show that serially correlated unobservable heterogeneity will lead to biased estimates of the parameters of the structural addiction model. The structural addiction model with heterogeneity maps into alternative hypotheses about the relationships between vaping and smoking. The National Academy of Sciences (2018) reviews the research related to three of

\footnotetext{
${ }^{41}$ Dave and Saffer (2013) also provide direct evidence on the cross-price elasticity of smokeless tobacco use. They find that a $\$ 1$ increase in cigarette excise taxes reduces smokeless tobacco use by $1.3 \%$. This translates into a crossprice elasticity of -0.57 and suggests cigarettes and smokeless tobacco are complements.
} 
these hypotheses. First, the common liability hypothesis suggests that there might be a noncausal positive association between vaping and smoking if the behaviors are influenced by a common set of social, familial, individual, and genetic factors. Second, the catalyst hypothesis suggests that there might be a causal positive relationship between vaping and smoking if ecigarettes attract lower risk-taking adolescents and then catalyzes them to move into riskier smoking behavior. Third, the diversion hypothesis suggests that there might be a causal negative relationship between vaping and smoking if e-cigarettes attract risk-taking adolescents and provide a diversion that prevents them from experimenting with combustible cigarettes. In economic terms, the common liability hypothesis corresponds to unobservable heterogeneity (i.e., omitted variables bias), while the catalyst and diversion hypotheses correspond to forms of cross-product time-adjacent complementarity and substitutability, respectively.

While there is a nascent public health literature examining these questions, Etter (2018) criticizes this literature for failing to account for unobserved heterogeneity. This core selection problem has not yet been addressed adequately in empirical studies, which highlights the need for more high-quality work examining the intertemporal relationships between cigarettes and ecigarettes among youth. This is a ripe area for future research that will shed new light on an important rationale for e-cigarette taxation and regulation.

Abouk and Adams (2017), Friedman (2015), and Pesko and Currie (2019) estimate a version of a reduced-form equation of the demand for adolescent smoking at time $t$ as a function of the non-monetary cost of e-cigarettes at time $t-1$. The non-monetary cost is created by laws establishing a minimum purchase age for e-cigarettes. These studies provide mixed evidence on whether e-cigarettes and cigarettes are intertemporal substitutes or complements among youth. Because the studies rely on variation in purchase-age laws across states, they are only able to use data for the relatively short time window when vaping was becoming popular but before FDA regulation established a national purchase age for e-cigarettes.

One way to avoid cigarette taxes is to quit smoking, and substitution to other tobacco products can facilitate cessation. In a randomized clinical trial among smokers at cessation clinics in the United Kingdom, the one-year abstinence rate from cigarettes among smokers assigned to use e-cigarettes for cessation was 18 percent, almost double the 9.9 percent abstinence rate among those assigned to use a nicotine-replacement product such as the nicotine patch (Hajek et al.. 2019). In observational data from the 2016 National Health Interview 
Survey, 19 percent of recent (past-year) adult former smokers and four percent of non-recent former smokers regularly vape. Of course, the patterns in the observational data do not necessarily mean that e-cigarette use caused smoking cessation, but the United Kingdom study is a rare example of experimental evidence on the question of product substitutability

\subsubsection{Alcohol and Marijuana}

In addition to substitution across tobacco products, one can avoid cigarette taxes by consuming other goods that are not subject to these taxes. The most commonly studied goods are alcohol and marijuana. Whether alcohol or marijuana are substitutes to or complements with tobacco is an open question in the literature: cigarettes can be a gateway to consuming these other drugs, or cigarette taxes can induce substitution. This is ultimately an empirical question on which there is little research. We review the small literature on these substitution behaviors, but we emphasize that this is a burgeoning area of much importance that would benefit from more research by economists.

The clearest evidence on how cigarette prices/taxes affect alcohol consumption comes from Krauss et al. (2014). They estimate state-year level panel models of how cigarette prices affect per-capita cigarette and alcohol sales using taxed sales data from 1980-2009. Importantly, they examine cigarette prices rather than taxes, which is potentially problematic because price variation is more likely to be endogenously related to unobserved demand heterogeneity within states over time. They find that alcohol is a complement to cigarettes: a $1 \%$ increase in cigarette prices leads to a -0.083 percent reduction in per-capita alcohol sales. Separating by alcohol type, they show that the complementarity is the strongest for beer and spirits, while there is little evidence that wine sales respond to cigarette prices. Interestingly, they show that this complementarity exists only prior to 1995 - from 1995-2009 there is no relationship between cigarette prices and alcohol sales. That this is the time period in which cigarette taxes were growing most rapidly suggests that cigarette tax increases do not induce substitution towards or away from alcohol consumption. ${ }^{42}$ Direct assessment of this claim using cigarette excise tax data would add much to the literature.

\footnotetext{
${ }^{42}$ Goel and Morey (1995) conduct a similar analysis using state-year level data from 1959-1982, controlling for lagged cigarette or alcohol sales and state fixed effects. They find evidence that alcohol and cigarettes are substitutes: cross-price elasticities are positive and statistically significant. It is unclear why these estimates differ from those in Krauss et al. (2014).
} 
Picone, Sloan, and Trogdon (2004) present evidence that cigarettes and alcohol are substitutes. Using data on older Americans (51-61 years old) from the Health and Retirement Study from 1992-2002, they estimate panel models at the individual level that incorporate lagged consumption behavior. They instrument for lagged alcohol and tobacco consumption using lagged prices and tobacco control measures. As with Krauss et al. (2014), they examine prices rather than taxes. While they employ an instrumental variables strategy, lagged prices are unlikely to sidestep the identification concern that price variation is correlated with unobserved demand heterogeneity. They find suggestive evidence that cigarette prices induce more alcohol consumption, indicating alcohol is a substitute for cigarettes, but the estimates tend not to be statistically significantly different from zero at even the $10 \%$ level. The point estimates are much larger for men than for women as well.

With the legalization of marijuana for medical and recreational use in many states, there is increased interest in how regulating one of these goods affects consumption of the other. Farrelly, Bray, Zarkin, and Wendling (2001) use data from the National Household Survey on Drug Abuse (NHSDA) from 1990-1996 on individuals aged 12-20. They estimate models with state and year fixed effects that include controls for cigarette taxes and the likelihood of a marijuana arrest. Focusing on the tax estimates, they find evidence of negative cross-price elasticities of marijuana participation from cigarette tax changes. While this evidence suggests that cigarettes and marijuana are complements, the cross-price elasticities are small and for participation are not statistically different from zero.

Choi, Dave, and Sabia (2019) examine this question using changes in medical marijuana laws (MMLs) across states. While not directly relevant to the substitution effects of tobacco regulation, how marijuana restrictions affect smoking provides important evidence on whether cigarettes and marijuana are complements or substitutes. Using several datasets that include information on cigarette smoking, they estimate models that include state and year fixed effects to examine how medical marijuana law passage across states over time affects smoking behavior. Critically, they show that future MML passage does not predict smoking or marijuana usage. This suggests MML passage is exogenous with respect to smoking both cigarettes and marijuana. The main findings indicate that MMLs increase marijuana usage and have a negative effect on cigarette consumption. In contrast to Farrelly, Bray, Zarkin, and Wendling (2001), this suggests 
that cigarettes and marijuana are substitutes. With the passage of recreational marijuana laws in many states and further expansions of MMLs, this is an important area for future analysis.

In a recent working paper, Anderson, Matsuzawa, and Sabia (2020) estimate the impact of increases in state cigarette excise taxes on teen marijuana use with data from the 1991-2017 Youth Risk Behavior Surveys. Despite the relatively large tax increases over this time period, the authors find no systematic evidence of a relationship, either positive or negative. As such, their findings support neither the hypothesis that higher cigarette taxes might lead youth to substitute away from cigarettes to marijuana, nor that which suggests that cigarettes are a gateway drug. Interestingly, in what the authors describe as preliminary results due to limited policy variation, they find that the adoption of state-level e-cigarette taxes is associated with a decline in youth marijuana use. This finding suggests that e-cigarettes might be a gateway product to marijuana use. However, it is notable that the authors are not able to distinguish between use of nicotine e-cigarettes and use of illegal, and hence untaxed, e-cigarettes that contain THC, the active ingredient in marijuana. It is possible that the implied complementarity is driven by substitution from taxed nicotine e-cigarettes to untaxed, illegal THC-containing ecigarettes, which could explain the observed progression to standard marijuana use.

\subsubsection{Food and Obesity}

Nicotine is an appetite suppressant, which means that tax-induced reductions in smoking can lead to increases in food consumption and associated health concerns (e.g., obesity). Longstanding anecdotal evidence implies that smoking cessation is associated with weight gain. In turn, such weight gain may be of concern if it reduces health. Post-smoking weight gain tends to be attributed to the appetite-suppressing qualities of nicotine, which induces increased calorie consumption after smoking cessation (c.f., Dallosso and James 1984; Stamford et al. 1986). Recent experimental findings generally support this anecdotal evidence. Courtemanche, Tchernis, and Ukert (2018), for example, exploit data from the Lung Health Study, which involved a randomized trial of various treatments designed to induce smoking cessation. The authors found that treatment-induced smoking cessation led to an average permanent weight gain of roughly 10-12 pounds for an average weight individual.

If higher cigarette taxes induce smokers to reduce or quit smoking, it is possible that the resulting higher prices lead to increases in body mass index. Indeed, the first study to explicitly examine this relationship found a positive association between cigarette price and body mass 
index (Chou, Grossman and Saffer 2004). Subsequent studies, however, have found no evidence of an effect, or even an inverse effect - that is, cigarette price increases lead to reductions in body mass index (Gruber and Frakes 2006; Courtemanche 2009; Nonnemaker et al. 2009; Wehby and Courtemanche 2012).

Wehby and Courtemanche (2012) examine potentially important heterogeneity in the impact of cigarette price on BMI and find a generally inverse relationship between them. Moreover, these authors find that their estimated effect grows in magnitude moving up the BMI distribution, suggesting that such weight loss may well translate into improved health (i.e., they find that heavier individuals are induced to lose more weight). While these authors suggest that their estimates may be due to increased levels of physical exercise following smoking cessation, more recent work finds no systematic relationship between cigarette taxes and exercise (Conway and Niles 2017). As a result, the pathways through which these more recent findings may operate is unclear. These weight-reducing findings also are inconsistent with the experimental results of Courtemanche, Tchernis and Ukert (2018). More work examining how cigarette taxes affect eating, exercise and body weight clearly is needed.

\section{Place-based Smoking Bans}

\subsection{Background}

In the economics of tobacco regulation, place-based smoking bans represent an area of substantial and rapidly increasing research interest. Governments around the world have implemented smoking bans sporadically over the past five decades, but they have become much more prevalent in North America and Europe over the past two decades. Generally speaking, such bans prohibit smoking in public places such as hospitals, public transportation, government buildings, commercial buildings, schools, workplaces, restaurants, and now, in many places, even drinking establishments (i.e., bars). Workplace smoking bans may have the greatest impact, since individuals likely spend the greatest amount of time covered by a ban while at work. Smoking bans have tended to occur generally at two levels in most countries: local and regional, with local laws tending to be more robust, consistent with the collective smoking-related preferences of often more homogeneous local populations. Moreover, to the extent that they reflect greater unanimity in these preferences, local bans may be more strictly enforced than bans made at a more aggregate level (e.g., state level bans in the United States). Such factors make 
policy endogeneity a particularly important issue with regards to estimating the impact of these bans on a variety of smoking-related outcomes.

Unlike our discussion of cigarette excise taxes, which was dominated by U.S. based studies, research on the impact of smoking bans comes from all over the industrialized world. In this section, we focus primarily on studies from North America and Europe, though we reference studies from other nations of the world as well. In the North American context, the first smoking ban was implemented by the state of Arizona in the early 1970s. And, while California cities like San Louis Obispo often get credit for introducing smoking bans at the municipal level, Connecticut and Minnesota also restricted smoking in restaurants and private workplaces, respectively, shortly thereafter. In 1998, California became the first state to ban smoking in bars, something that still has not been implemented in all fifty U.S. states. New York City implemented a wide-reaching smoking ban in restaurants, non-governmental workplaces and even bars in 2003. The past fifteen years have seen literally hundreds of bans at the local level in the United States as well as substantial state action. While most of this action has occurred in states with other anti-smoking regulations, there are notable exceptions, such North Carolina, which in 2010 implemented a comprehensive ban on smoking in bars and restaurants.

Like their U.S. counterparts, Canadian municipalities and provinces have implemented many place-based smoking bans over the past fifteen years. Perhaps the most well-know is Ontario's Smoke Free Law of 2006, which banned smoking in all private workplaces and public places including restaurants and bars, as well as private clubs, sports arenas, and entertainment venues, including casinos. ${ }^{43}$ Canada's second largest province, Quebec, also first implemented smoking restrictions in 2006 and beefed them up substantially a decade later to outlaw even smoking on terraces, a popular summer pastime.

European nations, though now perhaps more enthusiastic in their banning of smoking than the United States and Canada, implemented the majority of their smoking bans even more recently. In Europe, Finland is the first nation to implement smoking bans via its 1976 Tobacco Control Act. While weak by today's standards, it was extended in 2007 to ban smoking at most workplaces and most restaurants and bars. Though not an exhaustive list, several other European countries, either nationally or via their state-level equivalent jurisdictions, implemented

\footnotetext{
${ }^{43}$ This law had many other components - notably, it also completely banned the display of tobacco products and advertising, including at the point of sale.
} 
relatively comprehensive smoking bans in the mid-to-late 2000s, including Ireland (2004), Sweden (2005), Norway (2006), Scotland (2006), Italy (2007), Denmark (2007), Wales, England and Northern Ireland (2007), France (2007-2008), Germany (2008), the Netherlands (2008), and Greece (2009). ${ }^{44}$ As with related North American-based research, many of the European-based studies we cite exploit these more recent reforms.

The stated rationales for place-based smoking bans are to reduce the exposure of nonsmoking individuals to second-hand tobacco smoke as well as to deter smoking behavior. With regard to the latter, it is possible that place-based smoking bans could reduce smoking on both the extensive and intensive margins. If large enough, the reduction in smoking behavior may have implications for the health of smokers and/or non-smokers who otherwise would have been exposed to greater levels of cigarette smoke. In addition, since many comprehensive smoking bans target restaurants and, more recently, bars, it is possible that smoking bans affect the viability of such establishments. While it often is assumed that bans will harm restaurants and, perhaps especially, bars, increased business activity is possible if there exist marginal customers who place enough value on a smoke-free environment and/or the behavior of smokers who frequent such establishments is sufficiently inelastic.

As with the studies that we reviewed in Section 4, we focus on studies that attempt to estimate the impact of smoking bans, rather than other methods such as policy simulation, which are sometimes seen in the related literature. Note that studies on the impact of place-based smoking bans on smoking behavior, second-hand smoke exposure, and other outcomes of interest are subject to the types of estimation-related issues we discussed at the start of Section 4, principally policy endogeneity. For this reason, we give more credence to those studies that are able to deal most credibly with this important issue. In the following subsections, we review the research on the impact of place-based smoking bans on smoking behavior, hospitality-related establishments and, following a newer line of research, on aspects of health that may plausibly be impacted by the implementation and/or augmentation of smoking bans.

\subsection{The Impact of Place-based Smoking Bans on Smoking Behavior}

Smoking bans can affect smoking behavior on both the extensive margin and intensive margins. Regarding the latter margin, since nearly all related research focuses on adult smoking,

\footnotetext{
${ }^{44}$ In addition to European countries, New Zealand (2004) and Uruguay (2006) have implemented various comprehensive smoking bans over the same period.
} 
these studies focus on smoking cessation. Unlike tax-related work, place-based smoking bans have a much shorter history, and hence the related studies do not extend as far back in time. As detailed below, North American-based research shows a decidedly mixed impact of smoking bans on smoking behavior, while European studies more strongly suggest the existence of a systematic reduction, albeit small to moderate in magnitude, in such behavior.

Early research in this area examined the impacts of smoking bans that were decided by private venues, rather than those of public, jurisdiction-wide bans. Evans, Farrelly, and Montgomery (1999), for example, examine the effect of private workplace bans on workers' smoking participation and the daily amount smoked by smokers. They find reductions of five percentage points and ten percent, respectively. The authors acknowledge that their estimates are susceptible to omitted variable bias, particularly since more health-conscious workers may sort into employment by firms that proactively ban smoking on their premises. Based on corresponding structural estimates, they claim that omitted variable bias is not an issue for their study, despite the fact that a reduction in smoking participation of five percentage points implies a seemingly very large fifteen percent reduction in smoking participation due to one's employer imposing a smoking ban at work. With the rise in public smoking bans, and because of transparent endogeneity concerns like those in Evans, Farrelly, and Montgomery (1999), the literature has moved largely into evaluating the impact of these public policies.

The North American literature is decidedly mixed on the question of whether place-based smoking bans reduce smoking behavior. Some studies find evidence that place-based bans reduce smoking (c.f., Carton et al. 2016; Bitler, Carpenter and Zavodny 2010; Tauras 2006; Yurekli and Zhang 2000), while others find no or less evidence of ban-induced reductions (c.f., Nesson 2017a; Cotti, Nesson and Tefft 2016; Carpenter, Postolek and Warman 2011; Adda and Cornaglia 2010; Liu 2010; Carpenter 2009). Unfortunately, it is not easy to reconcile these different findings across studies. Indeed, several of these conflicting studies use the same data, with the latest ones using the same cutting-edge econometric techniques and following the consensus that comprehensive smoking bans are what should be evaluated. It is possible that differences in enforcement drive the observed differences across studies, but this seems unlikely since many of them evaluate the same bans. Clearly, more work needs to be done to reconcile these disparate results. 
While North American-related research is mixed, findings from European studies of the impact of place-based bans on smoking behavior tell a clearer story. Several studies find evidence of reduced smoking participation and/or reduced daily consumption (Pfeifer, Reutter, and Strohmaier forthcoming; Boes, Marti, and Maclean 2015; Buonanno and Ranzani 2013; Pieroni et al. 2013; Anger, Kvasnicka, and Siedler 2011), though some European-based studies find no evidence of such reductions in smoking (Jones et al. 2015) or merely a short-run effect (Federico et al. 2012). Of all the European countries that imposed smoking bans in the mid-tolate 2000s, Italy's experience following its 2005 ban is the most studied. Work by Buonanno and Ranzani (2013) and Pieroni et al. (2013) find evidence of ban-induced reductions in Italian smoking behavior. In the case of the former, the authors find that smoking participation fell by just over one percent and daily smoking by smokers fell by eight percent. Pieroni et al. (2013) find significant reductions in both daily cigarette consumption and smoking participation, with the latter declining by roughly two percentage points as a result of the 2005 ban. In contrast, a study by Federico et al. (2012) suggests that any reduction associated with Italy's smoking ban may have been short-lived, though realistically longer-run policy impacts are notoriously difficult to credibly estimate. We also highlight that these Italian studies use interrupted time series methods and thus cannot plausibly account for confounding shocks that align with the timing of the ban.

It is not clear exactly why findings from the North American and European studies differ. One explanation is methodological: the federalist system in the US generates much variation at the state and local level, while in European countries there is less local autonomy and the bans tend to be national in scope. As a result, most of the European studies employ interrupted time series or cross-country comparisons across a small number of countries (e.g., England and Scotland). Such approaches are highly sensitive to bias from secular shocks that align with the timing of ban passage. A small number of European studies use sub-national variation across German states (Pfeifer, Reutter, and Strohmaier forthcoming; Anger, Kvasnicka, and Siedler 2011) or across Swiss Cantons (Boes, Marti, and Maclean 2015). While the most credible, with only 16 German states and 26 Swiss Cantons, the local variation in Europe is less extensive than in the US, which may drive some of the differences in findings. Differences in European and US estimates may also be driven in part by the local context of smoking behavior. Many European countries have higher smoking rates than those seen in North America, and smoking tends to be 
strongly associated with "going out" behavior in Europe. Finally, we note that the future of place-based smoking bans is in the direction of banning smoking in outdoor spaces such as public parks, rather than smaller enclosed places like workplaces, restaurants and bars. While the rationale for outdoor smoking bans differs from their more prevalent indoor counterparts because second-hand smoke exposure is less prevalent outdoors, their impact on smoking behavior will be of interest going forward.

\subsection{The Impact of Place-based Smoking Bans on Hospitality-related Establishments}

The rise in smoking bans in restaurants and bars has led to an increase in the number of studies investigating the impact of these bans on the hospitality industry. Generally speaking, these studies can be classified into two groups: those that investigate the impact of restaurant and bar smoking bans on objective business-related measures (e.g., sales, employment, revenue) and those that examine their impact on subjective measures such as the perceptions of establishment owners regarding their business or potential customers regarding their willingness to frequent bars and restaurants before and after a smoking ban. While studies that examine subjective outcomes are more likely to find a negative effect of these smoking bans, the general consensus of the U.S. literature is that smoking bans tend to have no, or very small, negative economic impacts on the hospitality industry. The corresponding European literature suggests that smoking bans have small to moderately negative economic impacts.

Adams and Cotti (2007) examine the effect of smoking bans on the employment level of full-service restaurants and drinking establishments (i.e., bars) using county-level data from the Quarterly Census of Employment and Wages (QCEW) between 2001 and 2004 in the US. The authors find that smoking bans reduce employment in bars but have a small positive effect on restaurant employment. These effects are broadly aligned with what is found in other highquality US-based studies. The positive restaurant employment effect is driven by counties in warmer climates (i.e., which can offer smokers outdoor patios as alternative seating). Their barrelated results are bolstered by their discovery that as smoking participation in a county increases, the negative employment effects of these bans become larger. In other words, bar bans have more negative employment effects where the potential customer base who might like to smoke in a bar is larger. Given the proliferation of smoking bans in the U.S. since 2004, a follow-up to this study would be of great interest. 
European studies suggest somewhat more negative effects than what is found in Adams and Cotti. As noted earlier, many of the more comprehensive European restaurant and bar smoking bans came later than those in the United States. As a result, there is relatively more recent European research in this area. For example, a study by Adda et al. (2012) examines the effect of a public smoking ban in Scotland in 2006 that included restaurants and bars. The authors compare economic outcomes before and after the ban by comparing outcomes in Scotland to those in northern England, which they use as control group since this area experienced no such smoking ban. Using proprietary survey data, they find that the Scottish smoking ban reduced public house (i.e., pub) sales that were not driven by changes in price. The authors also conduct an event study of the stock market performance of Scottish pub-holding firms and find a reduction in share price, consistent with their finding of a reduction in sales.

Other recent European studies present evidence of moderately negative economic effects. Kvasnicka and Tauchmann (2012), for example, find a moderately negative impact of state-level German smoking bans in restaurants and bars on establishment sales but find no effect on establishment closure rates, while Cornelson and Normand (2012) find in a time series analysis that Ireland's comprehensive smoking ban in all enclosed places of work led to a nearly five percent reduction in bar sales. Similarly, Pieroni, Daddi and Salmasi (2013) find a small negative impact on sales relative to the rest of the EU, but no effect on employment or profits after a smoking ban in Italy, while Marti and Schläpfer (2014) also find a small negative impact on sales in discotheques but no widespread effect on the economic activity of bars and restaurants due to Canon-level smoking bans in Switzerland. Finally, Melberg and Lund (2012) find no long-run effect of Norway's relatively early smoking bans in restaurants and pubs on revenue generated by these hospitality venues using time series variation in Norway. While their findings suggest some sort of customer and/or establishment adjustment to the bans, estimating long-run effects is very difficult given that the number of potential confounders increases with time.

\subsection{The Effect of Place-based Smoking Bans on Exposure to Second-hand Smoke}

While any health impacts of smoking surely are borne by smokers themselves, exposure to second-hand smoke (SHS) presents the possibility of harm to non-smokers. A core motivation for place-based smoking bans is to reduce SHS exposure, but credibly estimating whether these policies have such an effect faces many challenges. The first is the availability of data that 
contain information - either direct or indirect - on SHS exposure. Generally speaking, such data are not widely available, and often crude proxies are used (e.g., early studies on the SHS exposure of children measured exposure by whether at least one of their parents smoked). The second is that, conditional on availability, common measures of SHS exposure are obtained via self-reports. As a result, measurement error becomes an important issue, though most likely in terms of the extent of SHS exposure rather than its discrete occurrence. Studies that examine the effect of place-based smoking bans on SHS exposure focus on binary exposure measures. Random measurement error in the dependent variable results in greater residual variance and, in turn, standard errors that are biased upwards, implying a greater chance of a Type II error. Importantly, we know very little about the nature of measurement error in regard to many smoking related outcomes, including exposure to SHS. If, for example, the error in measuring SHS exposure is related to smoking bans (e.g., people are less likely to report SHS exposure in areas that passed smoking bans), then estimates of the relationship between smoking bans and SHS exposure may be biased in unknown ways.

An important issue related to the measurement of place-based smoking bans is the degree to which they affect existing smokers (i.e., the degree to which they bind). It seems useful to consider the case of smoking bans in the workplace, which are thought to be the most potentially impactful of all smoking bans, due to the amount of time they might bind per day. Suppose that a state or local government implements a workplace ban and a researcher attempts to evaluate it. One key piece of information, which is almost always unknown to the researcher, is which workplaces have already banned smoking prior to implementation of the legislated smoking ban. In such a situation, it is difficult to gauge whether standard econometric estimates of the relationship between the legislated smoking ban and exposure to SHS are generalizable to other contexts. A study by Bitler, Carpenter and Zavodny (2010) investigates these issues, combining state-level smoking bans related to twelve specific venues with data from the TUS-CPS that includes information on a wide range of employment characteristics, including the existence of private workplace smoking bans and detailed smoking information. These authors find little evidence that state-level workplace bans increase reports of restrictions on smoking in the workplace. The findings of Bitler, Carpenter and Zavodny (2010) suggest that state-level smoking bans may be less than fully binding, perhaps due to their prior private existence, or perhaps due to lackluster enforcement. 
Another complication in understanding how place-based smoking bans affect SHS exposure is that reductions in exposure to SHS in one place (e.g., a workplace covered by a ban) may be displaced to another, uncovered place (e.g., home or an automobile). To provide some evidence on this question, Adda and Cornaglia (2010) investigate the effect of place-based smoking bans on time use. They use data from the American Time Use Survey and find that smoking bans in restaurants and bars reduce the time smokers spend in these places by roughly twenty minutes per week. This extra time is spent at home. Next, the authors used data from the National Health and Nutrition Examination Surveys to estimate the impact of these smoking bans in restaurants, bars and workplaces on child cigarette smoke exposure. Consistent with the implied timing, they find evidence that smoking bans in restaurants and bars increased biological markers of exposure to cigarette smoke in children surveyed on the weekend and, by contrast, workplace smoking bans increase these biological markers in children surveyed on weekdays. Taken together, the findings of Adda and Cornaglia (2010) suggest that there may be significant displacement of SHS exposure occurring.

Other more recent studies find less evidence of such displacement. For example, Carpenter, Postolek and Warman (2011), using detailed Canadian data, investigate smoking bans in municipal and provincial jurisdictions and exposure to SHS. They find that smoking bans reduced self-reported SHS exposure in bars and restaurants but do not find a corresponding increase in such exposure in non-covered places like automobiles or in the home. These results indicate a lack of displacement and hence imply an overall reduction in exposure to SHS. Nguyen (2013) used detailed Canadian data to examine the effect of a smoking ban in automobiles when children are present and finds that children's exposure to SHS while traveling in automobiles decreases. There is no evidence of higher exposure (i.e., displacement) in other non-covered venues as well. Cheng et al. (2017) find that increased exposure to workplace bans at the local, county and state levels reduced SHS exposure of non-smokers by twenty-eight percent, although the authors did not explicitly look for evidence of increases in other places like the home and/or automobile. Given the relative paucity of studies, the evidence on displacement is mixed. Since it is an important question in understanding the net welfare effects of smoking bans, it will likely remain an area of great interest that will be addressed again as data that allow for such detailed analyses become available. 
The effect of smoking bans on second-hand smoke exposure has been studied much less outside of North America. Moreover, existing studies are confined to public health journals and most are largely descriptive in nature or measure potential SHS exposure rather than measures that may proxy for actual exposure. Filippidis et al. (2016) is representative of much of this literature. Using a single cross-section of roughly twenty-six thousand adults from twenty-seven EU nations, they find that higher scores on the European Tobacco Control Scale, which are positively correlated with the breadth and enforcement of smoking bans, lead to lower levels of self-reported SHS exposure. The authors' results were strongest for bars and weakest for workplace exposure. Many other studies exist that measure potential SHS exposure by taking measurements of particulate matter and airborne nicotine levels in public venues. The majority of these studies find that such potential exposure to SHS is reduced by smoking bans, but again, since they do not assess to what extent individuals are actually exposed, they cannot address the issue of displacement discussed above (Lopez et al. 2012; Nebot et al. 2009). Other studies focus only on the exposure of hospitality venue staff members (Allwright et al. 2005).

\subsection{The Effect of Place-based Smoking Bans on Health Outcomes}

As with most of the literature, research on the impact of place-based smoking bans on health outcomes is relatively new. These studies generally fall into two categories: one set of studies examines the health of smokers while the other examines the health of non-smokers whose health may be impacted by exposure to second-hand smoke. As with other outcomes, valid identification of the effects of public policies on health is extremely challenging. In particular, many of the negative effects of cigarette smoke occur over the course of many years, perhaps decades, while modern econometric techniques are best at identifying changes in health outcomes that may plausibly respond relatively quickly to the implementation or augmentation of smoking-related policies.

A large proportion of the research on the impact of smoking bans on smokers' health examines myocardial infarctions (i.e., heart attacks). In principle, this outcome may be affected by short-run changes in smoking behavior, as opposed to lung cancer and emphysema, which, though strongly associated with cigarette smoking, develop over relatively long time periods. In a recent study, Pell et al. (2008) find that a smoking ban implemented in Scotland in 2006 reduced coronary-related hospitalizations. In separate studies, Mackay et al. $(2012,2013)$ find evidence that this particular Scottish smoking ban reduced the incidence of stroke. While 
provocative, these studies were restricted to a pre-post research design, since the ban in question covered all of Scotland, and are therefore susceptible to secular trends in such hospitalizations or correlated shocks from other policies or macroeconomic conditions.

In the U.S. context, Shetty et al. (2011) examine the relationship between state, county and city-level smoking bans and short-term health outcomes by exploiting the differential timing of these laws. These authors find no impact on mortality, admissions for heart attacks, or chronic obstructive pulmonary disease. Interestingly, Shetty et al. (2011) do find some evidence of an increase in asthma admissions for minors, perhaps consistent with the displacement effect in Adda and Cornaglia (2010). In contrast, research by Adams, Cotti and Fuhrmann (2013) indicate that local and state workplace smoking bans reduced fatal heart attacks among Americans aged 25-54 years old. The authors note that while their findings are robust to a number of reasonable perturbations, they are smaller than published case studies documenting the experiences of particular communities.

Kvasnicka, Siedler and Ziebarth (2018) find reductions in cardiovascular-related hospital admissions, as well as asthma-related hospital admissions, following the rollout of smoking bans in sixteen German federal states over a period of eighteen months using the universe of hospital admissions data from 2000-2008. These authors note that their estimated reductions are driven by changes in warm-weather admissions, which is aligned with periods of greater smoking prevalence and ambient air pollution. Consistent with this evidence, Mazzonna and Salari (2018) investigates the implementation of smoking bans across cantons in Switzerland to estimate effects of these laws on acute myocardial infarction (AMI) rates. Their results show a large negative effect on AMI, which is most prominent for men and is largest for 50-65-year olds. Related estimates suggest that secondhand smoke exposure is the main mechanism driving the estimated effects.

Another strand of this sub-literature examines the impact of place-based smoking bans on birth and infant health outcomes. The few studies that exist are mixed with respect to their findings. Using Norwegian administrative data, Bharadwaj, Johnsen, and Løken (2014) examine the impact of a Norwegian ban on smoking in restaurants and bars on the health of children born to female bar and restaurant workers. The authors found that newborns of such mothers were less likely to be born as "very low" birthweight (i.e., less than 1500 grams) and less likely to be born prematurely but found no evidence of an impact of on APGAR scores or a variety of birth 
defects. Using detailed smoking history data from these mothers, the authors conclude that most of the improvement was generated by the mother's own reduction in smoking, rather than a reduction in exposure to second-hand smoke. While interesting, it seems difficult to generalize these findings beyond women who work in bars and restaurants, who it seems should be most affected by such laws given their potentially high level of exposure to first and second-hand tobacco smoke. Perhaps these results are best viewed as an upper bound of the impact of this particular smoking ban in Norway on infant health.

A recent study by Hajdu and Hajdu (2018) finds more generalizable effects of a ban on restaurant and bar smoking in Hungary in 2012. Their results point to a reduction in the probability of low and very low birthweight (i.e., 2500 grams and 1500 grams, respectively) births as well as premature birth in a more broad-based sample of women. Moreover, their findings are concentrated among mothers with relatively low educational attainment whom the authors suggest should be most impacted by such legislation. Finally, in the only U.S.-based economics study on this question, Gao and Baughman (2017) investigate similar birth outcomes using U.S. Natality Detail File data from 1995-2009. They find very little evidence that countylevel smoking bans impact birth outcomes among U.S. women.

Overall, credible research linking smoking bans and health is scarce, and this is likely due to the recency of many of the most comprehensive smoking bans. We expect that this will change in time as these laws, and the degree to which they are enforced, grow in number and even better data on amenable health outcomes become available. However, it also is important to note that the rise of e-cigarettes will likely have important implications for research on placebased smoking bans in the very near term, as states and local governments begin to increasingly institute place-specific e-cigarette bans that could interact with the impact of place-specific smoking bans.

\section{Attribute-Based Product Regulation}

Public policies that regulate attributes of tobacco products are growing in popularity. These policies include regulations on warning labels, packaging, and advertising. An emerging policy approach regulates internal product attributes as well, including flavoring and nicotine content. Attribute-based regulations are advocated as a way to make tobacco products less attractive. Compared to taxation, attribute-based regulation might be a more effective way to 
reduce demand if some consumers are price-inelastic but highly value certain non-price attributes. In this section, we review evidence on the effectiveness of attribute-based regulations.

\subsection{Required Warning Labels}

Perhaps the most common attribute-based regulations require health warning labels on cigarette packaging and advertising. Following authoritative reports of the health consequences of smoking, in the 1960s the U.S. and many other countries began to require such warning labels. The first warning labels were text statements, but many countries now require graphic warning labels that typically include color images such as a diseased lung. Some countries, including Australia and the United Kingdom, also have enacted plain packaging requirements that limit the size and color of the cigarette brand name and logo. Another feature of cigarette packaging is whether it includes information on tar and nicotine content. Based on the lack of evidence that low-tar and -nicotine cigarettes pose lower health risks, the 2009 U.S. TCA banned misleading terms including "light" in packaging and advertising.

The 2009 TCA also has led to new warning labels. The TCA requirement that cigarette packaging and advertisements include graphic warning labels has been delayed by legal challenges from cigarette manufacturers. In response to the court cases, the FDA conducted additional research and in 2019 issued a new proposal for 13 graphic warning labels. The new labels focus on less well-known health consequences of smoking, including erectile dysfunction, type 2 diabetes, and age-related macular degeneration and cataracts that can lead to blindness. The FDA additionally has issued requirements for new text warnings on e-cigarettes and other tobacco products. In October 2019, the FDA authorized a snus manufacturer to market its products as "modified risk" products that pose lower risks than combustible cigarettes (FDA 2019). In particular, based on the scientific evidence submitted to the FDA the manufacturer is allowed to make the claim: "Using General Snus instead of cigarettes puts you at a lower risk of mouth cancer, heart disease, lung cancer, stroke, emphysema, and chronic bronchitis." To date, the FDA has not approved an application submitted by a manufacturer of a heat-not-burn product to similarly market its product as a modified-risk tobacco product.

Although cigarette warning labels are very well-established policies, research design challenges make it difficult to quantify their effectiveness. The regulations typically are enacted at the national level, so studies have not been able to estimate state-level difference-in-difference models. Public health research uses individual-level data to conduct cross-sectional and before- 
and-after studies of the associations between graphic warning labels and awareness of health warnings, health beliefs, and attitudes (Hammond 2011). However, it is difficult to determine with this method if graphic warning labels changed smoking behaviors. For example, although adult smoking prevalence in Canada fell after graphic warning labels were introduced, Hammond (p. 31) stresses that "there is no way to attribute these declines to the new health warnings" because graphic warning labels have often been enacted as part of broader antismoking campaigns.

Another line of public health research has conducted focus groups and randomized controlled laboratory experiments of the impact of different warning labels on consumers' attitudes (Hammond 2011). Studies that take this approach are part of the evidence base for the FDA's new graphic warning labels requirements. The studies provide evidence on the relative impacts of different designs and also provide insights into how the labels might work to change behavior. For example, although economists typically focus on warning labels as a source of information, the experimental results from several studies do not find strong evidence that graphic warning labels increase the perceived health risks of smoking (Byrne et al. 201, Skurka et al. 2018). Instead, the labels elicit emotional responses, such as fear or disgust. A general limitation to the laboratory approach is that the results might lack external validity when extrapolated to the impact of graphic warning labels on consumer market behavior. For example, in many countries where graphic warning labels are required, consumers can purchase cigarette cases and covers to avoid seeing the labels. Using a credible research design to identify the impact of warning labels in observed market data would be a useful direction for future research.

\subsection{Regulating Tobacco Advertising}

Most countries regulate cigarette advertising, which is usefully analyzed as a product attribute. Historically, cigarettes were among the most heavily advertised products. In 1971, the U.S. banned cigarette advertising on television and radio. Cigarette advertising in magazines remains legal, although the 1998 Master Settlement Agreement between cigarette manufacturers and state Attorneys General restricted advertising targeted towards children. U.S. cigarette manufacturers continue to make substantial promotional expenditures; most of this spending is on price promotions such as "buy one, get one free," rather than on advertising. The U.S. FDA is considering new restrictions on the advertising of menthol cigarettes and on the advertising of ecigarettes. Many other countries ban all forms of cigarette advertising (WHO 2017). 
Cigarette advertisements fit the Becker and Murphy (1993) model of advertising as a complement to the advertised good. Regulations that restrict the cigarette industry's supply of advertisements to consumers are thus predicted to decrease consumer demand for cigarettes. Although advertising might expand the size of the entire cigarette market, manufacturers have profit incentives to supply advertisements that promote their brand over competing brands. Hence, advertising may merely reshuffle smokers from one brand to another. Econometric studies provide little evidence that cigarette advertising strongly expands the size of the cigarette market (Gallet and List 2003, Dave and Kelly 2014). In sharp contrast, public health research based on less credible causal methods reaches a consensus that cigarette advertising encourages youth initiation (Lovato, Watts, and Stead 2011), which is consistent with a market-expanding impact. These studies fail to consider that unobserved heterogeneity and youths' choices make the advertising measures potentially endogenous, however (Heckman, Flyer, and Loughlin 2008, Nelson 2010). In addition to consumer choices, it also is crucial that studies of advertising take into account the choices of profit-maximizing manufacturers who target their cigarette advertising to reach potential consumers. Kenkel, Mathios, and Wang (2018) study advertisements for menthol cigarettes and exploit quasi-experimental variation in advertising exposure created by sharply different supply-side variation in menthol and nonmenthol advertising. While they find that menthol advertisements are targeted to reach likely menthol smokers, there is little evidence that menthol advertising expands the size of the cigarette market or the menthol market. The results are consistent with advertising for brand share, but the study is unable to test that hypothesis. These results suggest that menthol advertising in magazines does not harm public health through any effects on users or nonusers. While the FDA has considered banning menthol advertising, they have not yet done so, and the findings of Kenkel, Mathios, and Wang (2018) provide little support for such regulation. Furthermore, the possibility of FDA regulation of menthol advertising may become moot if the FDA bans the sale of menthol cigarettes altogether (see discussion below).

Dave and Saffer (2013) examine how smokeless tobacco advertising and cigarette taxes affect smokeless tobacco use (chewing tobacco and snuff). The main innovation of this study is to follow the approach developed by Avery et al. (2007) and employ data from the National Consumer Survey which contains information on the magazine reading habits of respondents as well as smokeless tobacco advertising in these magazines. Within magazine types, variation in 
exposure to ads is driven by variation across magazines as well as variation within magazines over time. Variation in exposure to smokeless tobacco ads hence is based on what magazines one reads, how often one reads them, and when one reads them. This exposure measure handles some of the identification concerns related to selection into reading specific magazines and the associated targeting of ads. However, if tobacco companies have sufficient information, they still can target ads to specific magazines at specific times that generate a selection problem. Nonetheless, this is one of the more careful analyses in the literature on how tobacco advertisements affect behavior. They estimate panel models that include magazine, state, and year fixed effects as well as controls for cigarette taxes at the state-year level and find that ad exposure increases smokeless tobacco consumption by $6 \%$.

Two recent studies that use different datasets and different identification strategies find evidence that e-cigarette advertisements encourage smokers to substitute towards e-cigarettes (Tuchman 2019, Dave et al. 2019). Unlike cigarette advertisements, in the U.S., e-cigarette advertisements are currently allowed on television as well as in print media. Tuchman (2019) uses the Nielsen Retailer Scanner data from 2010-15. Her identification strategy is a hybrid regression discontinuity/differences-in-differences approach. She exploits discontinuities in exposure to television advertising created by the borders of local television markets as defined by Nielsen Designated Market Areas (DMAs). Firms purchase local television advertising at the DMA level. To control for other possible differences across DMAs, Tuchman restricts the sample to retailers in counties on either side of a DMA border. The border creates quasiexperimental variation in exposure to local television advertisements for e-cigarettes. Tuchman estimates that a 10 percent increase in e-cigarette advertising increases e-cigarette sales by 0.8 percent and decreases combustible cigarette sales by 0.2 percent.

Using 2013-15 data from the Simmons National Consumer Survey, Dave et al. (2019) estimate that smokers who are exposed to more television advertisements for e-cigarettes are more likely to quit smoking. The identification strategy uses the quasi-random variation in advertising exposure that remains after including fixed effects for calendar time and television time slot, program, and channel. The identifying variation is thus between consumers who are exposed to different numbers of e-cigarette advertisements because they watched the same television programs but in different quarters or years. Dave et al. (2019) find that increases in 
advertisement exposure lead to a statistically significant but quantitatively small increase in the probability of quitting smoking.

In addition to advertisements in traditional media, tobacco products are increasingly advertised over the Internet and through social media. The major manufacturers of cigarettes in the U.S. are required to provide information to the Federal Trade Commission (FTC) about their expenditures on advertising and promotion. In 2017 (the latest year of data available), the companies reported spending \$25.1 million on company websites and no spending on social media (FTC 2019). ${ }^{45}$ For comparison, the companies reported spending \$14.9 million on magazine advertising and $\$ 48.5$ million on point-of-sale advertising, amounts which are dwarfed by the over $\$ 7$ billon spent on price discounts to retailers and wholesalers. We are not aware of systematic evidence about expenditures for online and social media advertising of other tobacco products. Haardörfer et al. (2017) report that of two of the four major e-cigarettes manufacturers spent very little for online advertising in 2013-2014, but given the rapid evolution of the ecigarette market this might no longer be true. The current market-leading e-cigarette manufacturer, Juul Labs, maintains a strong presence on social media. The 2016 Surgeon General's Report on e-cigarette use provides more discussion of the extent of advertising and promotion of e-cigarettes online and through social media (U.S. Department of Health and Human Services 2016).

Public health research documents associations between exposure to online advertising and ecigarette use (U.S. Department of Health and Human Services 2016). This line of research faces the same challenges discussed above regarding identifying the causal impact of advertising on other media. Blake, Nosko, and Todelis (2015) report the results of controlled experiments of online advertising conducted by eBay, Inc. Although the experiments do not include tobacco product advertising, they provide evidence on the challenges of identifying the causal impact of online advertising in general. Blake, Nosko, and Todelis (2015) provide an empirical example where failing to control for the endogeneity of online advertising exposure yields very large estimates of the return on investment, while their experimental results reject the hypothesis of any positive return. A useful direction for future research is to use controlled experiments or

\footnotetext{
${ }^{45}$ One company reported spending on Internet advertising other than its website, but to protect confidentiality the FTC does not report the amount.
} 
other credible research designs applied to online and social media advertising of tobacco products.

Public health research also examines the content of online advertising of tobacco products, which is relevant to the economic distinction between persuasive "image advertising" versus informative advertising. The 2016 Surgeon General's Report concludes that e-cigarette marketing uses themes that parallel themes in combustible cigarette marketing, such as sexual content and customer satisfaction (U.S. Department of Health and Human Services 2016). A prominent concern is that the advertising themes encourage adolescents to use e-cigarettes. In 2018, the leading manufacturer of e-cigarettes announced that its social media advertisements will no longer feature models but will instead feature former smokers who had switched to ecigarettes (JUUL Labs 2018). In a content analysis of online and social media advertising for ecigarettes, Ramamurthi et al. (2016) find that $23 \%$ of the advertisements included cessation claims; most (83\%) of the cessation claims were implicit. The frequency of cessation claims might seem surprisingly low but reflects legal challenges to e-cigarette marketing. If e-cigarette advertising makes therapeutic claims, it might open the door for the FDA to regulate e-cigarettes as medical devices and to require the manufacturers to submit evidence from clinical trials about safety and efficacy. Kenkel (2016) notes that the legal challenges have essentially banned informative e-cigarette advertising and only permits persuasive advertising. The regulatory environment is continuing to evolve and may create quasi-experimental variation that would allow future research to study the effects of e-cigarette advertising content.

\subsection{Regulating Flavors and Other Product Attributes}

Bans on menthol and other flavors are prominent examples of an emerging policy approach to regulate product attributes. Menthol brands have about 28 percent of the U.S. market, with the market share ranging from 21 percent among white smokers to 74 percent among African American smokers (FDA 2013). Menthol's market share in most countries is much lower than in the U.S.; for example, in the United Kingdom and Canada it is about four percent (Giovino et al. 2004). Even when sales of cigarettes with flavors other than menthol were allowed, flavored cigarettes had very small market shares in the U.S. However, flavors are more popular for other tobacco products, including smokeless tobacco, little cigars, and electronic cigarettes. 
There is relatively little known about the impact of flavor bans, partly because they are a new policy approach and partly because it is difficult to develop a strong research design. The FDA continues to consider a ban on menthol cigarettes (Gottlieb 2018). Internationally, the United Kingdom, Canada, and a number of other countries have already banned menthol cigarettes; to date, the menthol bans have been enacted in countries where the menthol's pre-ban market shares were low. In a recent working paper, Carpenter and Nguyen (2020) study the impact of menthol bans implemented in seven Canadian provinces prior to Canada's nationwide ban. Menthol sales in the seven provinces fell to zero after the bans. The study finds evidence that menthol smokers substituted into non-menthol cigarettes; some smokers also avoided the ban by making purchases on First Nations reserves where menthol cigarettes were still available.

The 2009 TCA banned flavors other than menthol in cigarettes, but the pre-ban market share of the banned flavored cigarettes was low. Some U.S. localities including New York City have banned flavors in other tobacco products. In the fall of 2019, Michigan, New York, Rhode Island, and Washington announced state-level bans on flavored e-cigarettes; the legality of the bans has been challenged in the courts. In early 2020, the FDA announced new enforcement priorities that amount to at least a temporary ban of cartridge-based flavored e-cigarettes (other than menthol). In order to remain on the market, by May 2020 manufacturers of e-cigarettes must submit an application to the FDA demonstrating that their products are appropriate for the protection of public health (FDA 2020). This regulatory pathway means that flavored ecigarettes might return to the market, although it might require the manufacturers to take steps to prevent use by underage youth, such as reducing nicotine levels or adopting technologies such as thumb print scanners.

If consumers see the flavored and non-flavored tobacco products as close enough substitutes, the flavor bans might not have strong impacts on consumption, initiation, or cessation. One approach to develop empirical evidence on this question is to study the effects of local flavor bans. Kenkel and Somerville (2019) in a working paper use Nielsen Retailer Scanner data from 2006-16 to study the impact of the 2010 flavor ban in New York City. Because there is only one treated group, they use the synthetic control method of Abadie, Diamond, and Hainmueller (2010). They estimate that the sales of flavored small cigars would continue to increase in synthetic New York, so the treatment effect was to decrease sales by about 29,000 flavored cigars per month (a larger effect than implied by a simple before-and-after comparison). 
They do not find any evidence that the sales of non-flavored cigars increased. Somewhat surprisingly, flavored cigar sales in nearby jurisdictions that were not subject to the New York City ban also fell after the ban. Kenkel and Somerville speculate that due to retailer distribution networks, the effects of the New York City ban spilled over and reduced shipments of flavored cigars to retailers in nearby jurisdictions. As data become available to study the more recent bans in other localities, it should be possible to conduct additional research into their impacts.

Another approach to develop empirical evidence about the effects of flavor bans and other attribute-based regulations is to use stated-preference data from discrete choice experiments (DCEs). DCEs are commonly used in marketing research and economics to provide predictions of consumer demand in policy-relevant scenarios that are not yet observed in actual markets (e.g., Kesternich et al. 2013). The flexibility of DCEs make them well-suited to study the wide range of potential attribute-based tobacco product regulations. Pesko et al. (2016) report the results of an online DCE where adult smokers made hypothetical choices between ecigarettes, combustible cigarettes, and a nicotine-replacement product. The attributes of the ecigarette were varied experimentally to match potential FDA regulations and state policies. The results suggest that young adults are more likely to choose e-cigarettes when flavors are available. Higher e-cigarette prices and a strong warning label shift choices away from ecigarettes mainly towards combustible cigarettes. Kenkel et al. (2019) use the same data in a working paper to estimate a mixed logit model and use it to conduct counterfactual policy scenarios. Under pre-FDA regulation market conditions, their model predicts that 16 percent of current smokers will choose e-cigarettes versus 71 percent who will choose combustible cigarettes. In public policy counterfactuals, their model predicts that FDA regulations and state e-cigarette taxes could reduce the fraction who choose e-cigarettes to as low as 13 percent, while the fraction who choose combustible cigarettes shows a corresponding increase. In a counterfactual where e-cigarettes are banned - which is outside the range of the variation in experimental conditions - the fraction who choose combustible cigarettes increases to 82 percent.

Marti et al. (2019) report the results of an online DCE in which adult smokers were given three options: a disposable e-cigarette, a rechargeable e-cigarette, or a pack of combustible cigarettes. The attributes of the e-cigarette options are described in terms of whether e-cigarettes are healthier than combustible cigarettes, the effectiveness of e-cigarettes for smoking cessation, 
whether the use of e-cigarettes is banned in public places, and price. The definition of product attributes in this DCE makes it difficult to use the results to predict the impact of tobacco regulations. Although tobacco regulations can attempt to influence public perceptions about healthiness and cessation effectiveness, it is not known how specific policies such as warning labels and advertising campaigns will translate into changes in perceptions about healthiness and effectiveness. Marti et al. (2019) estimate a baseline conditional logit model and, in their preferred approach to study heterogeneity, a latent class logit model. They find that health concerns are more important determinants of e-cigarette choices than are smoking bans or prices.

Buckell and Hess (2019) report the results of a DCE that explored the impact of nicotine levels on adult smokers' tobacco product choices. The estimated multinomial logit model implies that consumers are less likely to choose tobacco products that are described as having "no nicotine" or "low nicotine" compared to a baseline of "medium nicotine." The pattern of results suggests that if the nicotine content of combustible cigarettes is regulated to very low levels, smokers may be willing to substitute into e-cigarettes that contain medium levels of nicotine. A major concern about this line of research is general skepticism that the experimental results from hypothetical choices in DCEs have external validity when extrapolated to real-world markets. Buckell and Hess (2019) discuss this concern in detail and show how revealed preference data from actual choices can be used to calibrate forecasts from models estimated with DCE data.

So far, the discussion has focused on the challenges of developing estimates of the causal effects of attribute-based tobacco regulations, typically considered one at a time. However, cigarette manufacturers might respond to the regulation of certain product attributes by changing other product attributes, including price. For example, if brand names and advertising create product differentiation, attribute-based regulations might lead to lower prices. However, Egger et al. (2019) find that cigarette prices in Australia increased after the implementation of plain packaging. After the 2009 TCA ban on the term "light," U.S. cigarette manufacturers of the affected brands were able to maintain their market shares through package colors and brand names, for example Marlboro Light became Marlboro Gold. In response to bans on menthol in the Canadian provinces of Nova Scotia, Alberta, and Ontario, cigarette manufacturers marketed "menthol replacement" brands with menthol-like qualities including colors (green or blue) and descriptors such as smooth (Brown et al. 2017, Borland et al. 2019). The degree to which this response offset the impact of the menthol bans is not known with certainty, but as noted above 
Carpenter and Nguyen (2020) find evidence that many menthol smokers substituted into nonmenthols.

Another set of responses about which little is known are potential consumer responses to circumvent the bans on attributes. For example, a potential response to a menthol ban is "postmarket mentholization," where the consumer adds menthol flavor to regular cigarettes (Tobacco Products Scientific Advisory Committee 2011). ${ }^{46}$ Bans on flavored e-cigarettes might lead to similar post-market responses. The extensive research discussed above on cigarette tax avoidance suggests that in response to state- and local-level attribute bans consumers might purchase their preferred products from jurisdictions where they remain legal. The FDA (2018) discusses the possibility of illicit trade in tobacco products after a national tobacco product standard, which could include a restriction of nicotine to non-addicting levels. The wide variety of possible responses to product-based regulations opens up a range of possible directions for future research.

\section{Conclusion}

Empirical questions about the impact of tobacco regulations involve interesting economic and econometric challenges that are central to policy debates. The broad summary of the extensive economic research on these questions is that tobacco product consumption responds predictably to the incentives created by tobacco regulations. The "devil in the details" is the difficulty in quantifying these responses.

Cigarette excise taxes are a core component of tobacco regulation in the US and around the world. The consensus from the last comprehensive review of the research that was conducted 20 years ago (Chaloupka and Warner 2000) indicates that adult cigarette demand is inelastic. More recent research from a time period of much higher cigarette taxes and lower smoking rates supports this consensus, however there also is evidence that traditional methods of estimating cigarette price responsiveness overstate price elasticities of demand. As well, more recent research casts doubt on the prior consensus that youth smoking demand is more price-elastic than

\footnotetext{
${ }^{46}$ This response would parallel the original development of menthol cigarettes in the early 1920s by Lloyd "Spud" Hughes, when he stored his cigarettes with the menthol crystals he used to treat his asthma. By 1932, the menthol brand he launched, Spuds, were the fifth leading brand in the U.S. (Tobacco Products Scientific Advisory Committee 2011).
} 
adult demand; the most credible studies on youth smoking indicate little relationship between smoking initiation and cigarette taxes.

The inelastic nature of cigarette demand suggests cigarette excise taxes are an efficient revenue-generating instrument. A central policy question is what the optimal level of cigarettes taxes is in the presence of internalities and externalities. Welfare analysis, especially in the presence of internalities, is both challenging and controversial. The public health community shares a consensus supporting additional policies to further reduce smoking. Fifty years after the first Surgeon General's Report on Smoking and Health, the 2014 Report concludes with discussions of "end-game" strategies to reduce cigarette consumption to zero. However, evidence on the magnitude of the externalities created by smoking does not necessarily support current tax levels. Behavioral welfare economics research suggests that the internalities of smoking provide a potentially stronger rationale for higher taxes and stronger regulations. But the empirical evidence on the magnitudes of the internalities from smoking is surprisingly thin. This is an important area for future research, but we recognize that it will be difficult to develop strong enough evidence to settle the debate. A more modest but important and more achievable goal is to contribute empirical evidence on the relative benefits and costs of alternative tobacco regulations. Among these costs and benefits, we note that there is currently not enough research on how tobacco regulations affect the use of public programs such as food stamps, public housing, and cash welfare. Understanding these relationships will help quantify the fiscal externalities associated with tobacco regulation.

Research on cigarette tax avoidance has been a very active area and provides the basis for a new consensus on its importance in cigarette markets. The evidence from multiple approaches indicates extensive cross-border cigarette tax evasion, which generates deadweight loss from avoidance and reduces the health benefits associated with cigarette taxes. While it is unclear what the optimal level of cigarette taxes is, our review of the literature suggests that it is suboptimal to have uneven taxes across uncontrolled borders.

Smoking bans have become an increasingly important part of tobacco control policies over the past 20 years. The different research findings on U.S. and European place-based bans prevents a consensus regarding their effectiveness. Heterogeneity in the scope and enforcement of these bans similarly makes it difficult to reach consistent policy conclusions. Due to research 
design challenges and their relatively novelty, it is also too soon to make definitive claims about the effectiveness of many product-based regulations.

Looking forward, even where there is a consensus about how tobacco regulations worked in the past, economic research will need to explore how past performance predicts future results. As highlighted throughout our review, over the past 20 years tobacco policies and market environments have rapidly evolved. Reduced-form studies that provide estimates of the local average treatment effects of tax hikes in the 2000s and 2010s might not extrapolate to the highertax environment of the 2020s. The rise of alternative tobacco products and legalized marijuana have the potential to substantially alter tobacco consumption and risky health behaviors among youth and adults. Basic economics predicts that the availability of more substitutes - including ecigarettes, heat-not-burn products, and modified risk products such as snus - should make cigarette demand more price-elastic. The research is nascent on how these new developments interact with the current regulatory structure. This is due in part to how new these products are and the recency of their popularity. The answer to how policymakers should treat e-cigarettes rests on questions such as whether e-cigarettes and cigarettes are substitutes or complements, the relative health costs of vaping vs. smoking, and the dynamic interplay between vaping and smoking (especially among teens). These are critical questions to answer in the development of optimal tobacco control policies, which underscores the importance of future research in this area.

This review has focused predominantly on tobacco regulation in the form of cigarette taxes and place-based smoking bans. This focus is driven by the large volume of research on these questions, but the regulatory landscape continues to evolve. On December 20, 2019, the minimum purchase age for all tobacco products including cigarettes and e-cigarettes was raised to 21 throughout the US. Many states have banned or placed significant restrictions on the sale of e-cigarettes and have included e-cigarettes in their place-based smoking bans. The FDA regulations that sprang from the 2009 TCA, including new warning labels on cigarettes and other tobacco products and restrictions on the marketing of flavored e-cigarettes also are likely to change tobacco markets. These regulations are so recent that little research has been done on them. Direct policy evaluations of these regulatory changes and how they impact consumer responses to taxes and place-based smoking bans provide ample opportunity for new research. 
Economic research on tobacco regulation has not focused much on how regulatory changes affect health. This is a critical area of exploration because of the central role of public health in motiving such wide-ranging regulatory policies. The lag between smoking consumption and any adverse health consequences makes this a particularly challenging problem, but it is of high importance to develop credible evidence on health impacts to guide public policy. Especially in light of alternatives to cigarettes (e.g., e-cigarettes) that may impact consumer health outcomes, identifying how current tobacco regulation affects health is of immense importance moving forward. With better data becoming more widely available and the advancement of econometric methods, we expect this to be an area of increased focus in the near future. 
Figure 1. Cigarette Excise Tax Trends, 1965-2018

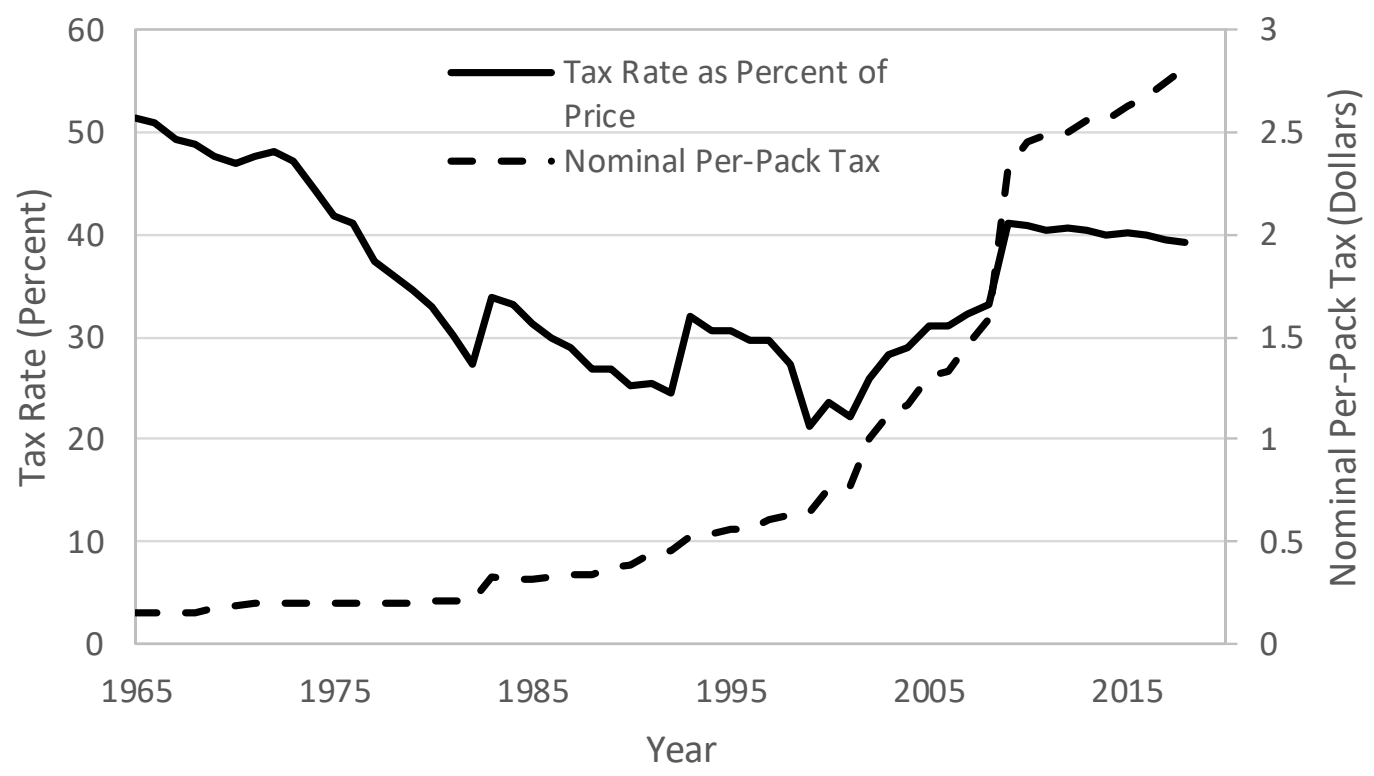

Source: Orzechowski and Walker (2018). All Taxes include state and federal excise taxes. Cigarette prices include generic and non-generic brands.

Figure 2. Adult Smoking Rate, 1965-2018

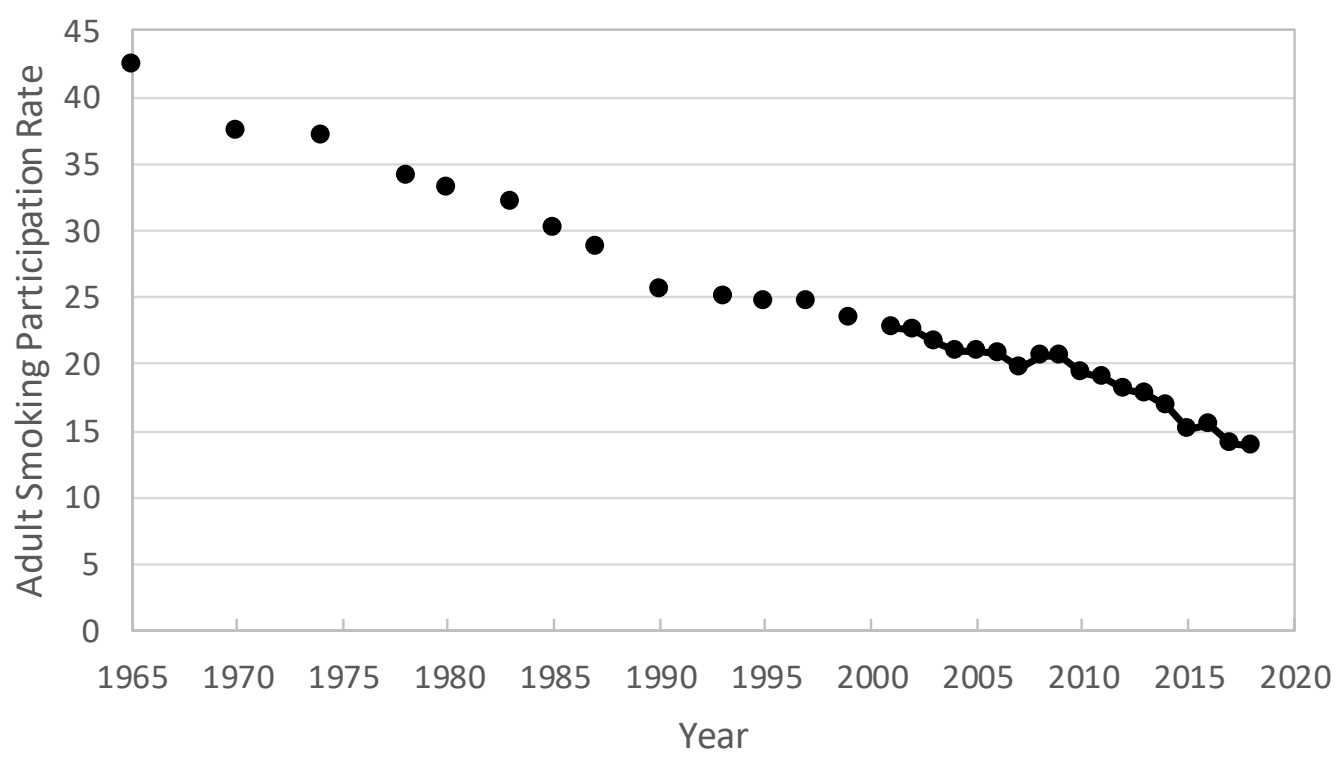

Source: National Health Interview Surveys, 1965-2018. 
Figure 3. Trends in the Smoking Participation Rate across Commonly Used Datasets

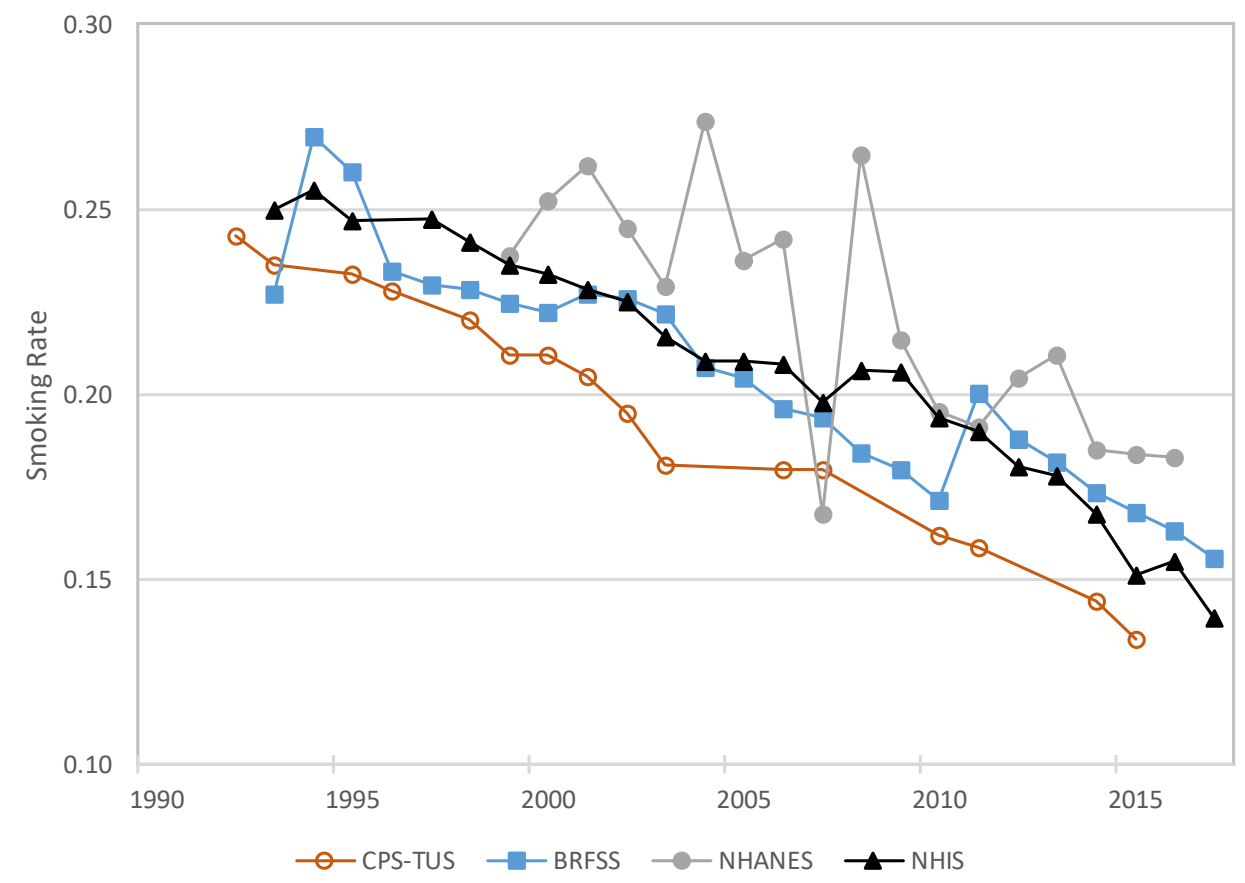

Note: Sample weights are used to construct yearly means in each dataset. All samples include the $18+$ population only.

Figure 4. Trends in Average Cigarettes Smoked Per Day (Including Zeros) across Commonly Used Datasets

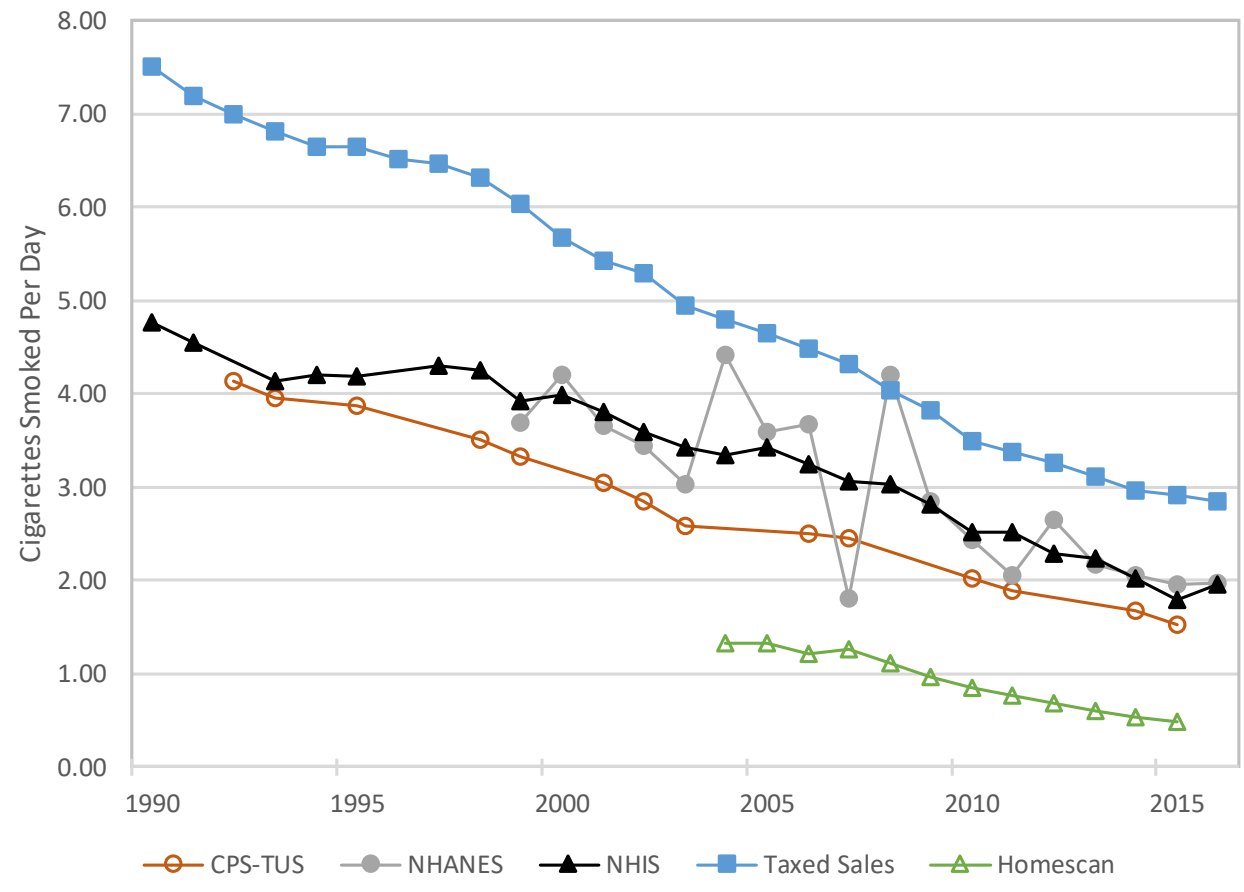


Note: Sample weights are used to construct yearly means in each dataset except for taxed sales. All samples include the $18+$ population only, except for taxed sales that include sales to all consumers.

Figure 5. Average Number of Cigarettes Smoked per Day by Income Bracket: 1992-1993 vs. 2014-2015 TUS-CPS

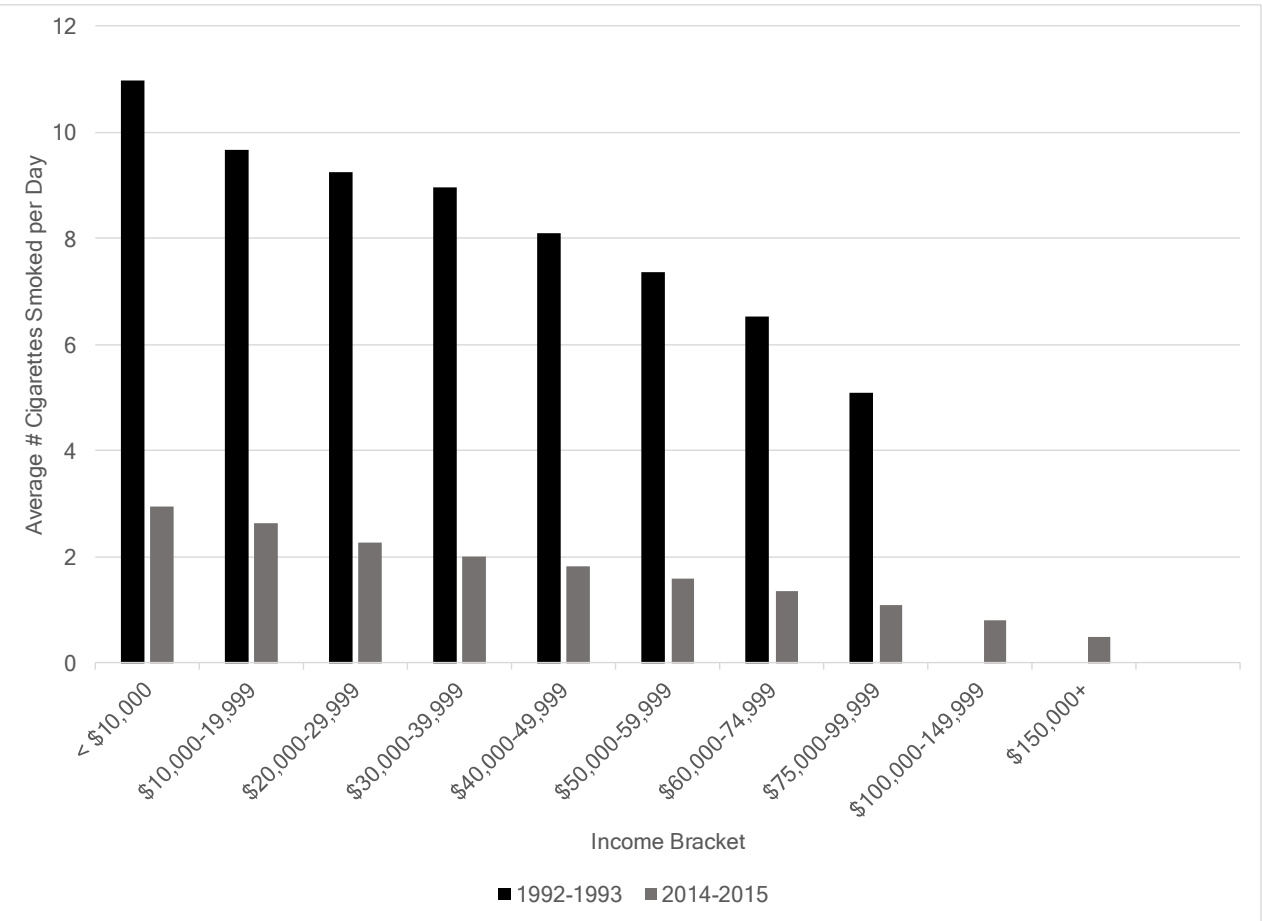

Note: The average number of cigarettes smoked per day, including zeros, is calculated using the answer to "On average, about how many cigarettes do you smoke a day?" All tabulations are weighted by the CPS sample weights. 
Figure 6. Average Implied Taxes Paid per Year by Income Bracket: 1992-1993 vs. 20142015 TUS-CPS

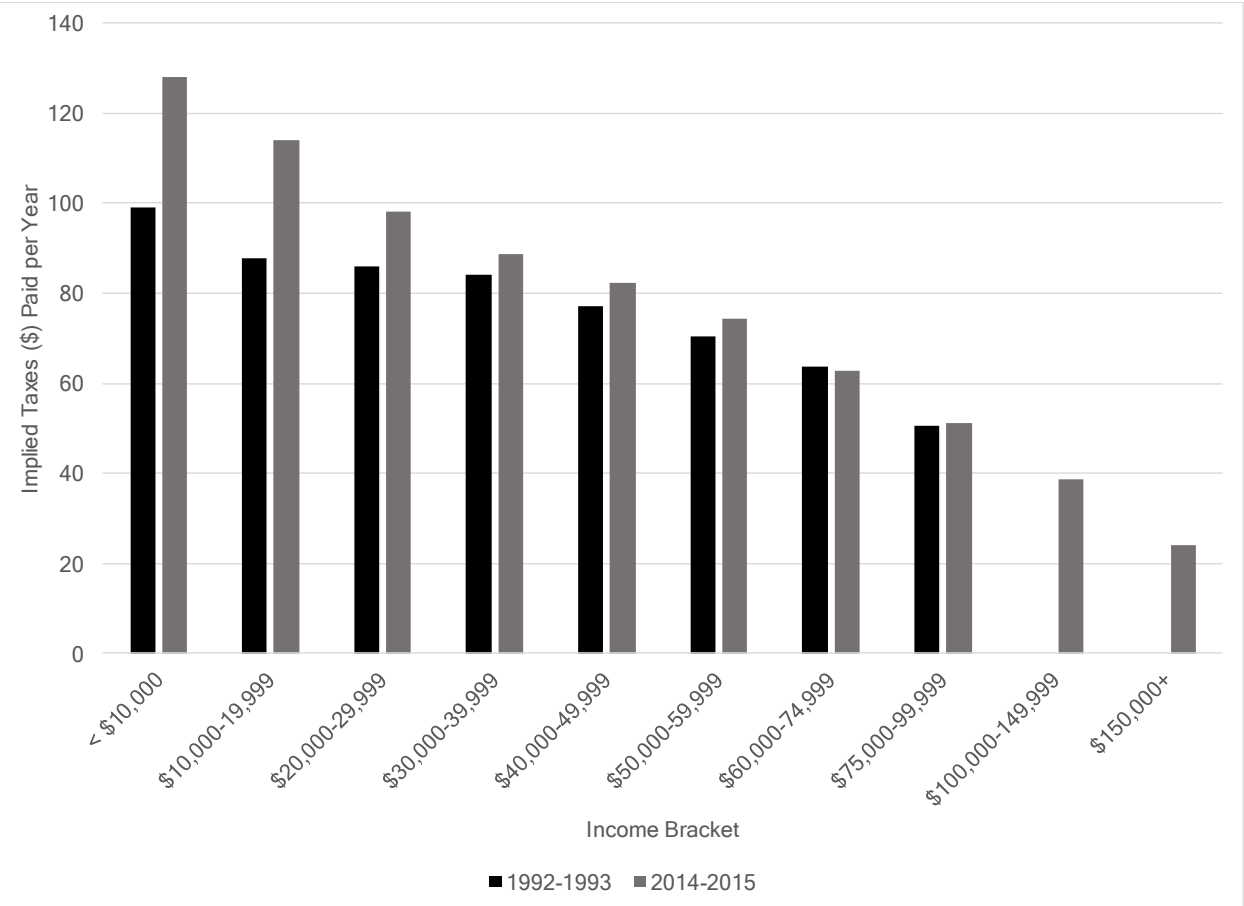

Note: The amount of cigarette taxes paid is calculated by multiplying the extrapolated number of cigarette packs smoked per year by each respondent with the per-pack tax level in the respondent's state and year. The number of cigarette packs smoked is calculated using the answer to "On average, about how many cigarettes do you smoke a day?", multiplying this number by 365 and dividing by 20 . All tabulations are weighted by the CPS sample weights. 
Figure 7. Cigarette Taxes Paid as a Percentage of Family Income by Income Bracket: 19921993 vs. 2014-2015 TUS

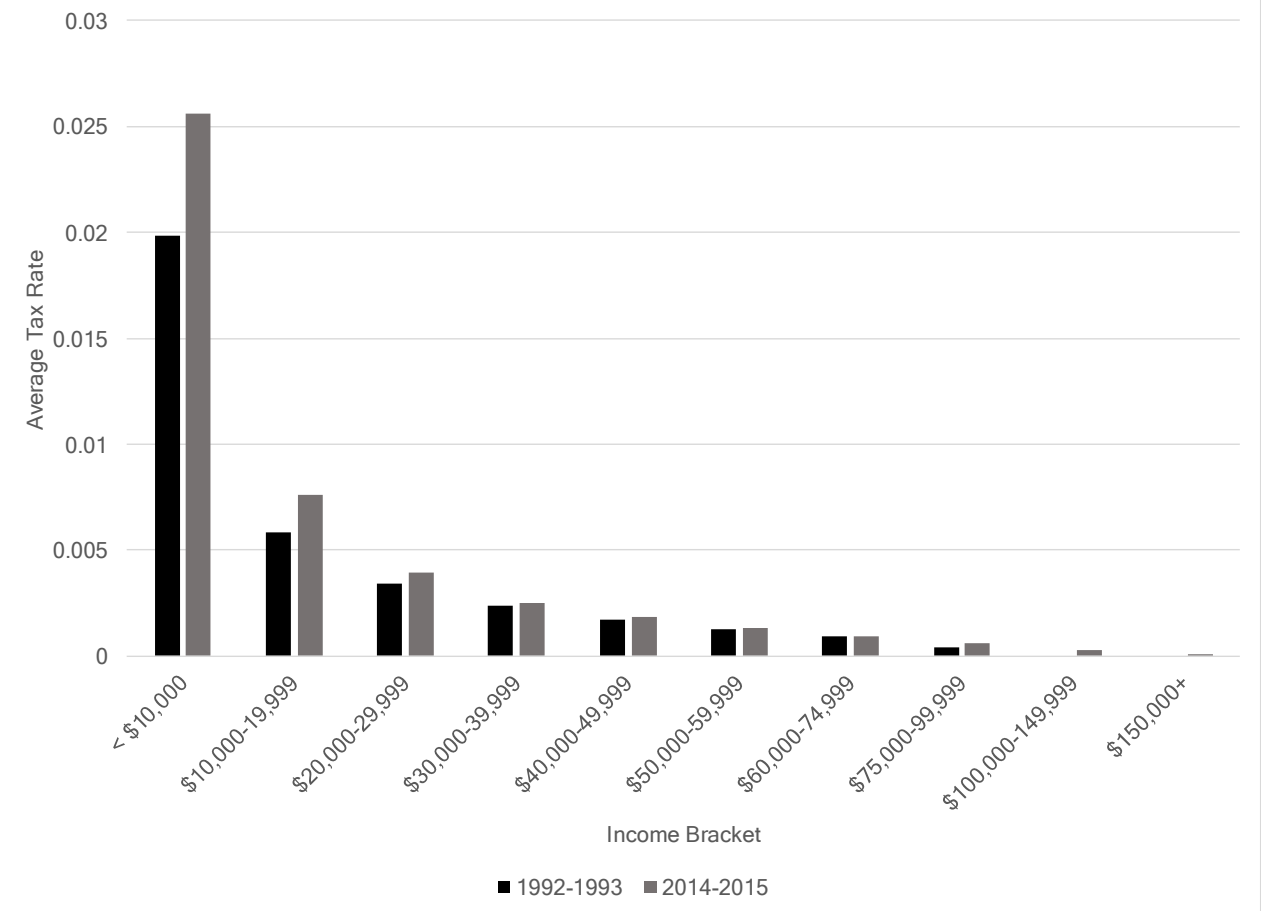

Note: The average cigarette tax rate is calculated by dividing the total cigarette taxes paid from Figure 6 by the median income in each income bracket. For the $\$ 150,000+$ group, we divide the total taxes paid by $\$ 150,000$. All tabulations are weighted by the CPS sample weights. 


\section{Figure 8. Cigarette Prices Surrounding Tax Changes}

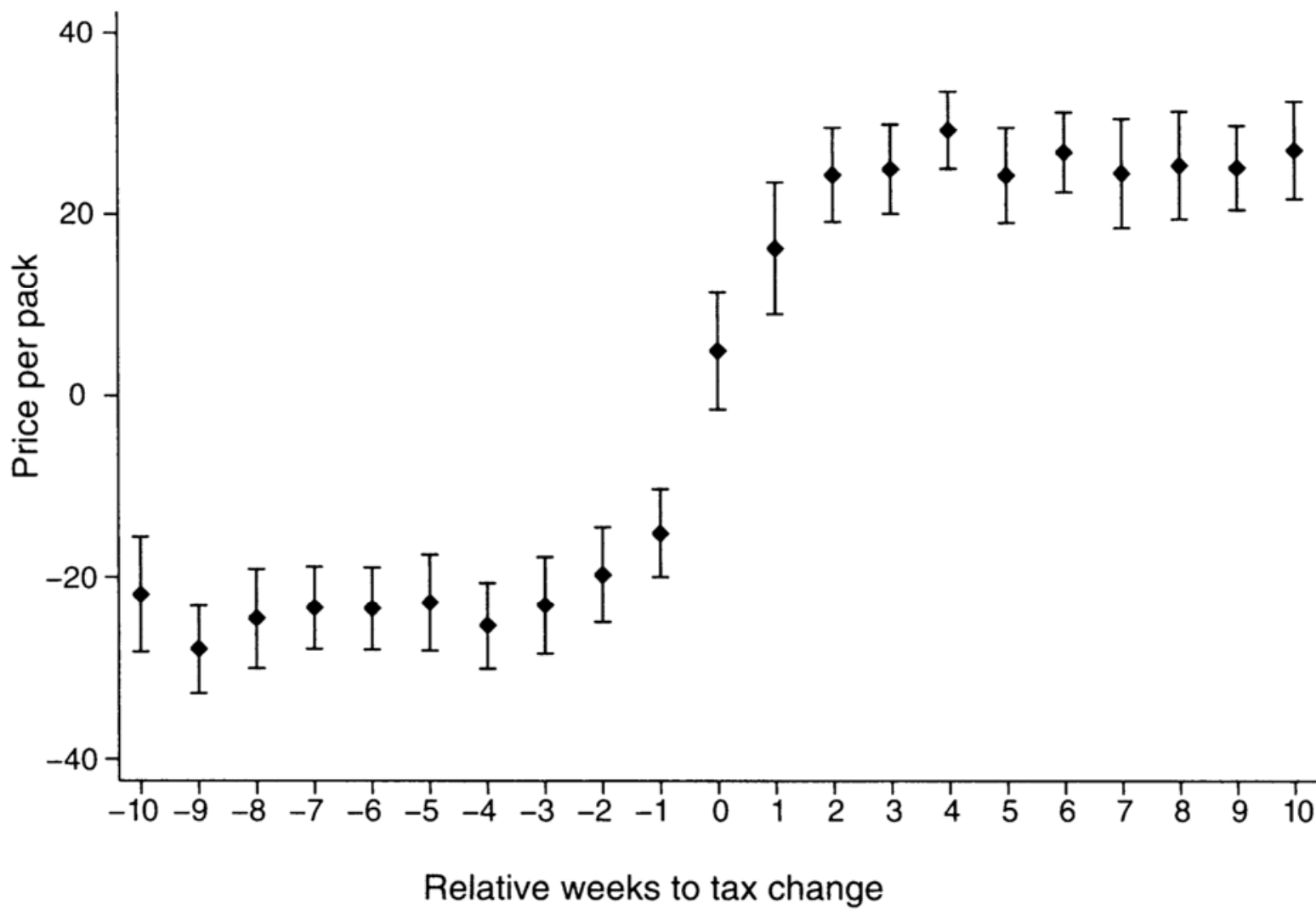

Source: Harding, Leibtag, and Lovenheim (2012), Figure 1.

Notes: This figure presents an event study of tax changes on prices, using tax changes in 12 states that increase their cigarette excise taxes in 2006 and 2007: New Jersey, North Carolina, Vermont, Arizona, South Dakoda, Texas, Iowa, Colorado, Indiana, Connecticut, New Hampshire, and Delaware. The implied pass-through rate is 0.9. Each point represents the coefficient estimate on the respective relative week to tax change indicator variable. Week zero is the week in which the tax is increased. The bars extending from each point represent the bounds of the 95 percent confidence interval calculated from standard errors that are clustered at the census tract level. Because all states are included in these models, all relative time coefficients show prices relative to prices paid in non-changing states and to prices paid in states that change their excise tax in time periods more than ten weeks to or since a tax change. The estimates include UPC, state, and month of purchase fixed effects. 
Figure 9. Magnitudes of Extensive Margin Tax/Price Elasticity Estimates by Median Year of Data

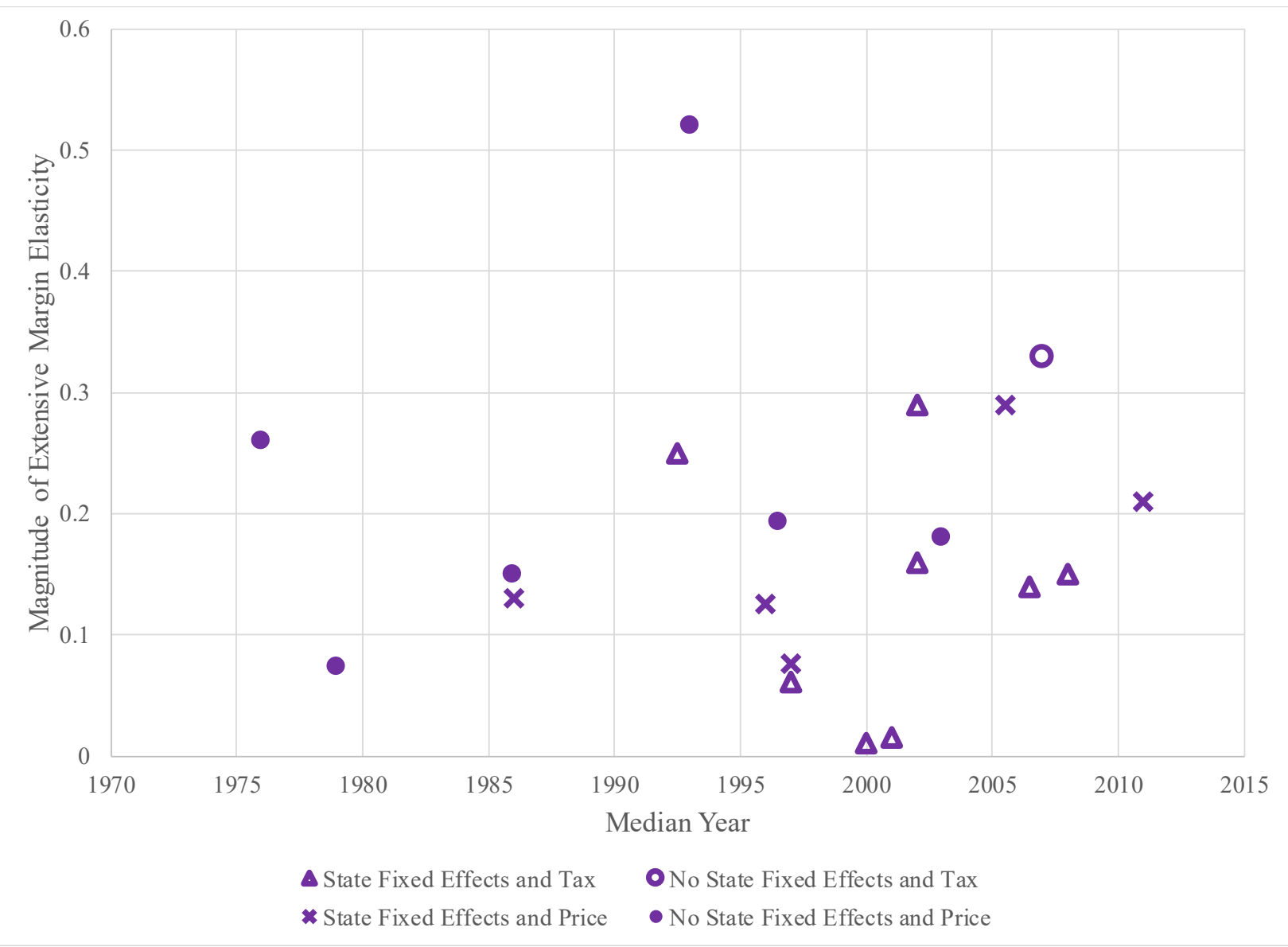

Sources: 1) No State Fixed Effects and Price: Lewit and Coate (1982); Wasserman et al. (1991); Chaloupka and Wechsler (1997); Franz (2008); Farrelly and Bray (1998); Saadatmand, Toma, and Choquette (2014); Chiou and Muehlegger (2008); 2) No State Fixed Effects and Tax: Wasserman et al. (1991); 3) State Fixed Effects and Price: Tauras (2006); Farrelly, Bray, Pechacek, and Woollery (2001); Bishop (2018); Farrelly et al. (2008); Pesko et al. (2017); 4) State Fixed Effects and Tax: Lovenheim (2008); Callison and Kaestner (2014); DeCicca and McLeod (2008); Maclean, Webber and Marti (2014); Nesson (2017a); Stehr (2007). 
Figure 10. Absolute Differences in Border Taxes, 2018.

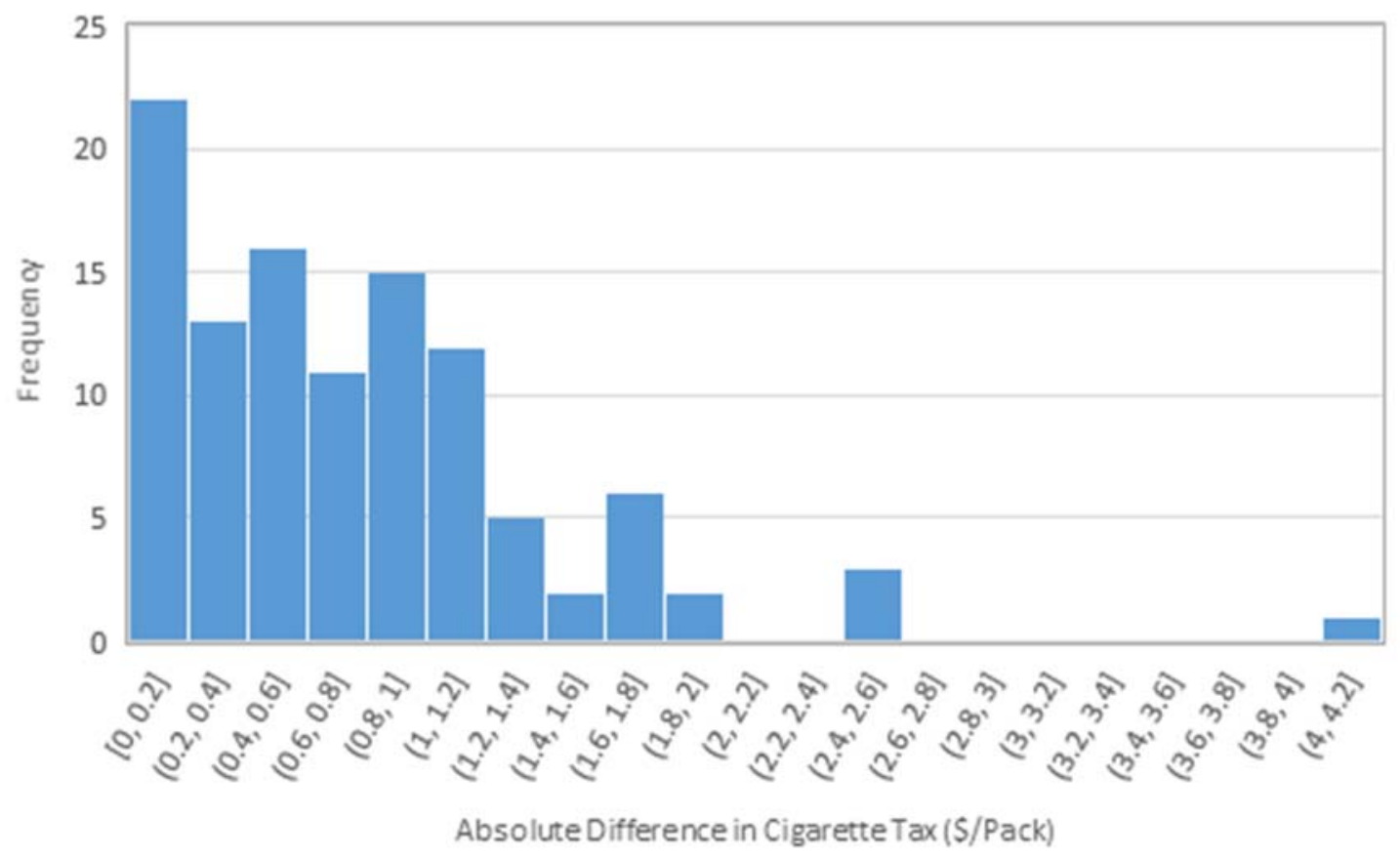

Source: Orzechowski and Walker (2018). This figure shows the absolute difference in per-pack state cigarette taxes across every border pair in the United States as of January 1, 2018. 


\section{Works Cited}

Abadie, Alberto, Alexis Diamond, and Jens Hainmueller. 2010. "Synthetic Control Methods for Comparative Case Studies: Estimating the Effect of California's Tobacco Control Program." Journal of the American Statistical Association 105 (490): 493-505.

Abouk, Rahi, and Scott Adams. 2017. "Bans on Electronic Cigarette Sales to Minors and Smoking Among High School Students.” Journal of Health Economics 54 (July): 17-24.

Adams, Scott, and Chad D. Cotti. 2007. "The Effect of Smoking Bans on Bars and Restaurants: An Analysis of Changes in Employment." The B.E. Journal of Economic Analysis \& Policy 7 (1): 1-32.

Adams, Scott, Chad Cotti, and Daniel Furhmann. 2013. "The Short-Term Impact of Smoke-Free Workplace Laws on Fatal Heart Attacks.” Applied Economics 45 (11): 1381-93.

Adda, Jérôme, Samuel Berlinski, and Stephen Machin. 2012. "Market Regulation and Firm Performance: The Case of Smoking Bans in the United Kingdom." The Journal of Law and Economics 55 (2): 365-91.

Adda, Jérôme, and Francesca Cornaglia. 2006. "Taxes, Cigarette Consumption, and Smoking Intensity." American Economic Review 96 (4): 1013-28.

Adda, Jérôme, and Francesca Cornaglia. 2010. "The Effect of Bans and Taxes on Passive Smoking." American Economic Journal: Applied Economics 2 (1): 1-32.

Advisory Commission on Intergovernmental Relations (ACIR). 1985. Cigarette Tax Evasion: A Second Look. Washington, D.C.: ACIR.

Allcott, Hunt, Benjamin B. Lockwood, and Dmitry Taubinsky. 2019. "Regressive Sin Taxes, with an Application to the Optimal Soda Tax." Quarterly Journal of Economics 134 (3): 1557626.

Allwright, Shane, Gillian Paul, Birgit Greiner, Bernie J. Mullally, Lisa Pursell, Alan Kelly, Brendan Bonner, Maureen D’Eath, Bill McConnell, James P. McLaughlin, Diarmuid O’Donovan, Eamon O'Kane, and Ivan J. Perry. 2005. "Legislation for Smoke-free Workplaces and Health of Bar Workers in Ireland: Before and After Study.” British Medical Journal 331 (7525): 1117-22.

Almond, Douglas, Kenneth Y. Chay, and David. S. Lee. 2005. "The Costs of Low Birth Weight." Quarterly Journal of Economics 120 (3): 1031-83.

American Lung Association (ALA). 2020. "E-Cigarettes”. Last modified January 10, 2020. http://www.lung.org/stop-smoking/tobacco-control-advocacy/federal/e-cigarettes.html.

Anderson, D. Mark, Kyutaro Matsuzawa, and Joseph J. Sabia. 2020. "Cigarette Taxes and Teen Marijuana Use.” NBER Working Paper No. 26780. 
Anger, Silke, and Michael Kvasnicka. 2010. "Does Smoking Really Harm Your Earnings So Much? Biases in Current Estimates of the Smoking Wage Penalty." Applied Economics Letters 17 (6): 561-4.

Anger, Silke, Michael Kvasnicka, and Thomas Siedler. 2011. "One Last Puff? Public Smoking Bans and Smoking Behavior.” Journal of Health Economics 30 (3): 591-601.

Angrist, Joshua D., and Jörn-Steffen Pischke. 2009. Mostly Harmless Econometrics: An Empiricist's Companion. Princeton: Princeton University Press.

Aristei, David, and Luca Pieroni. 2009. “Addiction, Social Interactions and Gender Differences in Cigarette Consumption.” Empirica 36 (3): 245-72.

Ashley, Elizabeth M., Clark Nardinelli, and Rosemarie A. Lavaty. 2015. "Estimating the Benefits of Public Health Policies that Reduce Harmful Consumption." Health Economics 24 (5): 617-24.

Auld, M. Christopher. 2005a. "Smoking, Drinking, and Income." Journal of Human Resources 40 (2): 505-18.

Auld, M. Christopher. 2005b. "Causal Effect of Early Initiation on Adolescent Smoking Patterns." Canadian Journal of Economics 38 (3): 709-34.

Avery, Rosemary, Donald Kenkel, Dean R. Lillard, and Alan Mathios. 2007. "Private Profits and Public Health: Does Advertising Smoking Cessation Products Encourage Smokers to Quit?" Journal of Political Economy 115 (3): 447-81.

Baltagi, Badi H., and Dan Levin. 1986. "Estimating Dynamic Demand for Cigarettes Using Panel Data: The Effects of Bootlegging, Taxation and Advertising Reconsidered." The Review of Economics and Statistics 68 (1): 148-55.

Baltagi, Badi H., and Dan Levin. 1992. "Cigarette Taxation: Raising Revenues and Reducing Consumption.” Structural Change and Economic Dynamics 3 (2): 321-35.

Beatty, Timothy K.M., Erling Røed Larsen, and Dag Einar Sommervoll. 2009. "Driven to Drink: Sin Taxes Near a Border." Journal of Health Economics 28 (6): 1175-84.

Becker, Gary S., Michael Grossman, and Kevin M. Murphy. 1994. “An Empirical Analysis of Cigarette Addiction.” American Economic Review 84 (3): 396-418.

Becker, Gary S., and Kevin M. Murphy. 1988. "A Theory of Rational Addiction.” Journal of Political Economy 96 (4): 675-700.

Becker, Gary S., and Kevin M. Murphy. 1993. "A Simple Theory of Advertising as a Good or Bad.” Quarterly Journal of Economics 108 (4): 941-64.

Bedard, Kelly, and Olivier Deschênes. 2006. "The Long-Term Impact of Military Service on Health: Evidence from World War II and Korean War Veterans." American Economic Review, 96 (1): 176-94. 
Bernheim, B. Douglas, and Antonio Rangel. 2004. "Addiction and Cue-Triggered Decision Processes." American Economic Review 94 (5): 1558-90.

Bernheim, B. Douglas, and Antonio Rangel. 2007. "Behavioral Public Economics: Welfare and Policy Analysis with Non-Standard Decision Makers.” In Behavioral Economics and Its Applications, edited by Peter Diamond and Hannu Vartiainen, 7-84. Princeton: Princeton University Press.

Besley, Timothy J., and Harvey S. Rosen. 1999. "Sales Taxes and Prices: An Empirical Analysis.” National Tax Journal 52 (2): 157-78.

Bharadwaj, Prashant, Julian V. Johnsen, and Katrine V. Løken. 2014. "Smoking Bans, Maternal Smoking and Birth Outcomes.” Journal of Public Economics 115 (July): 72-93.

Bhatnagar, Aruni, Laurie P. Whitsel, Kurt M. Ribisl, Chris Bullen, Frank Chaloupka, Mariann R. Piano, Rose Marie Robertson, Timothy McAuley, David Goff, and Neal Benowitz. 2014. "Electronic Cigarettes: A Policy Statement from the American Heart Association." Circulation 130 (16): 1418-36.

Bishop, James M. 2018. “Does Cigarette Smuggling Prop Up Smoking Rates?” American Journal of Health Economics 4 (1): 80-104.

Bitler, Marianne P., Christopher S. Carpenter, and Madeline Zavodny. 2010. "Effects of VenueSpecific State Clean Indoor Air Laws on Smoking-Related Outcomes.” Health Economics 19 (12): 1425-40.

Blake, Thomas, Chris Nosko, and Steven Tadelis. 2015. "Consumer Heterogeneity and Paid Search Effectiveness: A Large-Scale Field Experiment.” Econometrica 83 (1): 155-74.

Böckerman, Petri, Ari Hyytinen, and Jaakko Kaprio. 2015. "Smoking and Long-Term Labour Market Outcomes." Tobacco Control 24 (4): 348-53.

Boes, Stefan, Joachim Marti, and Johanna Catherine Maclean. 2015. "The Impact of Smoking Bans on Smoking and Consumer Behavior: Quasi-Experimental Evidence from Sweden." Health Economics 24 (11): 1502-16.

Borland, Tracey, Sandra A. D’Souza, Shawn O’Connor, Michael Oliver Chaiton, and Robert Schwartz. 2019. "Is Blue the New Green? Repackaging Menthol Cigarettes in Response to a Flavour Ban in Ontario, Canada.” Tobacco Control 28 (e1): e7-e12.

Bradford, W. David. 2003. "Pregnancy and the Demand for Cigarettes." American Economic Review 93 (5): 1752-63.

Brandt, Allan M. 2007. The Cigarette Century: The Rise, Fall, and Deadly Persistence of the Product that Defined America. New York: Basic Books.

Breslau, Naomi, and Edward L. Peterson. 1996. "Smoking Cessation in Young Adults: Age at Initiation of Cigarette Smoking and Other Suspected Influences." American Journal of Public Health 86 (2): 214-20. 
Brown, Jennifer, Teresa DeAtley, Kevin Welding, Robert Schwartz, Michael Chaiton, Deirdre Lawrence Kittner, and Joanna E. Cohen. 2017. "Tobacco Industry Response to Menthol Cigarette Bans in Alberta and Nova Scotia, Canada.” Tobacco Control 26 (e1): e71-4.

Browning, Edgar K. 1999. "The Myth of Fiscal Externalities.” Public Finance Review 27 (1): 318.

Buckell, John, and Stephane Hess. 2019. "Stubbing Out Hypothetical Bias: Improving Tobacco Market Predictions by Combining Stated and Revealed Preference Data." Journal of Health Economics 65 (May): 93-102.

Buonanno, Paolo, and Marco Ranzani. 2013. "Thank You for Not Smoking: Evidence from the Italian Smoking Ban.” Health Policy 109 (2): 92-9.

Byrne, Sahara, Sherri Jean Katz, Alan Mathios, and Jeff Niederdeppe. 2015. "Do the Ends Justify the Means? A Test of Alternatives to the FDA Proposed Cigarette Warning Labels." Health Communication (30) 7: 680-93.

Callison, Kevin, and Robert Kaestner. 2014. "Do Higher Tobacco Taxes Reduce Adult Smoking? New Evidence of the Effect of Recent Cigarette Tax Increases on Adult Smoking." Economic Inquiry 52 (1): 155-72.

Cameron, Lisa, and Jenny Williams. 2001. "Cannabis, Alcohol and Cigarettes: Substitutes or Complements?" Economic Record 77 (236): 19-34.

Carpenter, Christopher S. 2009. "The Effects of Local Workplace Smoking Laws on Smoking Restrictions and Exposure to Smoke at Work.” Journal of Human Resources 44 (4): 1023-46.

Carpenter, Christopher, and Philip J. Cook. 2008. "Cigarette Taxes and Youth Smoking: New Evidence from National, State, and Local Youth Risk Behavior Surveys." Journal of Health Economics 27 (2): 287-99.

Carpenter, Christopher, and Hai V. Nguyen. 2020. "Intended and Unintended Effects of Banning Menthol Cigarettes.” NBER Working Paper No. 26811.

Carpenter, Christopher, Sabina Postolek, and Casey Warman. 2011. "Public-Place Smoking Laws and Exposure to Environmental Tobacco Smoke (ETS)." American Economic Journal: Economic Policy 3 (3): 35-61.

Carter, Brian D., Christian C. Abnet, Diane Feskanich, Neal D. Freedman, Patricia Hartge, Cora E. Lewis, Judith K. Ockene, et al. 2015. "Smoking and Mortality-Beyond Established Causes." New England Journal of Medicine 372 (7): 631-40.

Carton, Thomas W., Michael Darden, John Levendis, Sang H. Lee, and Iben Ricket. 2016. "Comprehensive Indoor Smoking Bans and Smoking Prevalence: Evidence from the BRFSS." American Journal of Health Economics 2 (4): 535-56.

Casey, Betty Jo, Sarah Getz, and Adriana Galvin. 2008. “The Adolescent Brain.” Developmental Review 28 (1): 62-77. 
Cawley, John, and Christopher J. Ruhm. 2011. "The Economics of Risky Health Behaviors." In The Handbook of Health Economics, Volume 2, edited by Mark V. Pauly, Thomas C. McGuire, and Pedro P. Barros, 95-199. New York: North Holland.

Centers for Disease Control (CDC). 2019. "New Cases in Outbreak of E-Cigarette, or Vaping, Product Use-Associated Lung Injury (EVALI) on the Decline."

https://www.cdc.gov/media/releases/2019/p1220-cases-EVALI.html.

Chaloupka, Frank, and Michael Grossman. 1996. "Price, Tobacco Control Policies and Youth Smoking." NBER Working Paper No. 5740.

Chaloupka, Frank J., Jonathan Gruber, and Kenneth E. Warner. 2015. "Accounting for 'Lost Pleasure' in a Cost-Benefit Analysis of Government Regulation: The Case of the Food and Drug Administration's Proposed Cigarette Labeling Regulation.” Annals of Internal Medicine 162(1): 64-65.

Chaloupka, Frank J., Matthew R. Levy, and Justin S. White. 2019. "Estimating Biases in Smoking Cessation: Evidence from a Field Experiment." NBER Working Paper No. 26522.

Chaloupka, Frank, and Rosalie Liccardo Pacula. 1999. "Sex and Race Differences in Young People's Responsiveness to Price and Tobacco Control Policies." Tobacco Control 8 (4): 373-7.

Chaloupka, Frank J., and Henry Saffer. 1992. "Clean Indoor Air Laws and the Demand for Cigarettes." Contemporary Economic Policy 10 (2): 72-83.

Chaloupka, Frank J., and Kenneth E. Warner. 2000. “The Economics of Smoking.” Handbook of Health Economics, Volume 1, Part B, edited by Anthony J. Culyer and Joseph P. Newhouse, 1539-627. New York: North Holland.

Chaloupka, Frank J., and Henry Wechsler. 1997. "Price, Tobacco Control Policies and Smoking Among Young Adults." Journal of Health Economics 16 (3): 359-73.

Cheng, Kai-Wen, Feng Liu, MariaElena Gonzalez, and Stanton Glantz. 2017. "The Effects of Workplace Clean Indoor Air Law Coverage on Workers' Smoking-Related Outcomes." Health Economics 26 (2): 226-42.

Chernick, Howard, and David Merriman. 2013. "Using Littered Pack Data to Estimate Cigarette Tax Avoidance in NYC." National Tax Journal 66 (2): 635-68.

Chetty, Raj. 2009. "Sufficient Statistics for Welfare Analysis: A Bridge Between Structural and Reduced-Form Methods." Annual Review of Economics 1 (1): 451-488.

Chetty, Raj. 2015. "Behavioral Economics and Public Policy: A Pragmatic Perspective." American Economic Review 105 (5): 1-33.

Chiou, Lesley, and Erich Muehlegger. 2008. "Crossing the Line: Direct Estimation of CrossBorder Cigarette Sales and the Effect on Tax Revenue." The B.E. Journal of Economic Analysis \& Policy 8 (1): 1-39. 
Chiou, Lesley, and Erich Muehlegger. 2014. "Consumer Response to Cigarette Excise Tax Changes.” National Tax Journal 67 (3): 621-50.

Choi, Anna, Dhaval Dave, and Joseph J. Sabia. 2019. "Smoke Gets in your Eyes: Medical Marijuana Laws and Tobacco Cigarette Use." American Journal of Health Economics 5 (3): 30333.

Chou, Shin-Yi, Michael Grossman, and Henry Saffer. 2004. "An Economic Analysis of Adult Obesity: Results from the Behavioral Risk Factor Surveillance System.” Journal of Health Economics 23 (3): 565-587.

Chung, Woojin, Seungji Lim, Sunmi Lee, Sungjoo Choi, Kayoung Shin, and Kyungsook Cho. 2007. "The Effect of Cigarette Price on Smoking Behavior in Korea." Journal of Preventive Medicine and Public Health 40 (5): 371-80.

Coase, Ronald H. 1960. "The Problem of Social Cost." The Journal of Law and Economics 3: 144.

Coats, Morris R. 1995. "A Note on Estimating Cross-Border Effects of State Cigarette Taxes." National Tax Journal 48 (4): 573-84.

Colman, Greg, Michael Grossman, and Ted Joyce. 2003. "The Effect of Cigarette Excise Taxes on Smoking Before, During and After Pregnancy." Journal of Health Economics 22 (6): 105372.

Colman, Gregory J., and Dahlia K. Remler. 2008. "Vertical Equity Consequences of Very High Cigarette Tax Increases: If the Poor Are the Ones Smoking, How Could Cigarette Tax Increases Be Progressive?” Journal of Policy Analysis and Management 27 (2): 376-400.

Congressional Budget Office (CBO). 2012. Raising the Excise Tax on Cigarettes: Effects on Health and the Federal Budget. Washington, D.C.: CBO.

Conway, Karen Smith, and David P. Niles. 2016. "Cigarette Taxes, Smoking—and Exercise?" Health Economics 26 (8): 1019-36.

Cornelson, Laura, and Charles Normand. 2012. "Impact of the Smoking Ban on the Volume of Bar Sales in Ireland: Evidence from Time Series Analysis.” Health Economics 21 (5): 551-61.

Cotti, Chad, Erik Nesson, and Nathan Tefft. 2016. "The Effects of Tobacco-Control Policies on Tobacco Products, Tar, and Nicotine Purchases Among Adults: Evidence from Household Panel Data.” American Economic Journal: Economic Policy 8 (4): 103-23.

Cotti, Chad, Erik Nesson, and Nathan Tefft. 2018. "The Relationship Between Cigarettes and Electronic Cigarettes: Evidence from Household Panel Data." Journal of Health Economics 61 (September): 205-19.

Courtemanche, Charles. 2009. "Rising Cigarette Prices and Rising Obesity: Coincidence or Unintended Consequence?” Journal of Health Economics 28 (4): 781-98. 
Courtemanche, Charles, Rusty Tchernis, and Benjamin Ukert. 2018. "The Effect of Smoking on Obesity: Evidence from a Randomized Trial." Journal of Health Economics 57 (January): 31-44.

Cowan, Benjamin, and Benjamin Schwab. 2011. "The Incidence of the Healthcare Costs of Smoking.” Journal of Health Economics 30 (5): 1094-102.

Crowley, Ryan A. 2015. "Electronic Nicotine Delivery Systems: Executive Summary of a Policy Position Paper from the American College of Physicians." Annals of Internal Medicine, 162 (8): 583-4.

Cullen, Karen A., Bridget K. Ambrose, Andrea S. Gentzke, Benjamin J. Apelberg, Ahmed Jamal, and Brian A. King. 2018. "Notes from the Field: Use of Electronic Cigarettes and Any Tobacco Product Among Middle and High School Students—United States, 2011-2018." Morbidity and Mortality Weekly Report 67 (45): 1276-7.

Cutler, David M. 2002. "Health Care and the Public Sector." In Handbook of Public Economics, Volume 4, edited by Alan J. Auerbach and Martin Feldstein, 2143-243. New York: North Holland.

Cutler, David M., Amber Jessup, Donald Kenkel, and Martha A. Starr. 2015. "Valuing Regulations Affecting Addictive or Habitual Goods." Journal of Benefit-Cost Analysis 6 (2): $247-80$.

Dallosso, Helen M., and W.P. James. 1984. "The Role of Smoking in the Regulation of Energy Balance.” International Journal of Obesity 8 (4): 365-75.

Darden, Michael, Donna B. Gilleskie, and Koleman Strumpf. 2018. "Smoking and Mortality: New Evidence from a Long Panel.” International Economic Review 59 (3): 1571-619.

Dave, Dhaval, Daniel Dench, Michael Grossman, Donald S. Kenkel, and Henry Saffer. 2019. "Does E-Cigarette Advertising Encourage Adult Smokers to Quit?" Journal of Health Economics 68 (December): 1-13.

Dave, Dhaval M., and Inas R. Kelly. 2014. "Advertising as a Determinant of Health in the USA.” In Encyclopedia of Health Economics, Volume 1, edited by Anthony J. Culyer, 32-50. Amsterdam: Elsevier.

Dave, Dhaval, and Henry Saffer. 2013. "Demand for Smokeless Tobacco: Role of Advertising." Journal of Health Economics 32 (4): 682-97.

DeCicca, Philip, and Don Kenkel. 2015. "Synthesizing Econometric Evidence: The Case of Demand Elasticity Estimates.” Risk Analysis 35 (6): 1073-85.

DeCicca, Philip, Donald Kenkel, and Feng Liu. 2013a. "Who Pays Cigarette Taxes? The Impact of Consumer Price Search.” The Review of Economics and Statistics 95 (2): 516-29.

DeCicca, Philip, Donald Kenkel, and Feng Liu. 2013b. "Excise Tax Avoidance: The Case of State Cigarette Taxes." Journal of Health Economics 32 (6): 1130-41. 
DeCicca, Philip, Donald Kenkel, and Feng Liu. 2015. "Reservation Prices: An Economic Analysis of Cigarette Purchases on Indian Reservations." National Tax Journal 68 (1): 93-118.

DeCicca, Philip, Donald Kenkel, Feng Liu, and Hua Wang. 2017. "Behavioral Welfare Economics and FDA Tobacco Regulations." In Human Capital and Health Behavior (Advances in Health Economics and Health Services Research, Volume 25, edited by Kristian Bolin, Björn Lindgren, Michael Grossman, Dorte Gyrd-Hansen, Tor Iversen, Robert Kaestner, and Jody Sindelar, 143-79. Emerald Publishing Limited.

DeCicca, Philip, Donald Kenkel, and Alan Mathios. 2002. "Putting Out the Fires: Will Higher Taxes Reduce the Onset of Youth Smoking?" Journal of Political Economy 110 (1): 144-69.

DeCicca, Philip, Don Kenkel, and Alan Mathios. 2008. "Cigarette Taxes and the Transition from Youth to Adult Smoking: Smoking Initiation, Cessation, and Participation." Journal of Health Economics 27 (4): 904-17.

DeCicca, Philip, and Logan McLeod. 2008. "Cigarette Taxes and Older Adult Smoking: Evidence from Recent Large Tax Increases." Journal of Health Economics 27 (4): 918-29.

Dee, Thomas S. 1999. "The Complementarity of Teen Smoking and Drinking." Journal of Health Economics 18 (6): 769-93.

DellaVigna, Stefano. 2009. "Psychology and Economics: Evidence from the Field." Journal of Economic Literature 47 (2): 315-72.

Diamond, Peter A., and James A. Mirrlees. 1971. "Optimal Taxation and Public Production I: Production Efficiency.” American Economic Review 61 (1): 8-27.

Doll, Richard, Richard Peto, Jillian Boreham, and Isabelle Sutherland. 2004. "Mortality in Relation to Smoking: 50 Years' Observations on Male British Doctors." British Medical Journal 328 (7455): 1519-28.

Dube, Arindrajit, T. William Lester, and Michael Reich. 2010. "Minimum Wage Effects Across State Borders: Estimates Using Contiguous Counties." The Review of Economics and Statistics 92 (4): 945-64.

Egger, Sam, Suzan Burton, Rebecca Ireland, and Scott C. Walsberger. 2019. "Observed Retail Price of Australia's Market-Leading Cigarette Brand Before and up to 3 Years After the Implementation of Plain Packaging.” Tobacco Control 28 (e2): e86-e91.

Einav, Liran, Ephraim Leibtag, and Aviv Nevo. 2010. "Recording Discrepancies in Nielsen Homescan Data: Are They Present and Do They Matter?" Quantitative Marketing and Economics 8 (2): 207-39.

Emery, Sherry, Martha M. White, and John P. Pierce. 2001. "Does Cigarette Price Influence Adolescent Experimentation?” Journal of Health Economics 20 (2): 261-70.

Etter, Jean-François. 2018. "Gateway Effects and Electronic Cigarettes.” Addiction 113 (10): 1776-83. 
Evans, William N., and Matthew C. Farrelly. 1998. "The Compensating Behavior of Smokers: Taxes, Tar, and Nicotine." The RAND Journal of Economics 29 (3): 578-95.

Evans, William N., Matthew C. Farrelly, and Edward Montgomery. 1999. "Do Workplace Smoking Bans Reduce Smoking?” American Economic Review 89 (4): 728-47.

Evans, William N., and Jeanne S. Ringel. 1999. "Can Higher Cigarette Taxes Improve Birth Outcomes?” Journal of Public Economics 72 (1): 135-54.

Farrelly, Matthew C., and Jeremy W. Bray. 1998. "Responses to Increases in Cigarette Prices by Race/Ethnicity, Income, and Age Groups_-United States, 1976-1993. Morbidity and Mortality Weekly Report 47 (29): 605-9.

Farrelly, Matthew C., Jeremy W. Bray, Terry Pechacek, and Trevor Woollery. 2001. "Responses by Adults to Increases in Cigarette Prices by Sociodemographic Characteristics." Southern Economic Journal 68 (1): 156-65.

Farrelly, Matthew C., Jeremy W. Bray, Gary A. Zarkin, and Brett W. Wendling. 2001. "The Joint Demand for Cigarettes and Marijuana: Evidence from the National Household Surveys on Drug Abuse." Journal of Health Economics 20 (1): 51-68.

Farrelly, Matthew C., Terry F. Pechacek, Kristin Y. Thomas, and David Nelson. 2008. "The Impact of Tobacco Control Programs on Adult Smoking." American Journal of Public Health 98 (2): 304-9.

Federal Trade Commission (FTC). 2019. "Federal Trade Commission Cigarette Report for 2017." https://www.ftc.gov/system/files/documents/reports/federal-trade-commission-cigarettereport-2017-federal-trade-commission-smokeless-tobacco-report/ftc cigarette report_2017.pdf.

Federico, Bruno, Johan P. Mackenbach, Terje A. Eikemo, and Anton E. Kunst. 2012. "Impact of the 2005 Smoke-Free Policy in Italy on Prevalence, Cessation and Intensity of Smoking in the Overall Population and by Educational Group." Addiction 107 (9): 1677-86.

Fenelon, Andrew, and Samuel H. Preston. 2012. "Estimating Smoking-Attributable Mortality in the United States.” Demography 49 (3): 797-818.

Filippidis, Filippos T., Israel T. Agaku, Charis Girvalaki, Carlos Jiménez-Ruiz, Brian Ward, Christina Gratziou, Constantine I. Vardavas, and Tobacco Control Committee of the European Respiratory Society. 2016. "Relationship of Secondhand Smoke Exposure with Sociodemographic Factors and Smoke-Free Legislation in the European Union." European Journal of Public Health 26 (2): 344-9.

Fong, Geoffrey T., Tara Elton-Marshall, Pete Driezen, Annette R. Kaufman, K. Michael Cummings, Kelvin Choi, Jonathan Kwan, et al. 2019. "U.S. Adult Perceptions of the Harmfulness of Tobacco Products: Descriptive Findings from the 2013-14 Baseline Wave 1 of the PATH Study." Addictive Behaviors 91 (April): 180-7. 
Food and Drug Administration (FDA). 2013. Preliminary Scientific Evaluation of the Possible Public Health Effects of Menthol versus Nonmenthol Cigarettes.

http://www.fda.gov/downloads/UCM361598.pdf.-349.

Food and Drug Administration (FDA). 2018. "Illicit Trade in Tobacco Products After Implementation of an FDA Product Standard."

https://www.fda.gov/files/tobacco\%20products/published/Illicit-Trade-in-Tobacco-ProductsAfter-Implementation-of-an-FDA-Product-Standard.pdf.

Food and Drug Administration (FDA). 2019. "FDA Grants First-Ever Modified Risk Orders to Eight Smokeless Tobacco Products." https://www.fda.gov/news-events/pressannouncements/fda-grants-first-ever-modified-risk-orders-eight-smokeless-tobacco-products

Food and Drug Administration (FDA). 2020. "FDA Finalizes Enforcement Policy on Unauthorized Flavored Cartridge-Based E-Cigarettes That Appeal to Children, Including Fruit and Mint." https://www.fda.gov/news-events/press-announcements/fda-finalizes-enforcementpolicy-unauthorized-flavored-cartridge-based-e-cigarettes-appeal-children.

Franz, Gregor A. 2008. "Price Effects on the Smoking Behaviour of Adult Age Groups." Public Health 122 (12): 1343-8.

Friedman, Abigail S. 2015. "How Does Electronic Cigarette Access Affect Adolescent Smoking?" Journal of Health Economics 44 (December): 300-8.

Gallet, Craig A., and John A. List. 2003. "Cigarette Demand: A Meta-Analysis of Elasticities." Health Economics 12 (10): 821-35.

Gao, Jia, and Reagan A. Baughman. 2017. "Do Smoking Bans Improve Infant Health? Evidence from U.S. Births: 1995-2009.” Eastern Economic Journal 43 (3): 472-95.

Geller, Alan C., Vaughan W. Rees, and Daniel R. Brooks. 2016. "The Proposal for Smoke-Free Public Housing: Benefits, Challenges, and Opportunities for 2 Million Residents." Journal of the American Medical Association 315 (11): 1105-6.

Giovino Gary A., Stephen Sidney, Joseph C. Gfroerer, Patrick M. O’Malley, Jane A. Allen, Patricia A. Richter, and K. Michael Cummings. 2004. "Epidemiology of Menthol Cigarette Use." Nicotine and Tobacco Research 6 (Supplement 1): S67-S81.

Glasser, Allison M., Amanda L. Johnson, Shyanika W. Rose, Ollie Ganz, Jennifer Cantrell, Cristine Delnevo, and Andrea C. Villanti. 2017. "Correlates of Cigar Use by Type and Flavor Among U.S. Young Adults: 2011-2015.” Tobacco Regulatory Science 3 (Supplement 1): 59-71.

Glied, Sherry. 2002. "Youth Tobacco Control: Reconciling Theory and Empirical Evidence." Journal of Health Economics 21 (1): 117-35.

Glied, Sherry. 2003. "Is Smoking Delayed Smoking Averted?" American Journal of Public Health 93 (3): 412-6. 
Goel, Rajeev K., and Mathew J. Morey. 1995. "The Interdependence of Cigarette and Liquor Demand.” Southern Economic Journal 62 (2): 451-9.

Goldin, Jacob, and Tatiana Homonoff. 2013. "Smoke Gets in Your Eyes: Cigarette Tax Salience and Regressivity.” American Economic Journal: Economic Policy 5 (1): 302-36.

Gonzalez, MariaElena, Ashley Sanders-Jackson, Anna V. Song, Kai-wen Cheng, and Stanton A. Glantz. 2013. "Strong Smoke-Free Law Coverage in the United States by Race/Ethnicity: 20002009." American Journal of Public Health 103 (5): e62-e66.

Goodman-Bacon, Andrew. 2019. "Difference-in-Differences with Variation in Treatment Timing." https://cdn.vanderbilt.edu/vu-my/wpcontent/uploads/sites/2318/2019/07/29170757/ddtiming 729 2019.pdf. Accessed on 2020-0310 .

Goolsbee, Austan, Michael F. Lovenheim, and Joel Slemrod. 2010. "Playing with Fire: Cigarettes, Taxes, and Competition from the Internet." American Economic Journal: Economic Policy 2 (1): 131-54.

Gospodinov, Nikolay, and Ian Irvine. 2009. “Tobacco Taxes and Regressivity.” Journal of Health Economics 28 (2): 375-84.

Gottlieb, Scott. 2018. "Statement from FDA Commissioner Scott Gottlieb, M.D., on Proposed New Steps to Protect Youth by Preventing Access to Flavored Tobacco Products and Banning Menthol in Cigarettes." https://www.fda.gov/news-events/press-announcements/statement-fdacommissioner-scott-gottlieb-md-proposed-new-steps-protect-youth-preventing-access.

Goulder, Lawrence H., and Roberton C. Williams III. 2003. "The Substantial Bias from Ignoring General Equilibrium Effects in Estimating Excess Burden, and a Practical Solution." Journal of Political Economy 111 (4): 898-927.

Grafova, Irina B., and Frank P. Stafford. 2009. "The Wage Effects of Personal Smoking History." Industrial and Labor Relations Review 62 (3): 381-93.

Gruber, Jonathan, and Michael Frakes. 2006. "Does Falling Smoking Lead to Rising Obesity?" Journal of Health Economics 25 (2): 183-97.

Gruber, Jonathan, and Botond Kőszegi. 2001. "Is Addiction "Rational"? Theory and Evidence." The Quarterly Journal of Economics 116 (4): 1261-1303.

Gruber, Jonathan, and Botond Kőszegi. 2004. "Tax Incidence When Individuals Are TimeInconsistent: The Case of Cigarette Excise Taxes." Journal of Public Economics 88 (9-10): 1959-87.

Gruber, Jonathan, Anindya Sen, and Mark Stabile. 2003. "Estimating Price Elasticities When There is Smuggling: The Sensitivity of Smoking to Price in Canada." Journal of Health Economics 22 (5): 821-42. 
Gruber, Jonathan, and Jonathan Zinman. 2001. "Youth Smoking in the United States: Evidence and Implications." In Risky Behavior Among Youths: An Economic Analysis, edited by Jonathan Gruber, 69-120. Chicago: University of Chicago Press.

Gul, Faruk, and Wolfgang Pesendorfer. 2007. "Harmful Addiction." Review of Economic Studies 74 (1): 147-72.

Haardörfer, Regine, Zachary Cahn, Michael Lewis, Shreya Kothari, Raina Sarmah, Betelihem Getachew, and Carla J. Berg. 2017. "The Advertising Strategies of Early E-Cigarette Brand Leaders in the United States." Tobacco Regulatory Science 3 (2): 222-31.

Hajdu, Tamás, and Gábor Hajdu. 2018. "Smoking Ban and Health at Birth: Evidence from Hungary." Economics and Human Biology 30 (September): 37-47.

Hajek, Peter, Anna Phillips-Waller, Dunja Przulj, Francesca Pesola, Katie Myers Smith, Natalie Bisal, Jinshuo Li, et al. 2019. "A Randomized Trial of E-Cigarettes versus NicotineReplacement Therapy." New England Journal of Medicine 380 (7): 629-37.

Hamilton, Vivian H., Carey Levinton, Yvan St-Pierre, and Franque Grimard. 1997. "The Effect of Tobacco Tax Cuts on Cigarette Smoking in Canada." Canadian Medical Association Journal 156 (2): 187-91.

Hammond, David. 2011. "Health Warning Messages on Tobacco Products: A Review." Tobacco Control 20 (5): 327-37.

Hansen, Benjamin, Joseph J. Sabia, and Daniel I. Rees. 2017. "Have Cigarette Taxes Lost Their Bite? New Estimates of the Relationship between Cigarette Taxes and Youth Smoking." American Journal of Health Economics 3 (1): 60-75.

Hanson, Andrew, and Ryan Sullivan. 2009. "The Incidence of Tobacco Taxation: Evidence from Geographic Micro-Level Data.” National Tax Journal 62 (4): 677-98.

Harberger, Arnold C. 1962. "The Incidence of the Corporation Income Tax." Journal of Political Economy 70(3): 215-40.

Harberger, Arnold C. 1964. "Taxation, Resource Allocation, and Welfare.” In The Role of Direct and Indirect Taxes in the Federal Reserve System, edited by the National Bureau of Economic Research and The Brookings Institution, 25-80. Princeton: Princeton University Press.

Harding, Matthew, Ephraim Leibtag, and Michael F. Lovenheim. 2012. "The Heterogeneous Geographic and Socioeconomic Incidence of Cigarette Taxes: Evidence from Nielsen Homescan Data." American Economic Journal: Economic Policy 4 (4): 169-98.

Harding, Matthew, and Michael F. Lovenheim. 2017. "The Effect of Prices on Nutrition: Comparing the Impact of Product and Nutrient-Specific Taxes." Journal of Health Economics 53 (May): 53-71.

Harris, Jeffrey E., and Sandra W. Chan. 1999. "The Continuum-of-Addiction: Cigarette Smoking in Relation to Price Among Americans Aged 15-29." Health Economics 8 (1): 81-6. 
Hausman, Jerry A., Jason Abrevaya, and Fiona M. Scott-Morton. 1998. "Misclassification of the Dependent Variable in A Discrete-Response Setting." Journal of Econometrics 87 (2): 239-69.

HealthMarkets Insurance Agency. n.d. "What You Need to Know About Smoking and Health Insurance.” Accessed March 14, 2020. https://www.healthmarkets.com/content/smoking-andhealth-insurance.

Heckman, James J., Fredrick Flyer, and Colleen Loughlin. 2008. “An Assessment of Causal Inference in Smoking Initiation Research and a Framework for Future Research.” Economic Inquiry 46 (1): 37-44.

Herrnstein, Richard J., George F. Loewenstein, Drazen Prelec, and William Vaughan Jr. 1993. "Utility Maximization and Melioration: Internalities in Individual Choice." Journal of Behavioral Decision Making 6 (3): 149-85.

Hoynes, Hilary, Diane Whitmore Schanzenbach, and Douglas Almond. 2016. "Long-Run Impacts of Childhood Access to the Safety Net." American Economic Review 106 (4): 903-34.

Hyland, Andrew, and K. Michael Cummings. 1999. "Restaurant Employment Before and After the New York City Smoke-Free Act." Journal of Public Health Management and Practice 5 (1): $22-7$.

Institute of Medicine. 2010. Secondhand Smoke Exposure and Cardiovascular Effects: Making Sense of the Evidence. Washington, D.C.: The National Academies Press.

Jha, Prabhat, Chinthanie Ramasundarahettige, Victoria Landsman, Brian Rostron, Michael Thun, Robert N. Anderson, Tim McAfee, and Richard Peto. 2013. "21st-Century Hazards of Smoking and Benefits of Cessation in the United States." New England Journal of Medicine 368 (4): 34150 .

Jiménez-Martín, Sergi, José M. Labeaga, and Angel López. 1998. "Participation, Heterogeneity and Dynamics in Tobacco Consumption: Evidence from Cohort Data." Health Economics 7 (5): 401-14.

Jin, Lawrence, Don Kenkel, Feng Liu, and Hua Wang. 2015. "Retrospective and Prospective Benefit-Cost Analyses of U.S. Anti-Smoking Policies.” Journal of Benefit-Cost Analysis 6 (1): 154-86.

Jones, Andrew M. 1989. “A Double-Hurdle Model of Cigarette Consumption.” Journal of Applied Econometrics 4 (1): 23-39.

Jones, Andrew M., Audrey Laporte, Nigel Rice, and Eugenio Zucchelli. 2015. "Do Public Smoking Bans Have an Impact on Active Smoking? Evidence from the UK." Health Economics 24 (2): 175-92.

JUUL Labs. 2018. "JUUL Labs Implements New Social Media Policy for Instagram, Facebook, and Twitter.” https://newsroom.juul.com/juul-labs-implements-new-social-media-policy/. 
Kaplan, Cameron M., Ilana Graetz, and Teresa M. Waters. 2014. "Most Exchange Plans Charge Lower Tobacco Surcharges Than Allowed, But Many Tobacco Users Lack Affordable Coverage." Health Affairs 33 (8): 1466-73.

Kasza, Karin A., Bridget K. Ambrose, Kevin P. Conway, Nicolette Borek, Kristie Taylor, Maciej L. Goniewicz, K. Michael Cummings, et al. 2017. "Tobacco-Product Use by Adults and Youths in the United States in 2013 and 2014." New England Journal of Medicine 376 (4): 342-53.

Keeler, Theodore E., Teh-wei Hu, Paul G. Barnett, Willard G. Manning, and Hai-Yen Sung. 1996. "Do Cigarette Producers Price-Discriminate by State? An Empirical Analysis of Local Cigarette Pricing and Taxation." Journal of Health Economics 15 (4): 499-512.

Keeler, Theodore E., Teh-wei Hu, Willard G. Manning, and Hai-Yen Sung. 2001. "State Tobacco Taxation, Education and Smoking: Controlling for the Effects of Omitted Variables." National Tax Journal 54 (1): 83-102.

Kenkel, Donald S. 2016. "Healthy Innovation: Vaping, Smoking, and Public Policy." Journal of Policy Analysis and Management 35 (2): 473-9.

Kenkel, Donald, and Likwang Chen. 2000. "Consumer Information and Tobacco Use.” In Tobacco Control in Developing Countries, edited by Prabhat Jha and Frank J. Chaloupka, 177214. Oxford: Oxford University Press.

Kenkel, Donald S., Dean R. Lillard, and Alan Mathios. 2004. "Accounting for Misclassification Error in Retrospective Smoking Data." Health Economics 13 (10): 1031-44.

Kenkel, Donald, Alan Mathios, and Hua Wang. 2018. "Advertising and Health: A Case Study of Menthol Cigarette Advertising and Cigarette Demand." American Journal of Health Economics 4 (3): 263-86.

Kenkel, Donald S., Sida Peng, Michael F. Pesko, and Hua Wang. 2019. "Mostly Harmless Regulation? Electronic Cigarettes, Public Policy, and Consumer Welfare." National Bureau of Economic Research Working Paper 23710.

Kenkel, Donald, and Jason Somerville. 2019. "Regulating Flavors, Pack Sizes, and Prices in Tobacco Products." Unpublished.

Kesternich, Iris, Florian Heiss, Daniel McFadden, and Joachim Winter. 2013. "Suit the Action to the Word, the Word to the Action: Hypothetical Choices and Real Decisions in Medicare Part D." Journal of Health Economics 32 (6): 1313-24.

Krauss, Melissa J., Patricia A. Cavazos-Rehg, Andrew D. Plunk, Laura J. Bierut, and Richard A. Grucza. 2014. "Effects of State Cigarette Excise Taxes and Smoke-Free Air Policies on State Per Capita Alcohol Consumption in the United States, 1980 to 2009." Alcoholism: Clinical and Experimental Research 38 (10): 2630-8.

Kvasnicka, Michael, Thomas Siedler, and Nicolas R. Ziebarth. 2018. "The Health Effects of Smoking Bans: Evidence from German Hospitalization Data." Health Economics 27 (11): 173853. 
Kvasnicka, Michael, and Harald Tauchmann. 2012. "Much Ado about Nothing? Smoking Bans and Germany’s Hospitality Industry.” Applied Economics 44 (35): 4539-51.

Labeaga, José M. 1999. “A Double-Hurdle Rational Addiction Model with Heterogeneity: Estimating the Demand for Tobacco.” Journal of Econometrics 93 (1): 49-72.

Lakdawala, Leah K., and David Simon. 2017. "The Intergenerational Consequences of Tobacco Policy: A Review of Policy's Influence on Maternal Smoking and Child Health.” Southern Economic Journal 84 (1): 229-74.

Lakhdar, Christian Ben, Nicolas Gérard Vaillant, and François-Charles Wolff. 2016. "Does Smoke Cross the Border? Cigarette Tax Avoidance in France." The European Journal of Health Economics 17 (9): 1073-89.

Lariscy, Joseph T., Robert A. Hummer, and Richard G. Rogers. 2018. "Cigarette Smoking and All-Cause and Cause-Specific Adult Mortality in the United States." Demography 55 (5): 185585 .

Lee, Peter N. 2013. "Epidemiological Evidence Relating Snus to Health - An Updated Review Based on Recent Publications." Harm Reduction Journal 10 (1): 36-42.

Levine, Phillip B., Tara A. Gustafson, and Ann D. Velenchik. 1997. "More Bad News for Smokers? The Effects of Cigarette Smoking on Wages." Industrial and Labor Relations Review 50 (3): 493-509.

Levy, Douglas E., and Ellen Meara. 2006. "The Effect of the 1998 Master Settlement Agreement on Prenatal Smoking.” Journal of Health Economics 25 (2): 276-94.

Levy, Helen G., Edward C. Norton, and Jeffrey A. Smith. 2018. "Tobacco Regulation and CostBenefit Analysis: How Should We Value Foregone Consumer Surplus?" American Journal of Health Economics 4 (1): 1-25.

Lewit, Eugene M., and Douglas Coate. 1982. "The Potential for Using Excise Taxes to Reduce Smoking." Journal of Health Economics 1 (2): 121-45.

Lewit, Eugene M., Douglas Coate, and Michael Grossman. 1981. "The Effects of Government Regulation on Teenage Smoking." The Journal of Law and Economics 24 (3): 545-69.

Lien, Diana S., and William N. Evans. 2005. "Estimating the Impact of Large Cigarette Tax Hikes: The Case of Maternal Smoking and Infant Birth Weight." Journal of Human Resources 40 (2): 373-92.

Lightwood, James, and Stanton A. Glantz. 2016. "Smoking Behavior and Healthcare Expenditure in the United States, 1992-2009: Panel Data Estimates." PLoS Medicine 13 (5): 118.

Lillard, Dean R., Eamon Molloy, and Andrew Sfekas. 2013. "Smoking Initiation and the Iron Law of Demand." Journal of Health Economics 32 (1): 114-27. 
Liu, Feng. 2010. "Cutting Through the Smoke: Separating the Effect of Price on Smoking Initiation, Relapse and Cessation.” Applied Economics 42 (23): 2921-39.

López, Maria J., Esteve Fernández, Giuseppe Gorini, Hanns Moshammer, Kinga Polanska, Luke Clancy, Bertrand Dautzenberg, et al. 2012. "Exposure to Secondhand Smoke in Terraces and Other Outdoor Areas of Hospitality Venues in Eight European Countries." PloS One 7 (8): 1-7.

Lovato, Chris, Allison Watts, and Lindsay F. Stead. 2011. "Impact of Tobacco Advertising and Promotion on Increasing Adolescent Smoking Behaviours." Cochrane Database of Systematic Reviews (10): 1-41.

Lovenheim, Michael F. 2008. "How Far to the Border?: The Extent and Impact of Cross-Border Casual Cigarette Smuggling.” National Tax Journal 61 (1): 7-33.

Maciosek, Michael V., Xin Xu, Amy L. Butani, and Terry F. Pechacek. 2015. "SmokingAttributable Medical Expenditures by Age, Sex, and Smoking Status Estimated Using a Relative Risk Approach.” Preventive Medicine 77 (August): 162-7.

Mackay, Daniel F., Sally Haw, David E. Newby, Peter Langhorne, Suzanne M. Lloyd, Alex McConnachie, and Jill P. Pell. 2013. "Impact of Scotland's Comprehensive, Smoke-Free Legislation on Stroke." PLoS One 8 (5): 1-6.

Mackay, Daniel F., Scott M. Nelson, Sally J. Haw, and Jill P. Pell. 2012. "Impact of Scotland's Smoke-Free Legislation on Pregnancy Complications: Retrospective Cohort Study.” PLoS Medicine 9 (3): 1-9.

Maclean, Johanna Catherine, Asia Sikora Kessler, and Donald S. Kenkel. 2016. "Cigarette Taxes and Older Adult Smoking: Evidence from the Health and Retirement Study." Health Economics 25 (4): 424-38.

Maclean, Johanna Catherine, Douglas A. Webber, and Joachim Marti. 2014. "An Application of Unconditional Quantile Regression to Cigarette Taxes.” Journal of Policy Analysis and Management 33 (1): 188-210.

Manning, Willard G., Emmett B. Keeler, Joseph P. Newhouse, Elizabeth M. Sloss, and Jeffrey Wasserman. 1989. "The Taxes of Sin: Do Smokers and Drinkers Pay their Way?" Journal of the American Medical Association 261 (11): 1604-9.

Markowitz, Sara, E. Kathleen Adams, Patricia M. Dietz, Viji Kannan, and Van T. Tong. 2013. "Tobacco Control Policies, Birth Outcomes, and Maternal Human Capital." Journal of Human Capital 7 (2): 130-60.

Marti, Joachim, John Buckell, Johanna Catherine Maclean, and Jody Sindelar. 2019. "To "Vape" Or Smoke? Experimental Evidence on Adult Smokers.” Economic inquiry 57 (1): 705-25.

Marti, Joachim, and Jörg Schläpfer. 2014. "The Economic Impact of Swiss Smoking Bans on the Hospitality Sector.” Economics Letters 124 (1): 136-9. 
Mazzonna, Fabrizio, and Paola Salari. 2018. “Can a Smoking Ban Save Your Heart?" Health Economics 27 (10): 1435-49.

Meer, Jonathan, and Jeremy West. 2016. "Effects of the Minimum Wage on Employment Dynamics." Journal of Human Resources 51 (2): 500-22.

Melberg, Hans Olav, and Karl E. Lund. 2012. "Do Smoke-Free Laws Affect Revenues in Pubs and Restaurants?" The European Journal of Health Economics 13 (1): 93-9.

Mendez, David, Kenneth E. Warner, and Paul N. Courant. 1998. "Has Smoking Cessation Ceased? Expected Trends in the Prevalence of Smoking in the United States." American Journal of Epidemiology 148 (3): 249-58.

Merriman, David. 2010. "The Micro-Geography of Tax Avoidance: Evidence from Littered Cigarette Packs in Chicago.” American Economic Journal: Economic Policy 2 (2): 61-84.

Mikosz, Christina A., Melissa Danielson, Kayla N. Anderson, Lori A. Pollack, Dustin W. Currie, Rashid Njai, Mary E. Evans, et al. 2020. "Characteristics of Patients Experiencing

Rehospitalization or Death After Hospital Discharge in a Nationwide Outbreak of E-Cigarette, or Vaping, Product Use-Associated Lung Injury-United States, 2019." Morbidity and Mortality Weekly Report 68 (5152):1183-8.

Moore, Michael J. 1996. "Death and Tobacco Taxes." The RAND Journal of Economics 27 (2): 415-28.

Mullahy, John. 1985. "Cigarette Smoking: Habits, Health Concerns, and Heterogeneous Unobservables in a Microeconometric Analysis of Consumer Demand." Unpublished.

Mullainathan, Sendhil, Joshua Schwartzstein, and William J. Congdon. 2012. "A Reduced-Form Approach to Behavioral Public Finance." Annual Review of Economics 4 (1): 511-40.

National Academies of Sciences, Engineering, and Medicine. 2018. Public Health Consequences of E-Cigarettes. Washington, D.C.: The National Academies Press.

National Institute on Drug Abuse (NIDA). 2018. "Recent Research Sheds Light on Why Nicotine is So Addictive." https://www.drugabuse.gov/about-nida/noras-blog/2018/09/recentresearch-sheds-new-light-why-nicotine-so-addictive.

National Research Council and Institute of Medicine. 2015. Understanding the U.S. Illicit Tobacco Market: Characteristics, Policy Context, and Lessons from International Experiences. Washington, D.C.: The National Academies Press.

Nebot, Manel, Maria J. López, Carles Ariza, Mónica Pérez-Ríos, Marcela Fu, Anna Schiaffino, Gloria Muñoz, Esteve Saltó, and Esteve Fernández. 2009. "Impact of the Spanish Smoking Law on Exposure to Secondhand Smoke in Offices and Hospitality Venues: Before-and-After Study." Environmental Health Perspectives 117 (3): 344-7. 
Nelson, Jon P. 2010. "What Is Learned from Longitudinal Studies of Advertising and Youth Drinking and Smoking? A Critical Assessment." International Journal of Environmental Research and Public Health 7 (3): 870-926.

Nesson, Erik. 2017a. "Heterogeneity in Smokers' Responses to Tobacco Control Policies." Health Economics 26 (2): 206-25.

Nesson, Erik. 2017b. "The Impact of Tobacco Control Policies on Adolescent Smoking: Comparing Self-Reports and Biomarkers." American Journal of Health Economics 3 (4): 50727.

Neumark, David, J.M. Ian Salas, and William Wascher. 2014. "Revisiting the Minimum WageEmployment Debate: Throwing Out the Baby with the Bathwater?" Industrial and Labor Relations Review, 67 (3 Supplement): 608-48.

Nguyen, Hai V. 2013. "Do Smoke-Free Car Laws Work? Evidence from a Quasi-Experiment." Journal of Health Economics 32 (1): 138-48.

Nicholson, Andrew, Tracy M. Turner, and Eduardo Alvarado. 2016. "Cigarette Taxes and CrossBorder Revenue Effects: Evidence Using Retail Data." Public Finance Review 44 (3): 311-43.

Nonnemaker, James M., and Matthew C. Farrelly. 2011. "Smoking Initiation Among Youth: The Role of Cigarette Excise Taxes and Prices by Race/Ethnicity and Gender." Journal of Health Economics 30 (3): 560-7.

Nonnemaker, James, Eric Finkelstein, Mark Engelen, Thomas Hoerger, and Matthew Farrelly. 2009. "Have Efforts to Reduce Smoking Really Contributed to the Obesity Epidemic?" Economic Inquiry 47 (2): 366-76.

O’Donoghue, Ted, and Matthew Rabin. 2006. “Optimal Sin Taxes.” Journal of Public Economics 90 (10-11): 1825-49.

Orphanides, Athanasios, and David Zervos. 1995. "Rational Addiction with Learning and Regret." Journal of Political Economy 103 (4): 739-58.

Orzechowski and Walker. 2018. The Tax Burden on Tobacco. Volume 53.

Pell, Jill P., Sally Haw, Stuart Cobbe, David E. Newby, Alastair C.H. Pell, Colin Fischbacher, Alex McConnachie, et al. 2008. "Smoke-Free Legislation and Hospitalizations for Acute Coronary Syndrome.” New England Journal of Medicine 359 (5): 482-91.

Perkins, Kenneth A., Joshua L. Karelitz, and Margaret C. Boldry. 2017. "Nicotine Acutely Enhances Reinforcement from Non-Drug Rewards in Humans." Frontiers in Psychiatry 8 (Article 65): 1-11.

Pesko, Michael F., and Janet M. Currie. 2019. "E-Cigarette Minimum Legal Sale Age Laws and Traditional Cigarette Use Among Rural Pregnant Teenagers." Journal of Health Economics 66 (July): 71-90. 
Pesko, Michael F., Donald S. Kenkel, Hua Wang, and Jenna M. Hughes. 2016. "The Effect of Potential Electronic Nicotine Delivery System Regulations on Nicotine Product Selection." Addiction 111 (4): 734-44.

Pesko, Michael F., John A. Tauras, Jidong Huang, and Frank J. Chaloupka, IV. 2017. "The Influence of Geography and Measurement in Estimating Cigarette Price Responsiveness." NBER Working Paper No. 22296.

Pfeifer, Gregor, Mirjam Reutter, and Kristina Strohmaier. Forthcoming. "Goodbye Smokers' Corner: Health Effects of School Smoking Bans." Journal of Human Resources.

Picone, Gabriel A., Frank Sloan, and Justin G. Trogdon. 2004. "The Effect of the Tobacco Settlement and Smoking Bans on Alcohol Consumption." Health Economics 13 (10): 1063-80.

Pieroni, Luca, Manuela Chiavarini, Liliana Minelli, and Luca Salmasi. 2013. "The Role of AntiSmoking Legislation on Cigarette and Alcohol Consumption Habits in Italy." Health Policy 111 (2): 116-26.

Pieroni, Luca, Pierluigi Daddi, and Luca Salmasi. 2013. "Impact of Italian Smoking Ban on Business Activity of Restaurants, Cafés and Bars.” Economics Letters 121 (1): 70-3.

Preston, Samuel H., Dana A. Glei, and John R. Wilmoth. 2010. "A New Method for Estimating Smoking-Attributable Mortality in High-Income Countries.” International Journal of Epidemiology 39 (2): 430-8.

Ramamurthi, Divya, Phillip A. Gall, Noel Ayoub, and Robert K. Jackler. 2016. "Leading-Brand Advertisement of Quitting Smoking Benefits for E-Cigarettes." American Journal of Public Health 106 (11): 2057-63.

Ramsey, Frank P. 1927. "A Contribution to the Theory of Taxation." The Economic Journal 37 (145): 47-61.

Ribis1, Kurt M., Rebecca S. Williams, Ziya Gizlice, and Amy H. Herring. 2011. "Effectiveness of State and Federal Government Agreements with Major Credit Card and Shipping Companies to Block Illegal Internet Cigarette Sales." PLoS One 6 (2): 1-6.

Ringel, Jeanne S., and William N. Evans. 2001. "Cigarette Taxes and Smoking During Pregnancy." American Journal of Public Health 91 (11): 1851-6.

Robinson, Lisa A., and James K. Hammitt. 2011. "Behavioral Economics and the Conduct of Benefit-Cost Analysis: Towards Principles and Standards." Journal of Benefit-Cost Analysis 2 (2): $1-51$.

Rozema, Kyle, and Nicolas R. Ziebarth. 2017. "Taxing Consumption and the Take-Up of Public Assistance: The Case of Cigarette Taxes and Food Stamps." The Journal of Law and Economics 60 (1): 1-27.

Russell Michael A. H. 1976. "Low-Tar Medium-Nicotine Cigarettes: A New Approach to Safer Smoking.” British Medical Journal 1 (6023), 1430-3. 
Saadatmand, Yassaman, Michael Toma, and Jeremy Choquette. 2014. "The Effects of Excise Taxes and Clean Air Laws on Adult and High School Smoking Rates in the United States." International Journal of Business and Public Administration 11 (2): 98-106.

Saffer, Henry, Daniel L. Dench, Michael Grossman, and Dhaval M. Dave. 2019. "E-Cigarettes and Adult Smoking: Evidence from Minnesota." NBER Working Paper No. 26589.

Sen, Anindya, Hideki Ariizumi, and Daciana Driambe. 2010. "Do Changes in Cigarette Taxes Impact Youth Smoking? Evidence from Canadian Provinces." Forum for Health Economics \& Policy 13 (2): 1-23.

Sen, Anindya, and Tony Wirjanto. 2010. "Estimating the Impacts of Cigarette Taxes on Youth Smoking Participation, Initiation, and Persistence: Empirical Evidence from Canada." Health Economics 19 (11): 1264-80.

Shetty, Kanaka D., Thomas DeLeire, Chapin White, and Jayanta Bhattacharya. 2011. "Changes in U.S. Hospitalization and Mortality Rates Following Smoking Bans." Journal of Policy Analysis and Management 30 (1): 6-28.

Shoven, John B., Jeffrey O. Sundberg, and John P. Bunker. 1989. "The Social Security Cost of Smoking." In The Economics of Aging, edited by David A. Wise, 231-54. Chicago: University of Chicago Press.

Simon, David. 2016. "Does Early Life Exposure to Cigarette Smoke Permanently Harm Childhood Welfare? Evidence from Cigarette Tax Hikes.” American Economic Journal: Applied Economics 8 (4): 128-59.

Skurka, Chris, Deena Kemp, Julie Davydova, James F. Thrasher, Sahara Byrne, Amelia Greiner Safi, Rosemary J. Avery, et al. 2018. "Effects of 30\% and 50\% Cigarette Pack Graphic Warning Labels on Visual Attention, Negative Affect, Quit Intentions, and Smoking Susceptibility Among Disadvantaged Populations in the United States." Nicotine \& Tobacco Research 20 (7): 859-66.

Sloan, Frank A., Jan Ostermann, Gabriel Picone, Christopher Conover, and Donald H. Taylor, Jr. 2004. The Price of Smoking. Cambridge: MIT Press.

Sloan, Frank A., and Justin G. Trogdon. 2004. "The Impact of the Master Settlement Agreement on Cigarette Consumption." Journal of Policy Analysis and Management 23 (4): 843-55.

Stamford, Bryant A., Sharleen Matter, Ronald D. Fell, and Paula Papanek. 1986. "Effects of Smoking Cessation on Weight Gain, Metabolic Rate, Calorie Consumption and Blood Lipids." The American Journal of Clinical Nutrition 43 (4): 486-94.

Stehr, Mark. 2005. "Cigarette Tax Avoidance and Evasion." Journal of Health Economics 24 (2): 277-97.

Stehr, Mark. 2007. "The Effect of Cigarette Taxes on Smoking Among Men and Women." Health Economics 16 (12): 1333-43. 
Suranovic, Steven M., Robert S. Goldfarb, and Thomas C. Leonard. 1999. "An Economic Theory of Cigarette Addiction." Journal of Health Economics 18 (1): 1-29.

Tauras, John A. 2006. "Smoke-Free Air Laws, Cigarette Prices, and Adult Cigarette Demand." Economic Inquiry 44 (2): 333-42.

Thun, Michael J., Brian D. Carter, Diane Feskanich, Neal D. Freedman, Ross Prentice, Alan D. Lopez, Patricia Hartge, and Susan M. Gapstur. 2013. "50-Year Trends in Smoking-Related Mortality in the United States.” New England Journal of Medicine 368 (4): 351-64.

Thursby, Jerry G., and Marie C. Thursby. 2000. "Interstate Cigarette Bootlegging: Extent, Revenue Losses, and Effects of Federal Intervention.” National Tax Journal 53 (1): 59-77.

Tobacco Products Scientific Advisory Committee. 2011. "Menthol Cigarettes and Public Health: Review of the Scientific Evidence and Recommendations." https://wayback.archiveit.org/7993/20170405201731/https://www.fda.gov/downloads/AdvisoryCommittees/Committees MeetingMaterials/TobaccoProductsScientificAdvisoryCommittee/UCM269697.pdf.

Townsend, Joy, Paul Roderick, and Jacqueline Cooper. 1994. "Cigarette Smoking by Socioeconomic Group, Sex, and Age: Effects of Price, Income, and Health Publicity. British Medical Journal 309 (6959): 923-7.

Tuchman, Anna E. 2019. "Advertising and Demand for Addictive Goods: The Effects of ECigarette Advertising." Marketing Science 38 (6): 994-1022.

U.S. Department of Agriculture. 1995. Tobacco Situation and Outlook Report. TBS-232. Washington, DC: U.S. Department of Agriculture, Commodity Economics Division, Economic Research Service.

U.S. Department of Health and Human Services. 2012. "Preventing Tobacco Use Among Youth and Young Adults: A Report of the Surgeon General."

U.S. Department of Health and Human Services. 2014. "The Health Consequences of Smoking-50 Years of Progress: A Report of the Surgeon General."

U.S. Department of Health and Human Services. 2016. "E-Cigarette Use Among Youth and Young Adults: A Report of the Surgeon General."

U.S. National Cancer Institute and World Health Organization. 2017. "The Economics of Tobacco and Tobacco Control.” National Cancer Institute Tobacco Control Monograph 21.

Van Ours, Jan C. 2004. “A Pint a Day Raises a Man’s Pay; but Smoking Blows that Gain Away." Journal of Health Economics 23 (5): 863-86.

Viscusi, W. Kip. 1995. "Cigarette Taxation and the Social Consequences of Smoking." In Tax Policy and the Economy, Volume 9, edited by James M. Poterba, 51-101. Cambridge: MIT Press.

Viscusi, W. Kip. 1999. "The Governmental Composition of the Insurance Costs of Smoking." The Journal of Law and Economics 42 (2): 575-610. 
Viscusi, W. Kip. 2002. Smoke-Filled Rooms: A Postmortem on the Tobacco Deal. Chicago: University of Chicago Press.

Viscusi, W. Kip. 2016. "Risk Beliefs and Preferences for E-Cigarettes." American Journal of Health Economics 2 (2): 213-40.

Viscusi, W. Kip, and Joni Hersch. 2001. "Cigarette Smokers as Job Risk Takers." The Review of Economics and Statistics 83 (2): 269-80.

Viscusi, W. Kip, and Joni Hersch. 2008. "The Mortality Cost to Smokers.” Journal of Health Economics 27 (4): 943-58.

Wang, Shu, David Merriman, and Frank Chaloupka. 2019. "Relative Tax Rates, Proximity, and Cigarette Tax Noncompliance: Evidence from a National Sample of Littered Cigarette Packs." Public Finance Review 47 (2): 276-311.

Wang, Teresa W., Kat Asman, Andrea S. Gentzke, Karen A. Cullen, Enver Holder-Hayes, Carolyn Reyes-Guzman, Ahmed Jamal, Linda Neff, and Brian A. King. 2018. "Tobacco Product Use Among Adults — United States, 2017.” Morbidity \& Mortality Weekly Report 67 (44):122532.

Wang, Teresa W., Andrea S. Gentzke, MeLisa R. Creamer, Karen A. Cullen, Enver HolderHayes, Michael D. Sawdey, Gabriella M. Anic, et al. 2019. "Tobacco Product Use and Associated Factors Among Middle and High School Students—United States, 2019." Morbidity and Mortality Weekly Report Surveillance Summaries 68 (12):1-22.

Wang, Teresa W., Brandon Kenemer, Michael A. Tynan, Tushar Singh, and Brian King. 2016. "Consumption of Combustible and Smokeless Tobacco-United States, 2000-2015." Morbidity and Mortality Weekly Report 65 (48): 1357-63.

Warner, Kenneth E., and David Méndez. 2012. "Accuracy and Importance of Projections From a Dynamic Simulation Model of Smoking Prevalence in the United States." American Journal of Public Health 102 (11): 2045-8.

Wasserman, Jeffrey, Willard G. Manning, Joseph P. Newhouse, and John D. Winkler. 1991. "The Effects of Excise Taxes and Regulations on Cigarette Smoking." Journal of Health Economics 10 (1): 43-64.

Wehby, George L., and Charles J. Courtemanche. 2012. "The Heterogeneity of the Cigarette Price Effect on Body Mass Index." Journal of Health Economics 31 (5): 719-29.

World Health Organization. 2017. WHO Report on the Global Tobacco Epidemic, 2017: Monitoring Tobacco Use and Prevention Policies. Geneva: World Health Organization.

Xu, Xin, Ellen E. Bishop, Sara M. Kennedy, Sean A. Simpson, and Terry F. Pechacek. 2015. "Annual Healthcare Spending Attributable to Cigarette Smoking: An Update." American Journal of Preventive Medicine 48 (3): 326-33.

Yurekli, Ayda A., and Ping Zhang. 2000. "The Impact of Clean Indoor-Air Laws and Cigarette Smuggling on Demand for Cigarettes: An Empirical Model." Health Economics 9 (2): 159-70. 
Zhao, Xueyan, and Mark N. Harris. 2004. "Demand for Marijuana, Alcohol and Tobacco:

Participation, Levels of Consumption and Cross-Equation Correlations." Economic Record 80 (251): 394-410.

Zheng, Yuqing, Chen Zhen, Daniel Dench, and James M. Nonnemaker. 2017. "U.S. Demand for Tobacco Products in a System Framework.” Health Economics 26 (8): 1067-86.

Zheng, Yuqing, Chen Zhen, James Nonnemaker, and Daniel Dench. 2016. "Advertising, Habit Formation, and U.S. Tobacco Product Demand." American Journal of Agricultural Economics 98 (4): 1038-54. 


\section{ONLINE DATA APPENDIX}

\section{A-1. Current Population Survey - Tobacco Use Supplements (TUS-CPS)}

One of the most commonly used datasets in the study of tobacco regulation is the TUSCPS. ${ }^{47}$ The CPS is a nationally representative household-based survey of the noninstitutionalized population that is run by the US Bureau of Labor Statistics. Households are surveyed every month, and in certain months supplemental questionnaires are given that focus on certain topics. The tobacco use supplements were conducted in 1992-1993, 1995-1996, 19981999, 2000, 2001-2002, 2003, 2006-2007, 2010-2011, and 2014-2015. ${ }^{48}$ State identifiers are available in the data, and the sample sizes are large enough to generate representative estimates at the state level. The survey usually includes over 160,000 households per cycle, although the exact size varies across cycles. ${ }^{49}$

The main benefit of the TUS-CPS is that it can be linked to the general CPS survey. This linkage provides detailed information about respondent demographics, geographic location, and labor supply. Table A-1 shows the main questions used by researchers to determine smoking status and the number of cigarettes smoked by smokers. These questions are asked separately for every-day and some-day smokers (who also are asked how many times they smoked in the past 30 days), and there is a battery of questions for former smokers and about recent quit attempts. Beginning in 2003, smokers also were asked about whether they usually purchased cartons or packs, what the price is for the last carton/pack purchased, and in what state the last carton/pack was purchased. Respondents were asked as well about smoking menthol cigarettes beginning in 2003.

\section{A-2. National Health Interview Survey (NHIS)}

The National Health Interview Survey is a nationally representative dataset of the noninstitutionalized population that has surveyed individuals since 1957. The survey is run by the Centers for Disease Control and Prevention (CDC). The goal of the survey is to monitor the health of the nation, and since 1965 the survey has collected information on adult smoking. ${ }^{50}$ The NHIS provides nationally representative patterns on adult smoking. State identifiers are available

\footnotetext{
${ }^{47}$ These data can be accessed through the NBER Data Repository: https://www.nber.org/data/current-populationsurvey-data.html.

$\frac{48}{48}$ The May 2010 and the May 2011 Follow-Up form a special Longitudinal Cohort TUS-CPS.

${ }^{49}$ A cycle of the TUS-CPS typically is comprised of 3 waves across two years.

${ }^{50}$ These data are available at https://www.cdc.gov/nchs/nhis/tobacco.htm.
} 
in the data, but the sample sizes are too small to generate representative estimates at the state level. The survey includes about 100,000 individuals per year, although the exact size varies each year.

The specific language of the smoking questions has varied over time, but the questions listed in Table A-1 are consistently asked. These questions also align closely with the questions in the TUS-CPS, making comparisons among these datasets straightforward. Many of the NHIS surveys also ask about prior smoking behavior, when respondents initiated smoking, and past quit attempts. In 2014, NHIS began asking about e-cigarettes as well. Limited demographic information is included in the dataset, such as age and race/ethnicity.

While the NHIS does not include the wealth of demographic, household composition, and labor market outcomes that are available in the CPS, it includes rich information about other health behaviors and outcomes. Some of the major topics include physical and mental health, chronic conditions (e.g., diabetes), use of healthcare, health insurance coverage, type of health insurance, health-related behaviors (e.g., smoking, drinking, and physical activity), and disability. These data thus are particularly useful in understanding how smoking relates to other health behaviors and outcomes.

\section{A-3. National Health and Nutrition Examination Survey (NHANES)}

The National Health and Nutrition Examination Survey (NHANES) is a dataset designed to provide information about the health and nutritional status of adults in the US. It is administered by the CDC, and it is distinguished from NHIS in that it combines survey responses and physical examinations. Because the physical examinations are intensive, the sample sizes are rather small. State identification information is available, but the sample sizes are sufficiently small that the estimates are unlikely to be representative at the state level. NHANES surveys have been conducted somewhat regularly: 1971-1974 (NHANES I), 1976-1980 (NHANES II), 1988-1994 (NHANES III), and continuously in two-year cycles since 1999.

As shown in Table A-1, the cigarette smoking questions are similar to those in CPS and NHIS but differ slightly in wording. The specific wording also has changed over time across NHANES cohorts. NHANES additionally contains questions about the timing of smoking initiation and past quit attempts. The main advantage of the NHANES data is information on cotinine levels from blood tests. Cotinine is a chemical left in the bloodstream from smoking, which provides a clinical measure of smoking intensity. Combined with traditional self-reported 
questions on smoking, cotinine measures provide a check on survey-based measurement error. This measurement error can come from misreporting of smoking on the intensive and extensive margins. As argued by Adda and Cornaglia (2006), cotinine picks up intensity of how much each cigarette is smoked; they argue tax increases lead consumers to smoke more of each cigarette, which cannot be detected by sales or traditional consumption measures. The NHANES data include a rich set of clinical and survey information on health outcomes and behaviors, so like the NHIS it can be used to identify how smoking relates to other dimensions of health.

\section{A-4. National Survey on Drug Use and Health (NSDUH)}

The NSDUH is a nationally representative survey on $12+$ year olds that is designed to measure use of alcohol, tobacco, and illicit drugs. The survey is run by the Substance Abuse and Mental Health Services Administration (SAMHSA) and currently is administered by RTI International. Data are available online starting in 1979. From 1979-2002 the survey was called the National Household Survey on Drug Abuse and was conducted irregularly until 1991, after which it became an annual survey. State, county, CBSA, and Census tract identifiers are available, but researchers must obtain a restricted-access license to use these geocodes. The smoking questions in NSDUH are very similar to those used in the other national surveys that ask about tobacco use, as shown in Table A-1. This dataset can be used to link tobacco use with other substance use in a large, nationally representative sample.

\section{A-5. Behavioral Risk Factor Surveillance System (BRFSS)}

The BRFSS dataset comes from a telephone-based survey conducted by the CDC that measures health outcomes and behaviors for a representative sample of US households each year. ${ }^{51}$ Data collection began in 15 states in 1984 and increased to cover all 50 states by 1993 . Because it is telephone-based, it is a large survey that is designed to be representative at the state level. State identifiers are publicly available, as are county, metropolitan, and micropolitan statistical areas prior to 2013 when those areas are sufficiently large. In 2011 the survey started to include cell phones, and the proportion of those answering by cell phone has increased substantially over time.

The BRFSS questions on cigarette consumption match those in CPS and NHIS very closely (Table A-1). However, since 2001 the BRFSS no longer asks current smokers about how many cigarettes they smoke each day. The BRFSS includes questions related to recent quit

\footnotetext{
${ }^{51}$ The BRFSS data are available here: https://www.cdc.gov/brfss/index.html.
} 
attempts. The main advantage of the BRFSS data is the large sample size, while allows accurate estimates at the state and sub-state level. The data contain information on a wide range of health behaviors and outcomes as well, similar to NHANES and NHIS.

\section{A-6. Youth Risk Behavior Surveillance System (YRBSS)}

The YRBSS dataset is a national school-based survey conducted by the CDC designed to measure health-related behaviors among high school students. Surveys typically are conducted every two years in the spring semester. The national survey is representative of the public and private high school population in the US. The YRBSS also includes state, territorial, tribal government, and local school-based surveys of representative samples of high school students. However, the national surveys often differ from state and sub-state surveys. The survey began in 1991 and has surveyed student biannually since that time. State identifiers are available for the national survey and in the state surveys.

The YRBSS asks similar smoking questions to the other surveys discussed above, such as "Have you ever tried cigarette smoking, even one or two puffs?", "During the past 30 days, on how many days did you smoke cigarettes?, and "During the past 30 days, on the days you smoked, how many cigarettes did you smoke per day?" The dataset also includes a wide range of questions regarding alcohol and drug use, sexual behaviors, physical activity, and dietary behaviors. Like the BRFSS, a core strength of this dataset is the ability to link tobacco use with other health behaviors.

\section{A-7. Monitoring the Future (MTF)}

The Monitoring the Future dataset measures attitudes towards and use of tobacco, drugs, and alcohol among adolescents. The survey is funded by the National Institute on Drug Abuse and is administered by the University of Michigan Survey Research Center. Respondents report current, past-year, and lifetime usage of each substance, which allows researchers to measure time patterns of usage among adolescents. The survey has been run annually beginning in 1975 . It is a school-based survey that includes nationally representative samples of $8^{\text {th }}, 10^{\text {th }}$ and $12^{\text {th }}$ grade students. As shown in Table A-1, the cigarette smoking questions align closely with those

in other national surveys. State, county, and zip code geocodes are available for researchers who obtain a restricted-access data license.

\section{A-8. National Youth Tobacco Survey (NYTS)}


The National Youth Tobacco Survey is run by the CDC and measures tobacco use and attitudes among school-age children. It is a school-based, nationally representative survey that was conducted in 1999, 2000, 2002, 2004, 2006, 2009, 2011 and annually thereafter. Middle school (grades 6-8) and high school (grades 9-12) students are the focus of the survey. The questions on smoking are similar to those employed in other surveys, most notably YRBSS. The NYTS is distinguished by focusing on tobacco use and asking more in-depth questions about multiple forms of tobacco use and students' attitudes towards tobacco use. State identifiers are not available.

\section{A-9. National Longitudinal Surveys of Youth (NLSY)}

The National Longitudinal Surveys of Youth (1979 and 1997) are ongoing longitudinal surveys conducted by the Bureau of Labor Statistics. The NLSY79 cohort is comprised of 12,686 individuals who were 14-22 in 1979, while the 1997 cohort is comprised of 9,000 respondents who were 12-16 years old in 1997. The children of the 1979 NLSY cohort (CNLSY) was started in 1986 and includes all children born to NLSY79 female respondents.

The NLSY79 surveys have asked questions on smoking initiation and participation off and on over time. The 1984 survey asks questions on age at first use, most recent use, and smoking in the past 30 days. In 1992, 1994, 1998 and 2008-2014, respondents were asked about the number of cigarettes smoked per day and the number of months/years since they had last smoked daily. Several survey waves also ask female respondents about smoking while pregnant. The NLSY97 cohort was asked in the initial interview about whether (and at what age) they had smoked a cigarette. In each subsequent round, respondents are asked about new smoking initiation as well as among smokers the number of days they smoked during the 30 days prior to the interview and the number of cigarettes they usually had on the days they smoked during those 30 days. A similar set of questions were asked of the CNLSY sample to ascertain age of smoking initiation, recent smoking prevalence, and the amount smoked among smokers.

The defining characteristic of the NLSY data relative to other datasets is its longitudinal nature. Because the NLSY surveys focus on initiation and ask whether individuals currently smoke in each follow-up, one can trace smoking behaviors across the lifecycle. Since most smoking initiation begins prior to the age of 20, and much of it begins prior to the age of 18 , these data are useful in understanding how tobacco control policies affect initiation behavior as well as quit attempts and smoking intensity among smokers. The NLSY data also contain 
detailed information on childhood background, schooling, labor market outcomes, family formation, and cognitive and non-cognitive measures. The ability to link such information to smoking behavior is unique to the NLSY surveys. The data include state identifiers as well, but they require access to the restricted-use version of the data.

\section{A-10. Nielsen/IRI Homescan Data}

Homescan data are provided by AC Nielsen or IRI and contain transaction-level purchases for a demographically representative set of households in the US. For each product purchased, the data include the Universal Product Code (UPC), the price paid, and the time and store of purchase. The data thus provide unique insight into the exact cigarette products being purchased and prices paid by consumers. Additionally, the data contain household demographics that include labor supply, income, race/ethnicity, and the makeup of the household (overall size and age composition).

Households are provided with a scanner and are asked to scan all items following a purchase. The scanner scans the barcode and records the UPC code, and then households record the amount purchased and the price paid. If a purchase is made at certain stores at which Nielsen or IRI monitors store-level prices, they will use the price based on store records for the given week. ${ }^{52}$ Households are paid for their participation by earning points for data uploads. The points can be used in exchange for products similar to the way credit card points are used for merchandise. One concern is that households only report data from their main shopping trip. Harding, Leibtag, and Lovenheim (2012) provide evidence that households report cigarette-only purchases as well.

The Homescan data are useful because they are arguably less subject to measurement error from recall or from the stigma of smoking. They also contain detailed purchase information about other goods (e.g., food) as well as price information for every cigarette pack/carton purchased and the location of purchase. This type of detailed price and product information linked to household characteristics is not available in other datasets. Another advantage is that the Homescan data are longitudinal. Although the panel covers a shorter time period than the NLSY, the Homescan data provided much higher-frequency observations (e.g. weekly

\footnotetext{
52 Einav, Leibtag, and Nevo (2010) assess measurement error in these data by matching Homescan data with data provided by a large retailer. They find evidence of measurement error, but these errors are unlikely to be related to changes in tobacco control policies.
} 
purchases). The central drawback of the Homescan data is that they are household-based, so one cannot observe who smokes the purchased cigarettes in multi-person households. Unlike the other datasets discussed above, these data also must be purchased. ${ }^{53}$

\section{A-11. State Cigarette Taxed Sales Data}

Cigarette sales at the state-year level are available from the Orzechowski and Walker publication, The Tax Burden on Tobacco. All cigarettes that are legally sold in a state are reported to the state tax authorities in order to monitor excise tax compliance. These data are useful in providing administrative records on all cigarettes sold in a state. The main drawback is that one does not know who the consumers are who purchase the cigarettes. In particular, crossstate or Native American Reservation purchasing behavior leads state sales to be a problematic measure of cigarette consumption among state residents. See Section 5.1 for a more in-depth discussion of this issue.

\footnotetext{
${ }^{53}$ The Nielsen Homescan data are available to academic researchers through the Kilts Center for Marketing at the University of Chicago Booth School of Business. https://www.chicagobooth.edu/research/kilts/datasets/nielsen.
} 
Table A-1. Datasets Commonly Used to Study Cigarette Consumption

\begin{tabular}{|c|c|c|c|}
\hline Dataset & $\begin{array}{l}\text { Ages } \\
\text { Covered }\end{array}$ & Years Covered & Main Cigarette Questions \\
\hline $\begin{array}{l}\text { Current Population } \\
\text { Survey - Tobacco Use } \\
\text { Supplement (TUS-CPS) }\end{array}$ & $18+$ & $\begin{array}{l}1992-2017 \\
\text { (intermittent) }\end{array}$ & $\begin{array}{l}\text { - Have you smoked at least } 100 \\
\text { cigarettes in your entire life? } \\
\text { - Current Cigarette Smoking Status } \\
\text { - On average, about how many cigarettes } \\
\text { do you smoke a day? }\end{array}$ \\
\hline $\begin{array}{l}\text { National Health } \\
\text { Interview Survey } \\
\text { (NHIS) }\end{array}$ & $18+$ & $1957-2017$ & $\begin{array}{l}\text { - Have you smoked at least } 100 \\
\text { cigarettes in your entire life? } \\
\text { - Do you now smoke cigarettes every } \\
\text { day, some days or not at all? } \\
\text { - On the average, how many cigarettes } \\
\text { do you now smoke a day? }\end{array}$ \\
\hline NHANES & $18+$ & $\begin{array}{l}\text { 1971-2018 } \\
\text { (intermittent until } \\
1999 \text { and } \\
\text { continuous } \\
\text { thereafter) }\end{array}$ & $\begin{array}{l}\text { - Ever tried cigarette smoking? (early } \\
\text { surveys) } \\
\text { - Smoked at least } 100 \text { cigarettes in life } \\
\text { (later surveys) } \\
\text { - \# days smoked cigarettes in past month } \\
\text { (30 days) } \\
\text { - \# cigarettes per day during past month } \\
\text { - Cotinine levels from blood samples }\end{array}$ \\
\hline $\begin{array}{l}\text { National Survey on } \\
\text { Drug Use and Health } \\
\text { (NSDUH) }\end{array}$ & $12+$ & $\begin{array}{l}\text { 1971-present } \\
\text { (1979-present } \\
\text { available online) }\end{array}$ & $\begin{array}{l}\text { - Have you smoked at least } 100 \\
\text { cigarettes in your life? } \\
\text { - When was the most recent time you } \\
\text { had a cigarette? } \\
\text { - How many days smoked cigarettes in } \\
\text { past } 30 \text { days? } \\
\text { - Average number of cigarettes smoked } \\
\text { per day on days smoked }\end{array}$ \\
\hline $\begin{array}{l}\text { Behavioral Risk Factor } \\
\text { Surveillance System } \\
\text { (BRFSS) }\end{array}$ & $18+$ & $\begin{array}{l}\text { 1984-2018 (full } \\
\text { state coverage } \\
\text { from 1993); } \\
\text { questions on } \\
\text { cigarettes per day } \\
\text { were discontinued } \\
\text { in } 2001 .\end{array}$ & $\begin{array}{l}\text { - Have you smoked at least } 100 \\
\text { cigarettes in your entire life? } \\
\text { - Do you now smoke cigarettes every } \\
\text { day, some days, or not at all? } \\
\text { - On average, about how many cigarettes } \\
\text { do you smoke a day? (not included } \\
\text { 2001-2018) }\end{array}$ \\
\hline $\begin{array}{l}\text { Youth Risk Behavior } \\
\text { Surveillance System } \\
\text { (YRBSS) }\end{array}$ & $\begin{array}{l}\text { High } \\
\text { School } \\
\text { Students }\end{array}$ & $\begin{array}{l}\text { 1991-2017 } \\
\text { (biennial) }\end{array}$ & $\begin{array}{l}\text { - Have you ever tried cigarette smoking, } \\
\text { even one or two puffs? } \\
\text { - During the past } 30 \text { days, on how many } \\
\text { days did you smoke cigarettes? } \\
\text { - During the past } 30 \text { days, on the days } \\
\text { you smoked, how many cigarettes did } \\
\text { you smoke per day? }\end{array}$ \\
\hline
\end{tabular}




\begin{tabular}{|c|c|c|c|}
\hline $\begin{array}{l}\text { Monitoring the Future } \\
\text { (MTF) }\end{array}$ & $\begin{array}{l}8^{\text {th }}, 10^{\text {th }} \\
12^{\text {th }} \text { grade } \\
\text { students }\end{array}$ & 1975-present & $\begin{array}{l}\text { - Have you ever smoked cigarettes? } \\
\text { - How frequently have you smoked } \\
\text { cigarettes during the past } 30 \text { days? } \\
\text { - To be more precise, during the past } 30 \\
\text { days about how many cigarettes have } \\
\text { you smoked per day? }\end{array}$ \\
\hline $\begin{array}{l}\text { National Youth } \\
\text { Tobacco Survey }\end{array}$ & $\begin{array}{l}6^{\text {th }}-12^{\text {th }} \\
\text { grade } \\
\text { students }\end{array}$ & $\begin{array}{l}\text { 1999-present } \\
\text { (intermittent) }\end{array}$ & $\begin{array}{l}\text { - Have you ever tried cigarette smoking, } \\
\text { even one or two puffs? } \\
\text { - About how many cigarettes have you } \\
\text { smoked in your entire life? } \\
\text { - During the past } 30 \text { days, on how many } \\
\text { days did you smoke cigarettes? } \\
\text { - During the past } 30 \text { days, on the days } \\
\text { you smoked, how many cigarettes did } \\
\text { you smoke per day? }\end{array}$ \\
\hline $\begin{array}{l}\text { National Longitudinal } \\
\text { Surveys of Youth } \\
\text { (1979, 1997, and } \\
\text { Children of 1979) }\end{array}$ & $10+$ & $\begin{array}{l}\text { 1979-present } \\
\text { (1979 cohort); } \\
\text { 1997-present } \\
\text { (1997 cohort); } \\
\text { 1984-present } \\
\text { (CNLSY sample) }\end{array}$ & $\begin{array}{l}\text { Questions vary across surveys but } \\
\text { focus on age of initiation, current } \\
\text { smoking status, recent smoking } \\
\text { prevalence, and the number of } \\
\text { cigarettes smoked per day on average. }\end{array}$ \\
\hline $\begin{array}{l}\text { Nielsen/IRI Homescan } \\
\text { Data }\end{array}$ & $\begin{array}{l}\text { All } \\
\text { (Household } \\
\text { Based) }\end{array}$ & $\begin{array}{l}\text { Variable, depends } \\
\text { on dataset }\end{array}$ & $\begin{array}{l}\text { - Record of every cigarette purchased, if } \\
\text { scanned, including UPC code \& price. } \\
\text { - Location of purchase } \\
\text { - Day of purchase }\end{array}$ \\
\hline $\begin{array}{l}\text { State Taxed Cigarette } \\
\text { Sales }\end{array}$ & N/A & 1950-present & $\begin{array}{l}\text { - Sales of all cigarettes legally sold in } \\
\text { each state and year }\end{array}$ \\
\hline
\end{tabular}

